FINAL REPORT

U.S. Department of Energy

\title{
INTERFACIAL REDUCTION-OXIDATION MECHANISMS GOVERNING FATE AND TRANSPORT OF CONTAMINANTS IN THE VADOSE ZONE
}

\author{
Principal Investigator: Baolin Deng \\ Institution: Department of Civil and Environmental Engineering \\ University of Missouri-Columbia \\ DengB@,missouri.edu \\ Co-Principal Investigator: Edward C. Thornton \\ Institution: Environmental Technology Division \\ Pacific Northwest National Laboratory \\ edward.thornton@pnl.gov \\ Co-Principal Investigator: Kirk J. Cantrell \\ Institution: Environmental Technology Division \\ Pacific Northwest National Laboratory \\ Co-Principal Investigator: Khris B. Olsen \\ Institution: Environmental Technology Division \\ Pacific Northwest National Laboratory \\ Co-Principal Investigator: James E. Amonette \\ Institution: Environmental Molecular Sciences Laboratory (MSEL) \\ Pacific Northwest National Laboratory
}

Project Number: EMSP-70088

Grant Number: DE-FG07-99ER15011

Grant Project Officers: Roland Hirsch and Mark Gilbertson

Project Duration: 9/15/1999 - 9/14/2003 


\section{Table Of Contents}

Executive Summary

Acknowledgments

I. Introduction 6

II. Chromium(VI) Reduction by Hydrogen Sulfide in Aqueous Media: 7

Stoichiometry and Kinetics Introduction $\quad 7$

Materials and Methods $\quad 8$

$\begin{array}{ll}\text { Results and Discussion } & 10\end{array}$

Conclusions 17

III. Chromium(VI) Reduction by Sulfide under Anaerobic Conditions: Catalysis by 18 Elemental Sulfur Product

Introduction 18

Materials and Methods $\quad 19$

Results and Discussion $\quad 21$

Conclusions 25

IV. Effect of Various Soil Minerals on Cr(VI) Reduction by Sulfide 26

Introduction $\quad 26$

Materials and Methods $\quad 27$

Results $\quad 29$

Conclusions $\quad 37$

V. Oxidation of $\mathrm{H}_{2} \mathrm{~S}$ by Iron Oxides $\quad 38$

Introduction $\quad 38$

Background $\quad 38$

Experimental Methods $\quad 39$

Results and Discussion $\quad 40$

Conclusions $\quad 54$

VI. Influences of Water Vapor on Cr(VI) Reduction by Gaseous Hydrogen Sulfide 55

Introduction $\quad 55$

Materials and Methods $\quad 56$

Results $\quad 59$

Discussion $\quad 63$

VII. Immobilization of Chromium, Technetium, and Uranium in Soils from the $\quad 68$

Hanford Site, Washington $\begin{array}{ll}\text { Introduction } & 68\end{array}$

Gaseous Treatment of Tc-Contaminated Sediment 69

Gaseous Treatment of U-Contaminated Sediment 74

Evaluation of the ISGR PRB Concept for Immobilization of Chromium, $\quad 79$

Technetium, and Uranium in the Vadose Zone

Evaluation of the Potential for Long-Term Chromium Reoxidation in an $\mathrm{H}_{2} \mathrm{~S}-\quad 82$

Treated Sediment

$\begin{array}{lr}\text { Project Productivity } & 84\end{array}$

$\begin{array}{lr}\text { References } & 86\end{array}$ 


\section{EXECUTIVE SUMMARY}

Immobilization of toxic and radioactive metals (e.g., $\mathrm{Cr}, \mathrm{Tc}$, and $\mathrm{U}$ ) in the vadose zone by In Situ Gaseous Reduction (ISGR) using hydrogen sulfide $\left(\mathrm{H}_{2} \mathrm{~S}\right)$ is a promising technology for soil remediation. Earlier laboratory and field studies have shown that $\mathrm{Cr}(\mathrm{VI})$ can be effectively immobilized by treatment with dilute gaseous $\mathrm{H}_{2} \mathrm{~S}$. The objective of this project is to characterize the interactions among $\mathrm{H}_{2} \mathrm{~S}$, the metal contaminants, and soil components. Understanding these interactions is needed to assess the long-term effectiveness of the technology and to optimize the remediation system. Proposed research tasks include: (A) Evaluation of the potential catalytic effect of mineral surfaces on the rate of $\mathrm{Cr}(\mathrm{VI})$ reduction by $\mathrm{H}_{2} \mathrm{~S}$ and the rate of $\mathrm{H}_{2} \mathrm{~S}$ oxidation by air; (B) Identification of the reactions of soil minerals with $\mathrm{H}_{2} \mathrm{~S}$ and determination of associated reaction rates; (C) Evaluation of the role of soil water chemistry on the reduction of $\mathrm{Cr}(\mathrm{VI})$ by $\mathrm{H}_{2} \mathrm{~S}$; (D) Assessment of the reductive buffering capacity of $\mathrm{H}_{2} \mathrm{~S}$ reduced soil and the potential for emplacement of long-term vadose zone reactive barriers; (E) Evaluation of the potential for immobilization of Tc and $U$ in the vadose zone by reduction and an assessment of the potential for remobilization by subsequent reoxidation. Through a collaborative effort in the last four years, all the proposed research tasks have been completed, resulting in a much improved understanding of reaction kinetics and mechanisms involved in the $\mathrm{Cr}(\mathrm{VI})-\mathrm{H}_{2} \mathrm{~S}_{-}-\mathrm{O}_{2}$-Soil System and the treatability for Tc and $\mathrm{U}$. The project is renewed beginning FY04 to further study the complex interactions among the contaminants ( $\mathrm{U}$ and $\mathrm{Tc}), \mathrm{H}_{2} \mathrm{~S}$, and various soil constituents.

Chromium (VI) Reduction by Hydrogen Sulfide in Aqueous Media: Aqueous phase $\mathrm{Cr}(\mathrm{VI})$ reduction is being examined as a function of $\mathrm{pH}, \mathrm{Cr}(\mathrm{VI})$ concentration, sulfide concentration, temperature, and ionic strength. Experiments with excess [Cr(VI)] over $\left[\mathrm{H}_{2} \mathrm{~S}\right]_{\mathrm{T}}$ indicated that the molar amount of sulfide required for the reduction of one molar of $\mathrm{Cr}(\mathrm{VI})$ was 1.5 , suggesting the following stoichiometry: $2 \mathrm{CrO}_{4}{ }^{2-}+3 \mathrm{H}_{2} \mathrm{~S}+4 \mathrm{H}^{+} \rightarrow$ $2 \mathrm{Cr}(\mathrm{OH})_{3(\mathrm{~S})}+3 \mathrm{~S}_{(\mathrm{S})}+2 \mathrm{H}_{2} \mathrm{O}$. Further study with Transmission Electron Microscopy (TEM) and Energy-Dispersive X-Ray Spectroscopy (EDS) confirmed that chromium hydroxide and elemental sulfur were the stable products under the anaerobic condition.

The kinetics of $\mathrm{Cr}(\mathrm{VI})$ reduction by hydrogen sulfide was measured under various initial concentrations of $\mathrm{Cr}(\mathrm{VI})$ and sulfide, as well as pHs controlled by HEPES, phosphate, and borate buffers. Results showed that the overall reaction was second order, i.e., first order with respect to $\mathrm{Cr}(\mathrm{VI})$ and first order to sulfide. The reaction rate increased as $\mathrm{pH}$ was decreased, and the $\mathrm{pH}$ dependence correlated well with the fraction of fully protonated sulfide $\left(\mathrm{H}_{2} \mathrm{~S}\right)$ in the $\mathrm{pH}$ range of 6.5 to 10 . The nature of buffers didn't influence the reaction rate significantly in the homogeneous system. A three-step mechanism was proposed for the reaction: formation of an inner sphere chromate-sulfide complex formation, intramolecular electron transfer to form intermediate $\mathrm{Cr}(\mathrm{IV})$ species, and subsequent fast reactions leading to the formation of $\mathrm{Cr}(\mathrm{III})$. Kinetic data under various $\mathrm{pHs}$, ionic strengths, and concentrations of $[\mathrm{Cr}(\mathrm{VI})]$ and $\left[\mathrm{H}_{2} \mathrm{~S}\right]_{\mathrm{T}}$ agreed with this mechanism. 
Catalysis of Elemental Sulfur Product on Cr(VI) Reduction by sulfide: Through wellcontrolled batch experiments performed in an anaerobic chamber, it is observed that while $\mathrm{Cr}(\mathrm{VI})$ reduction by sulfide can be described by a pseudo first order kinetics with respect to $[\mathrm{Cr}(\mathrm{VI})]$ initially, the rate was significantly accelerated at the later stage of the reaction. Such an acceleration is likely due to the formation of some reaction intermediates and products. The $\mathrm{Cr}(\mathrm{III})$ species, mainly in the form of $\mathrm{Cr}(\mathrm{OH})_{3(\mathrm{~s})}$ under the experimental condition, didn't demonstrate any discernible effect on the reaction kinetics. Elemental sulfur was found to be the main compound causing the accelerated $\mathrm{Cr}(\mathrm{VI})$ reduction.

Effect of Various Soil Minerals on Cr(VI) Reduction by Sulfide: Effects of mineral surfaces on $\mathrm{Cr}(\mathrm{VI})$ reduction by sulfide were investigated at $\mathrm{pH}$ range from7.67 to 9.07 buffered by borate under the anaerobic condition. Results showed that the minerals examined can be categorized into three groups. Illite exhibited dramatic catalytic effect on the reduction of $\mathrm{Cr}(\mathrm{VI})$ by sulfide. $\mathrm{Al}_{2} \mathrm{O}_{3}$ showed no obvious effect on the reaction. The third group, which includes kaolin, montmorillonite, $\mathrm{SiO}_{2}$ and $\mathrm{TiO}_{2}$, inhibited the reduction of $\mathrm{Cr}(\mathrm{VI})$ as compared to the control without minerals being present. In the illite system, low concentration of ferrous iron produced from the mineral dissolution is believed to be responsible for the rate acceleration by serving as an electron shuttle. The reaction rate increases with increasing Fe(II) concentration and at the later stage, the effect of elemental sulfur produced can be observed. When a strong Fe(II) chelating agent such as phenanthroline is added into the system, the effect of soluble iron from illite disappears. The inhibitive behavior observed for the third group is likely due to the uptake of elemental sulfur product on the mineral surfaces, so the catalytic effect from elemental sulfur is hindered.

Oxidation of $\mathrm{H}_{2} \mathrm{~S}$ by Iron Oxides: Iron oxides are well-known oxidizing reagents and oxidation catalysts for $\mathrm{H}_{2} \mathrm{~S}$. It is thus expected that the quantity of $\mathrm{H}_{2} \mathrm{~S}$ required to remediate a site and the rate of treatment will typically be dependent upon the quantity and form of the iron oxides in the soils and not on the amount of contaminants present. A detailed experimental and modeling study was conducted to understand the interactions among hydrogen sulfide and iron oxides coated onto the quartz sand. The results illustrate that the reactions involving the ferric oxide ferrihydrite with $\mathrm{H}_{2} \mathrm{~S}$ under anaerobic and aerobic conditions can be largely understood from a mechanistic standpoint. The modeling effort provided significant insights on the processes controlling the $\mathrm{H}_{2} \mathrm{~S}$ breakthrough.

Influences of Water Vapor on $\mathrm{Cr}(\mathrm{VI})$ Reduction by Gaseous Hydrogen Sulfide: $\mathrm{Cr}(\mathrm{VI})$ reduction by gaseous $\mathrm{H}_{2} \mathrm{~S}$ was examined under various relative humidities (0$96.7 \%)$, concentrations of $\mathrm{Cr}(\mathrm{VI})\left(127-475 \mu \mathrm{g} / \mathrm{g}\right.$ of solid) and $\mathrm{H}_{2} \mathrm{~S}\left(0-800 \mathrm{ppm}_{\mathrm{v}}\right)$, and by using $\mathrm{Cr}(\mathrm{VI})$ compounds with different solubilities. Glass beads with various average diameters $(\mathrm{GA}=0.600 \mathrm{~mm}$; $\mathrm{GB}=0.212-0.300 \mathrm{~mm}$; and $\mathrm{GC}=0.106 \mathrm{~mm}$ ) and Silica (SA $=0.075-0.150 \mathrm{~mm}$ ) were used as matrices to support $\mathrm{K}_{2} \mathrm{CrO}_{4}, \mathrm{CaCrO}_{4}, \mathrm{PbCrO}_{4}$ or $\mathrm{BaCrO}_{4}$, and reduction of these compounds by gaseous $\mathrm{H}_{2} \mathrm{~S}$ were monitored by $\mathrm{Cr}(\mathrm{VI})$ analysis following extractions with distilled water or hot alkali solution. The results showed that $\mathrm{Cr}(\mathrm{VI})$ reduction relied on both the relative humidity of the gaseous stream 
and the size of particles onto which $\mathrm{Cr}(\mathrm{VI})$ was deposited. The relative humidity required for fast $\mathrm{Cr}(\mathrm{VI})$ reduction was $85 \%$ for $\mathrm{GA}, 61 \%$ for $\mathrm{GB}, 6 \%$ for $\mathrm{SA}$, and $0 \%$ for $\mathrm{GC}$. It was believed that a water film formed on the particle surfaces under appropriate humidity conditions, resulting in $\mathrm{Cr}(\mathrm{VI})$ compound dissolution and subsequent reduction. For nonsoluble $\mathrm{Cr}(\mathrm{VI})$ compounds including $\mathrm{PbCrO}_{4}$ and $\mathrm{BaCrO}_{4}$, no reduction by $\mathrm{H}_{2} \mathrm{~S}$ was observed, even at high relative humidity (96.7\%), due to lack of dissolution. This study indicated that ISGR treatment in soils requires appropriate moisture content in the subsurface or maintaining a suitable humidity in the treatment gas stream to maximize chromium immobilization.

Immobilization of $\mathbf{C r}, \mathbf{T c}$, and $\boldsymbol{U}$ in Soils from Hanford Site: Preliminary tests were conducted to determine (i) if Tc and $\mathrm{U}$ in contaminated sediments can be effectively immobilized by exposure to diluted hydrogen sulfide gas and (ii) if $\mathrm{H}_{2} \mathrm{~S}$-treated sediments can effectively retard the migration of $\mathrm{Cr}$, $\mathrm{Tc}$, and $\mathrm{U}$ in solutions that may potentially infiltrate through the treated zone. The results showed that the $\mathrm{H}_{2} \mathrm{~S}$ treatment resulted in about $50 \%$ of Tc being immobilized, but no significantly immobilization for U. Soils treated with $\mathrm{H}_{2} \mathrm{~S}$ could generate certain reductive capacity in soils and thus can be used as a permeable reactive barrier (PRB) for effective immobilization of $\mathrm{Cr}$ and to a lesser degree, for Tc. Uranium was also immobilized in the soil columns, but the mechanism was unclear.

A long-term test lasting 835 days was conducted to provide information regarding whether or not reoxidation of chromium could occur after $\mathrm{Cr}(\mathrm{VI})$ was reduced in a contaminated sediment by gas treatment. No $\mathrm{Cr}(\mathrm{III})$ reoxidation was observed for the experimental time period. 


\section{ACKNOWLEDGMENTS}

This project is supported by the Environmental Management Science Program (EMSP) of the Office of Science and Technology of the U.S. Department of Energy. The research was conducted at the Pacific Northwest National Laboratory (Richland, Washington), New Mexico Institute of Mining and Technology (Socorro, NM), and the University of Missouri-Columbia (Columbia, $\mathrm{MO})$. 


\section{INTRODUCTION}

Chromium contamination in the vadose zone has been identified at a number of DOE sites (e.g., Hanford, Pantex, and the Chemical Waste Landfill), as well as numerous nonfederal sites. Subsurface contamination with radionuclides such as technetium (Tc) and uranium (U) also takes place. For example, Tc is a constituent of the underground waste storage tanks at the Hanford Site and is present in the vadose zone owing to tank leakage. When surface water infiltrates through or groundwater level rises to the contaminated zone, $\mathrm{Cr}$ and the radionuclides leached out from the soil could serve as a constant source for groundwater contamination.

A promising technology for metal immobilization in the vadose zone, In-Situ Gaseous Reduction (ISGR), is developed by PNNL staff for the U.S. Department of Energy (DOE) (Thornton et al., 1999). Laboratory investigations have shown that $\mathrm{Cr}(\mathrm{VI})$ in soil samples can be effectively immobilized by treatment with diluted $\mathrm{H}_{2} \mathrm{~S}$. A field test at White Sand Missile Range, New Mexico, has also been completed that resulted in $70 \%$ immobilization of $\mathrm{Cr}(\mathrm{VI})$. The field demonstration has further shown that $\mathrm{H}_{2} \mathrm{~S}$ gas can be handled safely for field application and residual $\mathrm{H}_{2} \mathrm{~S}$ gas can be recovered, so no secondary contamination takes place (ASME,1999). There are, however, many related scientific questions that need to be addressed. The exact immobilization kinetics and mechanism, including the reaction stoichiometry between $\mathrm{Cr}(\mathrm{VI})$ and hydrogen sulfide, are unknown. It is unclear whether the reduced chromium will remain in the stabilized form in the long term. Similar to chromium, Tc and U demonstrate substantially lower mobility in their reduced forms than in their oxidative species, and thus, may be immobilized by $\mathrm{H}_{2} \mathrm{~S}$ treatment. A sound mechanistic understanding of the geochemical processes as related to this process is critical to ensure successful deployment of ISGR for $\mathrm{Cr}$ and to explore whether this technology can be applied to other contaminants.

The primary objective of this study is to improve our understanding of the complex interactions among the contaminant metals, hydrogen sulfide $\left(\mathrm{H}_{2} \mathrm{~S}\right)$, and various soil constituents. Critical areas include the reaction kinetics and mechanisms for $\mathrm{Cr}(\mathrm{VI})$ reduction, assessment of potential catalysis by soil matrices, interaction of $\mathrm{H}_{2} \mathrm{~S}$ with iron oxides, and treatability of Tc and $\mathrm{U}$ by the gaseous $\mathrm{H}_{2} \mathrm{~S}$.

The approach employed in this study consisted of conducting batch and column experiments to collect kinetic information, coupled with microscopic and spectroscopic studies and modeling effort, for acquiring a much better understanding of the reaction mechanisms. Aqueous batch tests were performed under well-controlled systems, including the use of pure oxides (e.g., $\mathrm{Al}_{2} \mathrm{O}_{3}$, $\mathrm{SiO}_{2}, \mathrm{FeOOH}, \mathrm{Fe}_{2} \mathrm{O}_{3}$ ) as surrogates of soil components, to obtain information regarding the major reactions and their associated rates and products. Effects of relative humidity on the reaction were also investigated. Soil column tests were conducted to obtain information regarding catalytic processes associated with $\mathrm{H}_{2} \mathrm{~S}$ oxidation and the consumption of $\mathrm{H}_{2} \mathrm{~S}$ by soil minerals, and the changes in soil reduction capacity associated with $\mathrm{H}_{2} \mathrm{~S}$ treatment. This was needed to predict the longevity of a reduced permeable barrier in the vadose zone.

Substantial progress has been made to better understand the interactions among $\mathrm{Cr}(\mathrm{VI})$, sulfide and soil minerals, as being summarized in the Sections II - VI. Preliminary studies on the contaminant immobilization in the Hanford soil samples are described in Section VII. 


\title{
II. CHROMIUM(VI) REDUCTION BY HYDROGEN SULFIDE IN AQUEOUS MEDIA: STOICHIOMETRY AND KINETICS
}

\author{
(Chulsung Kim, Qunhui Zhou, Baolin Deng, Edward C. Thornton, Huifang Xu)
}

\section{INTRODUCTION}

Chromium contamination has been found in many industrial and federal sites in the United States, due to accidental leakages and improper disposals associated with its widespread usage (Nriagu and Nieboer, 1988; Katz and Salem, 1994; Thornton and Amonette, 1999). Since some chromium chemicals are known to be toxic and carcinogenic (Costa, 1997), site remediation is often needed in order to reduce the risk to humans and ecosystems. Chromium exists as either $\mathrm{Cr}(\mathrm{VI})$ or $\mathrm{Cr}(\mathrm{III})$ species in natural water and soils and is redox active. The mobility of chromium in the environment largely depends on its oxidation states. Generally, $\mathrm{Cr}(\mathrm{VI})$ is quite mobile in soils and aquifers, whereas $\mathrm{Cr}$ (III) is mostly precipitated as hydroxides and adsorbed onto mineral surfaces. As a result, $\mathrm{Cr}(\mathrm{VI})$ could be immobilized and become less bioavailable when reduced to $\mathrm{Cr}(\mathrm{III})$.

Reduction of $\mathrm{Cr}(\mathrm{VI})$ could be coupled with the oxidation of numerous reductants including zero valent iron (Blowes et al., 1997; Pratt et al., 1997), divalent iron (Eary and Rai, 1988; 1989; Fendorf and Li, 1996; Sedlak and Chan, 1997; Pettine et al., 1998; Buerge and Hug, 1997; 1998; 1999; Seaman et al. 1999), Fe(II)-bearing minerals (Eary and Rai, 1989; Anderson et al., 1994; Ilton and Veblen, 1994; Ilton et al., 1997; Peterson et al., 1997), organic compounds (James and Bartlett, 1983; Goodgame and Hayman, 1984; Eary and Rai, 1991; Wittbrodt and Palmer, 1995), and $\mathrm{H}_{2} \mathrm{~S}$ ( Schroeder and Lee, 1975; Smillie et al., 1981; Saleh et al., 1989; Pettine et al., 1994; 1998; Thornton and Amonette, 1999). Cr(VI) reduction is strongly $\mathrm{pH}$ dependent and subject to catalysis by dissolved and surface-bound metals (Deng and Stone, 1996a, b; Buerge and Hug, 1999).

Hydrogen sulfide is one of the strongest reductants that is capable of reducing $\mathrm{Cr}(\mathrm{VI})$. The reduction of $\mathrm{Cr}(\mathrm{VI})$ by $\mathrm{H}_{2} \mathrm{~S}$ has been demonstrated in a number of studies (Schroeder and Lee, 1975; Saleh et al., 1989; Fude et al., 1994) and may explain Cr(VI) reduction in the marine environment under sulfate-reducing conditions (Smillie et al., 1981). Pettine and co-workers $(1994,1998)$ reported that the kinetics of $\mathrm{Cr}(\mathrm{VI})$ reduction by $\mathrm{H}_{2} \mathrm{~S}$ under seawater conditions could be described by the following equation:

$$
\frac{d[C r(V I)]}{d t}=-k[C r(V I)]^{x}\left[H^{+}\right]^{y}\left[H_{2} S\right]_{T}^{z}
$$

and according to their experiments, the reaction was pseudo first-order with respect to [Cr(VI)], total hydrogen sulfide, and proton activity. They also showed that $\mathrm{Pb}^{2+}, \mathrm{Cu}^{2+}, \mathrm{Cd}^{2+}$, and $\mathrm{Ni}^{2+}$ at micromolar concentrations caused large increases of the reduction rates, while ionic strength had no effect on the reaction. Nevertheless, significant uncertainties in the reaction stoichiometries, kinetics, and mechanism still exist. Based on the large amount of sulfate production in the Cr(VI)-sulfide system, Pettine et al. (1994, 1998) suggested that sulfate was the major final product during the oxidation of sulfide by $\mathrm{Cr}(\mathrm{VI})$, but the exact reaction stoichiometry was not established. In fact, the amount of sulfate detected was much higher than the stoichiometric amount allowed via the reaction with $\mathrm{Cr}(\mathrm{VI})$ alone, which indicated the presence of other parallel reactions such as sulfide oxidation by oxygen.

Recently, the In Situ Gas Reduction (ISGR) approach has been under development for metal 
immobilization in the vadose zone (Thornton and Amonette, 1999), in which hydrogen sulfide is used as a reductant for $\mathrm{Cr}(\mathrm{VI})$ and other contaminant metals. Laboratory investigations have shown that $90 \%$ of $\mathrm{Cr}(\mathrm{VI})$ in soil samples can be immobilized by treatment with diluted $\mathrm{H}_{2} \mathrm{~S}$ (Thornton and Amonette, 1997). A field test at White Sand Missile Range, New Mexico, has resulted in 70\% immobilization of $\mathrm{Cr}(\mathrm{VI})$ (Thornton and Amonette, 1997). The field demonstration has further shown that $\mathrm{H}_{2} \mathrm{~S}$ gas can be handled safely for field application and residual $\mathrm{H}_{2} \mathrm{~S}$ gas can be recovered, so no secondary contamination takes place. There are, however, significant data gaps that needs to be addressed in order to properly evaluate the effectiveness of the technology.

As part of our overall effort to better understand the interactions among $\mathrm{Cr}(\mathrm{VI}), \mathrm{H}_{2} \mathrm{~S}$, and soil minerals, this paper examined $\mathrm{Cr}(\mathrm{VI})$ reduction by $\mathrm{H}_{2} \mathrm{~S}$ in homogeneous aqueous phases. Reaction stoichiometry was investigated by monitoring the degree of reaction and the analysis of solid reaction products with Transmission Electron Microscopy (TEM). Reaction kinetics was measured in a $\mathrm{pH}$ range of $6.5-10$ and a reaction mechanism was proposed to explain the reaction kinetics and the observed $\mathrm{pH}$ dependence.

\section{MATERIALS AND METHODS}

Milli-Q water (Millipore Corp., with resistivity of $18.2 \mathrm{M} \Omega-\mathrm{cm}$ ) was used for all experiments and the glassware was cleaned using $10 \mathrm{~N} \mathrm{HNO}_{3}$ and rinsed with Milli-Q water before use. Chemicals used were at least reagent grade and were from Sigma Chemicals (HEPES) and Fisher Scientific $\left(\mathrm{K}_{2} \mathrm{Cr}_{2} \mathrm{O}_{7}, \mathrm{Na}_{2} \mathrm{~S} \cdot 9 \mathrm{H}_{2} \mathrm{O}, \mathrm{H}_{3} \mathrm{BO}_{3}, \mathrm{KH}_{2} \mathrm{PO}_{4}\right)$. Sulfide stock solution was prepared by dissolving $\mathrm{Na}_{2} \mathrm{~S} \cdot 9 \mathrm{H}_{2} \mathrm{O}$ crystal in degassed water after rinsing to remove the oxidized surface layer. Sulfide stock solution was prepared anew immediately before the initiation of each experiment. $\mathrm{Cr}(\mathrm{VI})$ stock solution was prepared with $\mathrm{K}_{2} \mathrm{Cr}_{2} \mathrm{O}_{7}$ in an amber bottle with degassed water.

Solution $\mathrm{pH}$ was controlled by various buffers including HEPES (N-[2-hydroxyethyl] piperazine$\mathrm{N}^{\prime}$-[2-ethanesulfonic acid]) buffer ( $\mathrm{pH} 6.6$ to 8.2), phosphate buffer ( $\mathrm{pH} 6.5-8.2$ ), and borate buffer ( $\mathrm{pH} 8.2$ - 10.5). The concentration of each buffer was $0.08 \mathrm{M}$. Preliminary tests showed that there was no reactions between the buffers and $\mathrm{Cr}(\mathrm{VI})$ or buffers and sulfide.

Experimental procedures. $\mathrm{Cr}(\mathrm{VI})$ reduction in HEPES buffer solution followed the following procedure: $1000 \mathrm{ml}$ of water was transferred into an amber bottle and purged with nitrogen gas to decrease oxygen content for $1 \mathrm{hr}$. Crystal sodium sulfide was then introduced into the aqueous phase and the bottle was covered with a Teflon dispenser screwed cap. Once sodium sulfide was dissolved, sulfide concentration was standardized by iodometric titration. An adequate amount of sulfide stock solution was transferred into acid washed amber vials containing $\mathrm{Cr}$ (VI) stock solution, degassed Milli-Q water, and buffer solution. The vials were closed immediately with Teflon-lined septa and crimp-sealed with aluminum caps. Each vial contained a total of $14.0 \mathrm{ml}$ solution with a headspace less than $1 \%$ of the total volume. A typical reaction system had $20 \mu \mathrm{M}$ $\mathrm{Cr}(\mathrm{VI}), 200-800 \mu \mathrm{M}$ total sulfide, and $0.08 \mathrm{M}$ buffer with a target $\mathrm{pH}$ range of 6.6-8.2. Several tests contained $200 \mu \mathrm{M} \mathrm{Cr}(\mathrm{VI})$ and $100 \mu \mathrm{M}$ sulfide, which were designed to investigate the stoichiometric amount of sulfide required for $\mathrm{Cr}(\mathrm{VI})$ reduction. The prepared vials were mounted onto the rotating shaker (Bellco. Glass Inc.) at $10 \mathrm{rpm}$. All tests were conducted in a temperature controlled room at $23.5 \pm 0.5^{\circ} \mathrm{C}$.

For $\mathrm{Cr}(\mathrm{VI})$ reduction in phosphate and borate buffers, $60-\mathrm{ml}$ polypropylene syringes were used as 
reactors. Preliminary experiments using different types of reaction vessels, including $60 \mathrm{ml}$ polypropylene syringes, $14 \mathrm{ml}$ amber glass bottles sealed with Teflon-lined septa, and $250 \mathrm{ml}$ polypropylene bottles, gave the same kinetic results under otherwise the same experimental conditions. Preliminary experiments also showed that purging of $\mathrm{Q}-\mathrm{H}_{2} \mathrm{O}$ with $\mathrm{N}_{2}$ gas for one hour prior to use did not affect $\mathrm{Cr}(\mathrm{VI})$ reduction kinetics. This implied that either the dissolved oxygen was still present even in the $\mathrm{N}_{2}$-purged water in the experimental system or the oxidation of $\mathrm{H}_{2} \mathrm{~S}$ by oxygen didn't significantly affect the reduction of $\mathrm{Cr}(\mathrm{VI})$. This reaction vessel was a closed system to air after the system setup. Generally, reagents were prepared and added into the reaction vessel following the order: (1) preparing pH-buffered solution; (2) dissolving $\mathrm{Na}_{2} \mathrm{~S} \cdot 9 \mathrm{H}_{2} \mathrm{O}$ crystals rinsed with Milli-Q water in the pH-buffered solution; (3) splitting pH-buffered $\mathrm{Na}_{2} \mathrm{~S}$ solution into polyethylene beakers; (4) adding the $\mathrm{Cr}(\mathrm{VI})$ stock solution, (5) withdrawing the solution into a $60 \mathrm{ml}$ syringe, and (6) mixing on the rotor drum at $10 \mathrm{rpm}$ and sampling as a function of time. This procedure will be adapted to investigate $\mathrm{Cr}(\mathrm{VI})$ reduction in the presence of minerals.

Ionic strength was not controlled in this study because our preliminary experiments and the literature (Pettine et al., 1994) all indicate that the effect of ionic strength is negligible when it is between 0.0 and $1.0 \mathrm{M}$. In this study, the ionic strength was always less than $0.1 \mathrm{M}$.

Analytical Methods. Aqueous Cr(VI) concentration was determined using the diphenylcarbazide colorimetric method (APHA, 1992). The absorbance was measured in a $1-\mathrm{cm}$ cell at $540 \mathrm{~nm}$ on a spectrophotometer (Spectronic 20 Genesys, Spectronic Instruments). The method had a detection limit of $0.1 \mu \mathrm{M}$. Preliminary experiments showed that under the experimental concentration condition, the interference of reaction products such as elemental sulfur did not interfere with $\mathrm{Cr}(\mathrm{VI})$ analysis. Total $\mathrm{H}_{2} \mathrm{~S}$ in the stock solution was standardized with the standard iodometric titration method (APHA, 1992), and sulfide concentration during the reaction was monitored as a function of time by the methylene blue method (APHA, 1992). Sulfate in the samples was analyzed using turbidimetric method (APHA, 1992). For selected samples, sulfite and thiosulfate were analyzed by high-performance liquid chromatography (HPLC) after derivatization Rethmeier et al., 1997). A Perkin-Elmer HPLC system with an LC 410 pump and a LS 40 fluorescence detector was employed to perform this measurement. The detection limits for sulfite and thiosulfate was 5 and $1 \mu \mathrm{M}$, respectively. A UV spectrophotometer (Genesys 5, Milton Roy Company) was used to detect qualitatively the presence of polysulfide at the wavelength of $290 \mathrm{~nm}$ (Chen and Morris, 1972). An Orion 420A pH meter was used to measure $\mathrm{pH}$ after a 2point calibration.

In order to detect elemental sulfur formation without the interference from oxygen, a set of experiments was performed in an anaerobic chamber (Models 855-AC, Plas-Labs Inc.). Samples were prepared with $400 \mu \mathrm{M}$ of $\mathrm{Cr}(\mathrm{VI})$ and $200 \mu \mathrm{M}$ of sulfide at $\mathrm{pH}$ of 7.4 in HEPES buffer, following the same procedures as mentioned before. After 2 weeks of reaction, the solid products were analyzed with Transmission Electron Microscopy (TEM) and associated Energy-Dispersive $\mathrm{X}$-ray Spectroscopy (EDS). The solution containing colloidal particles of the reaction products was dropped on a holey $\mathrm{Cu}$ grids coated with carbon and allowed to dry. The grids were then placed in a specimen holder for analysis. All TEM and EDS results were carried out on a JEOL 2010 high-resolution TEM and an Oxford Link ISIS EDS system at the University of New Mexico. Mineral standards were used for quantification of collected EDS data (Xu and Wang, 2000). 


\section{RESULTS AND DISCUSSION}

Reaction Stoichiometry. While it is known that the reduction of $\mathrm{Cr}(\mathrm{VI})$ results in the production of $\mathrm{Cr}$ (III) species (Deng, 1995), oxidation of sulfide could potentially generate sulfur species in several oxidation states including $\mathrm{S}_{2} \mathrm{O}_{6}{ }^{2-}, \mathrm{SO}_{3}{ }^{2-}, \mathrm{SO}_{4}{ }^{2-}, \mathrm{S}^{0}$, and polysulfides. To illustrate, below are two possible stoichiometries corresponding to elemental sulfur and sulfate production:

$$
\begin{gathered}
2 \mathrm{CrO}_{4}^{2-}+3 \mathrm{H}_{2} \mathrm{~S}+4 \mathrm{H}^{+} \rightarrow 2 \mathrm{Cr}(\mathrm{OH})_{3(\mathrm{~S})}+3 \mathrm{~S}_{(\mathrm{S})}+2 \mathrm{H}_{2} \mathrm{O} \\
8 \mathrm{CrO}_{4}^{2-}+3 \mathrm{H}_{2} \mathrm{~S}+10 \mathrm{H}^{+}+4 \mathrm{H}_{2} \mathrm{O} \rightarrow 8 \mathrm{Cr}(\mathrm{OH})_{3(\mathrm{~S})}+3 \mathrm{SO}_{4}^{2-}
\end{gathered}
$$

The equilibrium constants for the reactions (2) and (3) at $\mathrm{pH} 7.00$ are $\log \mathrm{K}=91$, and 323 , respectively (calculated from data in 37 ), so both reactions are energetically favorable. Based on the reactions (2) and (3), the stoichiometric ratio of sulfide to $\mathrm{Cr}(\mathrm{VI})$ is 1.5 when elemental sulfur is stable in the system, and 0.38 when sulfate is the final product.

Earlier studies suggested that sulfate was the major product based on the very high concentration of sulfate detected during $\mathrm{Cr}(\mathrm{VI})$ reduction by $\mathrm{H}_{2} \mathrm{~S}$ (Pettine et al. 1994). This was not nearly conclusive, however, since sulfate concentration was significantly higher than the amount required by the reaction stoichiometry (Eq. 3). Similar results were observed in our experiments where high concentration of sulfate was detected after 2 hours of reaction. In addition, nonnegligible concentration of thiosulfate and low concentration of sulfite were also detected in the solution. Because sulfate, sulfite, and thiosulfate were known products of sulfide oxidation by oxygen (Cline \& Richards, 1969; O’Brien \& Birkner, 1977; Zhang \& Millero, 1993), these three sulfur species identified in our samples could be derived from the oxidation of sulfide with oxygen present in the reactor. These different forms of sulfur products therefore do not provide proof for sulfate as a final product of sulfide oxidation by $\mathrm{Cr}(\mathrm{VI})$.

In order to establish the correct reaction stoichiometry, we monitored the reaction between 200 $\mu \mathrm{M}$ of $\mathrm{Cr}(\mathrm{VI})$ and $106 \mu \mathrm{M}$ of sulfide in the HEPES buffer system $(\mathrm{pH}$ 8.2) until all sulfide was consumed. As shown in Fig. 2-1, the reduction of $200 \mu \mathrm{M}$ of $\mathrm{Cr}(\mathrm{VI})$ by $106 \mu \mathrm{M}$ of sulfide indicated that after sulfide was used up, aqueous $\mathrm{Cr}(\mathrm{VI})$ concentration remained constant at 128 $\mu \mathrm{M}$. The total amount of $\mathrm{Cr}(\mathrm{VI})$ reduced in the experiment is approximately $72 \mu \mathrm{M}$. Thus, the ratio of consumed $\left[\mathrm{H}_{2} \mathrm{~S}\right]$ to reduced $[\mathrm{Cr}(\mathrm{VI})]$ is about 1.5. Experiments at $\mathrm{pH} 7.8$ similarly generated stoichiometry ratios ranging from 1.44 to 1.60 with average value of 1.51 (data not shown). The results suggest that the appropriate reaction stoichiometry between $\mathrm{Cr}$ (VI) and sulfide is Eq. 2, in which elemental sulfur serves as the stable oxidation product of sulfide. Fig. 2-1 also shows that sulfide concentration in the control is decreased by approximately $4 \%$ at $1-\mathrm{hr}$, and $10 \%$ at $2-\mathrm{hr}$ in the absence of $\mathrm{Cr}(\mathrm{VI})$. Thus, the loss of sulfide, possibly due to evaporation or oxidation with oxygen, is not significant during the first 1 to $2 \mathrm{hrs}$ of kinetic data collection for most of the tests conducted in this study. The loss of sulfide through these processes under high $\mathrm{Cr}(\mathrm{VI})$ over sulfide as used for assessing the reaction stoichiometry should be even less due to the rapid oxidation by $\mathrm{Cr}(\mathrm{VI})$.

Fig. 2-2a is a TEM image of the stabilized final products of $\mathrm{Cr}(\mathrm{VI})$ reduction by sulfide. There are two distinct regions, area $\mathrm{A}$ with amorphous structure and area $\mathrm{B}$ consisting of particles with $100 \mathrm{~nm}$ in diameter. EDS spectra (Fig. 2-2b) shows that sulfur is the major species in area A, while in area B, sulfur, chromium, and oxygen coexist and chromium appears to be present as coatings of the sulfur layer. It is important to notice that the peak for oxygen is not associated with the sulfur peak as in area A, thus, the sulfur must be mainly in the form of elemental sulfur. Elemental sulfur as the oxidation product of sulfide by $\mathrm{Cr}(\mathrm{VI})$ has not been reported before. Direct detection of elemental sulfur here supports the conclusion that the overall reaction for 
Cr(VI) reduction by sulfide primarily follows the stoichiometry represented by Eq. 2 .

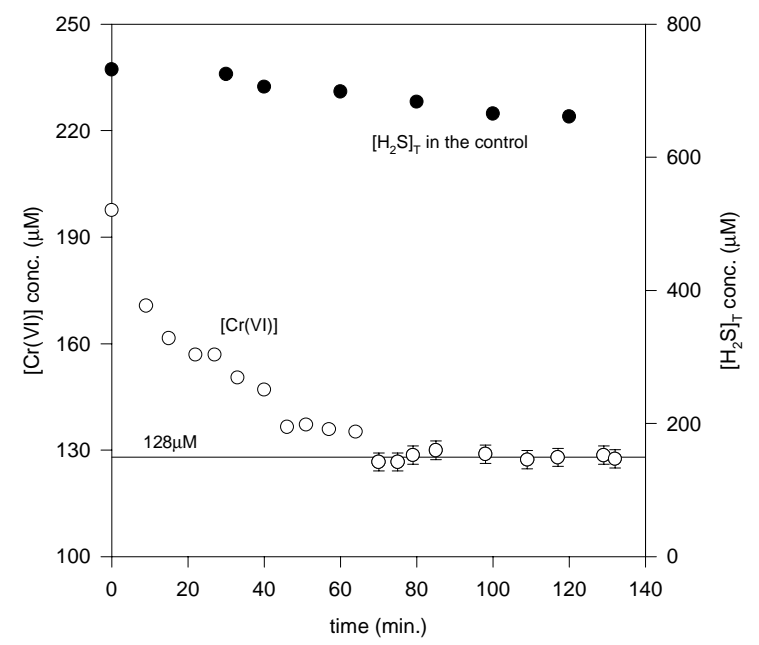

Figure 2-1. Reaction between $200 \mu \mathrm{M}$ Cr(VI) reduction with $106 \mu \mathrm{M}$ sulfide showed that the ratio of sulfide in the system to the amount of $\mathrm{Cr}(\mathrm{VI})$ consumed is close to 1.5. The figure also indicated that sulfide in the control was stable during the time period tested. ( $\mathrm{pH} 8.2$ controlled by HEPES buffer).

Reaction Kinetics. Kinetics of $\mathrm{Cr}(\mathrm{VI})$ reduction by hydrogen sulfide depends on reactant concentrations and $\mathrm{pH}$. The rate equation by Pettine et al. $(1994,1998)$ (see Eq. 1) was based on experiments at very low $\mathrm{Cr}(\mathrm{VI})(1.9 \mu \mathrm{M})$ and high $\mathrm{H}_{2} \mathrm{~S}(\sim 400-1400 \mu \mathrm{M})$ concentrations in the $\mathrm{pH}$ range of 7.5 - 10.5. Our experiments used much higher $\mathrm{Cr}(\mathrm{VI})$ concentrations that are likely to be present at hazardous waste sites and over a wider $\mathrm{pH}$ range, aiming to see whether the kinetics remain the same. According to Eq. 1, the rates of $\mathrm{Cr}(\mathrm{VI})$ reduction at constant $\mathrm{pH}$ can be expressed as:

$$
d[\mathrm{Cr}(\mathrm{VI})] / d t=-k[\mathrm{Cr}(\mathrm{VI})]^{x}\left[\mathrm{H}_{2} \mathrm{~S}\right]^{y}
$$

where $x$ and $y$ are the reaction order and $k$ is the overall rate constant. When sulfide concentration is much higher than $\mathrm{Cr}(\mathrm{VI})$ concentration, the rate equation can be simplified to:

$$
d[\mathrm{Cr}(\mathrm{VI})] / d t=-k_{o b s}[\mathrm{Cr}(\mathrm{VI})]^{x}
$$

with $k_{o b s}=k\left[\mathrm{H}_{2} \mathrm{~S}\right]^{y}$.

Rates of $\mathrm{Cr}(\mathrm{VI})$ reduction under various initial concentrations of $\mathrm{Cr}(\mathrm{VI})$ are presented in Fig. 2-4. Since $\operatorname{Cr}(\mathrm{VI})$ concentrations used $(20-40 \mu \mathrm{M})$ are much less than the sulfide concentration ( $800 \mathrm{mM}$ ), sulfide concentration will remain near constant during the initial stage of the reaction. It is clear that plots of $\log [\mathrm{Cr}(\mathrm{VI})]$ versus time are linear $\left(0.979<\mathrm{r}^{2}<0.983\right)$ under various initial $\mathrm{Cr}(\mathrm{VI})$ concentrations (Fig. 2-4), suggesting a first order reaction with respect to $\mathrm{Cr}(\mathrm{VI})$. This result agrees with the earlier studies (Pettine et al., 1994, 1998). The rate constants $k_{\text {obs }}$ obtained from our experimental results are $0.0305 \mathrm{~min}^{-1}$ (S.D.: 0.00057) in this HEPES buffered system at $\mathrm{pH} 7.4$. 


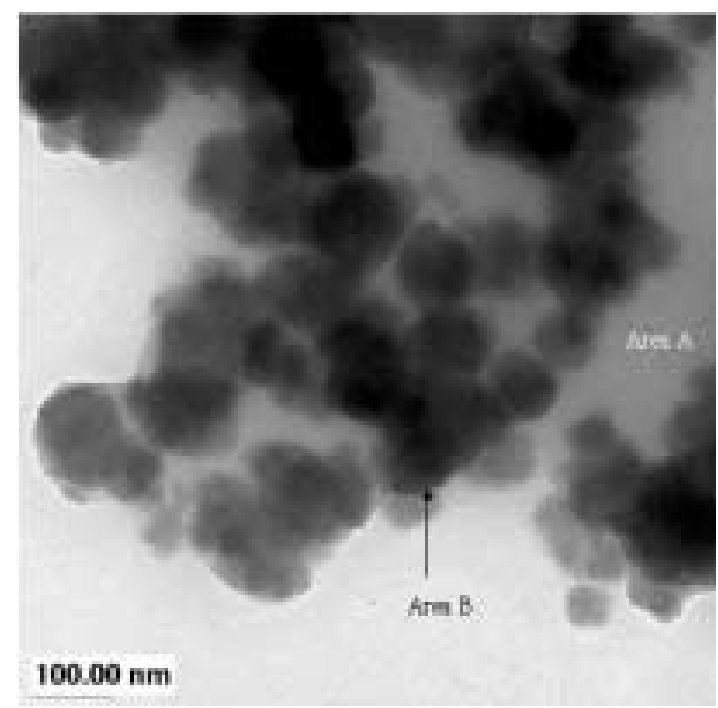

Figure 2-2. (a) Bright-field TEM image of the reaction products showing aggregates of elemental S (area A) and amorphous $\mathrm{Cr}$-hydroxide (area B). It is proposed that the reduced $\mathrm{Cr}$ is amorphous $\mathrm{Cr}(\mathrm{OH})_{3}$.
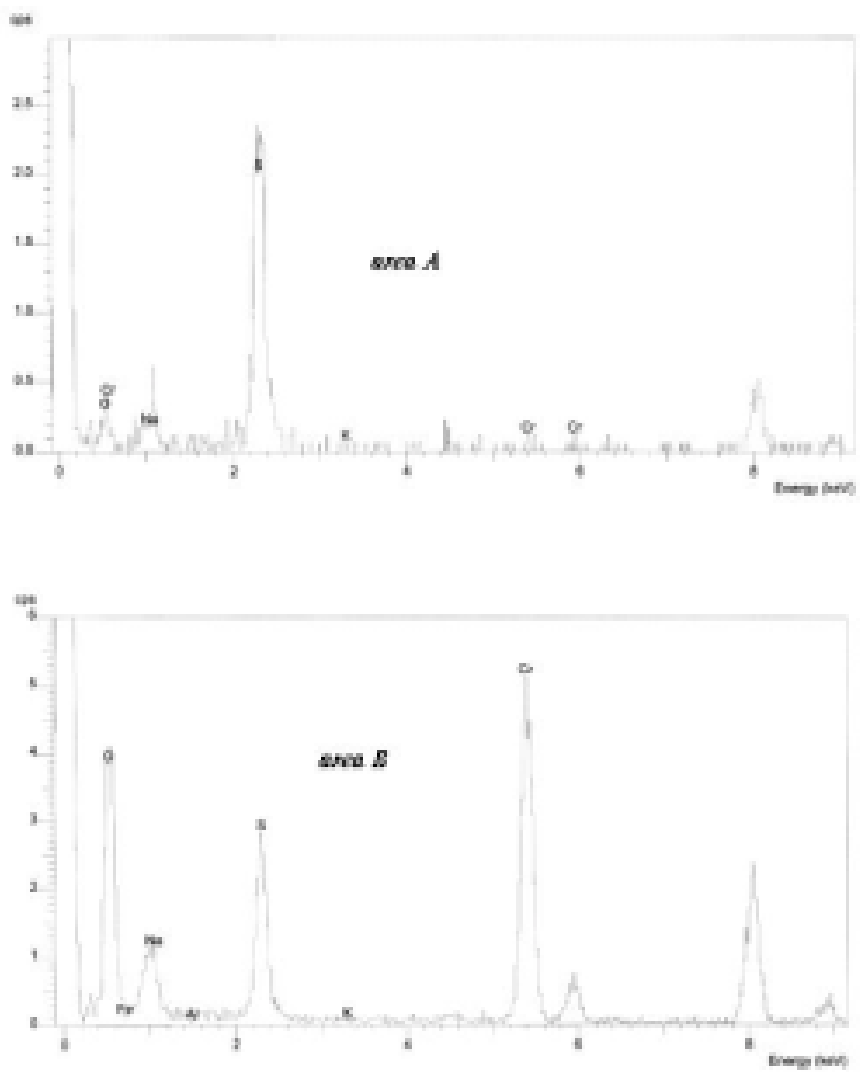

Figure 2-3. EDS spectra from area A and area B of the TEM image in Figure 2-2. The spectrum from area $\mathrm{B}$ shows $\mathrm{Cr}, \mathrm{O}$, and $\mathrm{S}$ peaks. The $\mathrm{S}$ peak results from elemental $\mathrm{S}$ coating Cr-hydroxide particles. All $\mathrm{Cu}$ peaks (both $\mathrm{K}$ and $\mathrm{L}$ lines) result from $\mathrm{Cu}$ grid holding the specimen. 


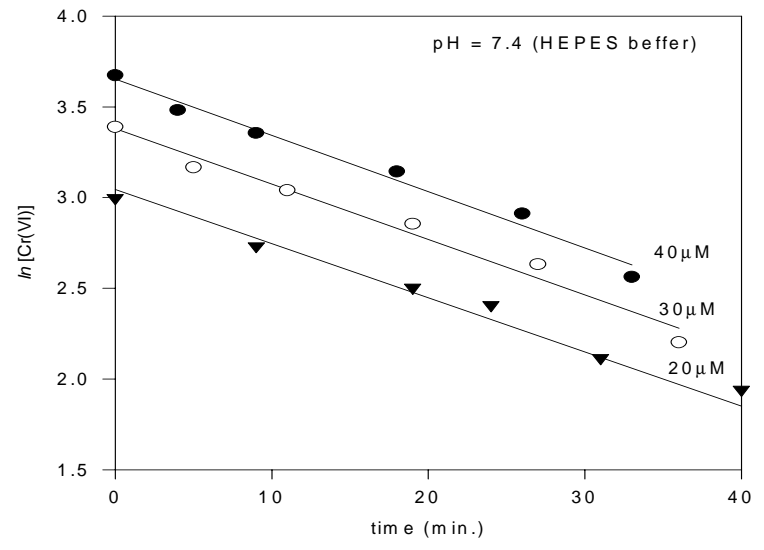

Figure 2-4. The $\log [\mathrm{Cr}(\mathrm{VI})]$ versus t plots under different initial $\mathrm{Cr}(\mathrm{VI})$ concentrations at $\mathrm{pH} 7.4$ (HEPES buffer). The reaction is pseudo-first order with respect to $\mathrm{Cr}(\mathrm{VI})$.

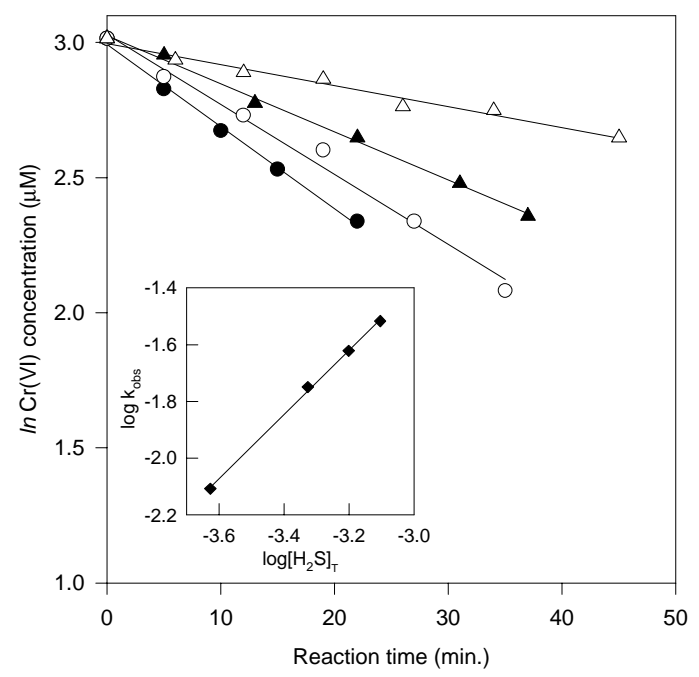

Figure 2-5. Effects of initial sulfide concentration on $\mathrm{Cr}(\mathrm{VI})$ reduction. The reaction is first-order with respect to the total sulfide concentration.

Effect of initial sulfide concentrations $(236-790 \mu \mathrm{M})$ on the reduction of $\mathrm{Cr}(\mathrm{VI})(20 \mu \mathrm{M})$ was also studied in HEPES buffered solutions with $\mathrm{pH}$ 7.4. As shown in Fig. 2-5, Cr(VI) reduction rate increases as initial sulfide concentration is increased. Linear plots of $\ln [\mathrm{Cr}(\mathrm{VI})]$ vs. $\mathrm{t}$ are obtained under all sulfide concentrations. The inset is a plot of $\log k_{o b s}$ versus $\log \left[\mathrm{H}_{2} \mathrm{~S}\right]_{\mathrm{T}}$. The data can be fitted by a straight line with a slope of $1.13\left(\mathrm{r}^{2}=0.9988\right)$, suggesting a first order reaction with respect to $\mathrm{H}_{2} \mathrm{~S}$. It is thus clear that Eq. 4 applies for $\mathrm{Cr}(\mathrm{VI})$ reduction in the concentration ranges used in this study.

Solution $\mathrm{pH}$ has a dramatic effect on $\mathrm{Cr}(\mathrm{VI})$ reduction by sulfide (Fig. 2-6). The reduction rate increased as $\mathrm{pH}$ was decreased. The linear plots of $\ln [\mathrm{Cr}(\mathrm{VI})]$ vs. $t$ indicate that the reaction was pseudo first order with respect to $\mathrm{Cr}(\mathrm{VI})$ in all buffer solutions. The slopes of these linear plots, i.e. the observed rate constants $\left(\mathrm{k}_{\mathrm{obs}}\right)$, are shown in Fig. $2-7$ as a function of $\mathrm{pH}$. The results reveal that $\mathrm{k}_{\mathrm{obs}}$ decreased significantly as $\mathrm{pH}$ was increased. It should be noted that the solid curve in the Fig. 2-6 is not the fitting curve of the data but the calculated mole fraction of hydrogen sulfide as a function of $\mathrm{pH}\left(\mathrm{f}=\left[\mathrm{H}_{2} \mathrm{~S}\right] /\left(\left[\mathrm{H}_{2} \mathrm{~S}\right]+\left[\mathrm{HS}^{-}\right]+\left[\mathrm{S}^{2-}\right]\right)\right.$. The curve and the data agree well, suggesting that the rate dependence on $\mathrm{pH}$ can be explained by assuming that $\mathrm{H}_{2} \mathrm{~S}$ is the major species involved in $\mathrm{Cr}(\mathrm{VI})$ reduction.

The types of buffers seemed to have no effect on the reaction rate in the homogeneous aqueous system. The $\mathrm{k}_{\mathrm{obs}}$ values of $\mathrm{Cr}(\mathrm{VI})$ reduction by $\mathrm{H}_{2} \mathrm{~S}$ at the same $\mathrm{pH}$ buffered with borate and 
phosphate were the same (results not shown). Additionally, the changes of $\mathrm{k}_{\mathrm{obs}}$ were smooth as a function of $\mathrm{pH}$.

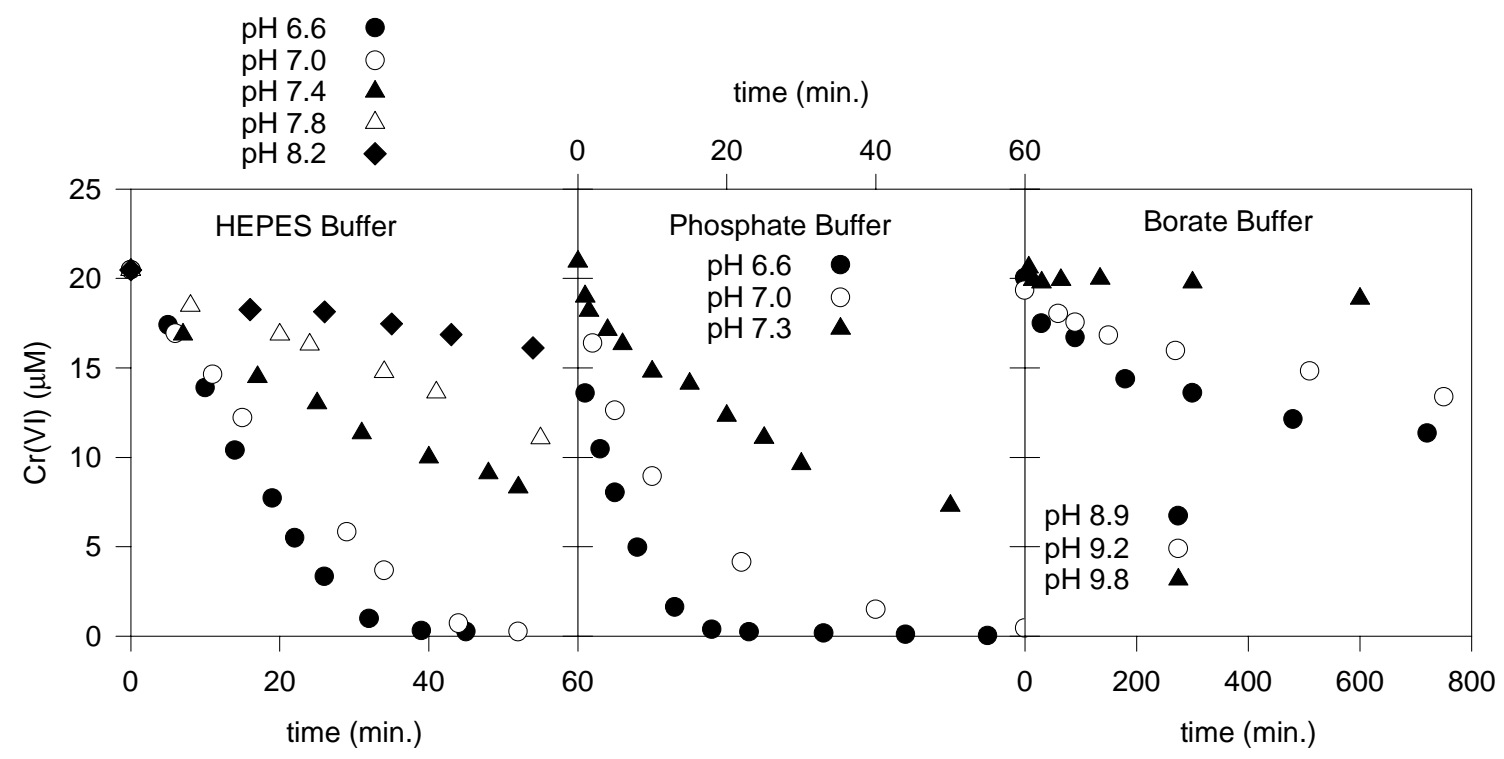

Figure 2-6. Effect of $\mathrm{pH}$ on $\mathrm{Cr}(\mathrm{VI})$ reduction in solutions buffered by HEPES (a), phosphate (b), and borate (c) buffers.

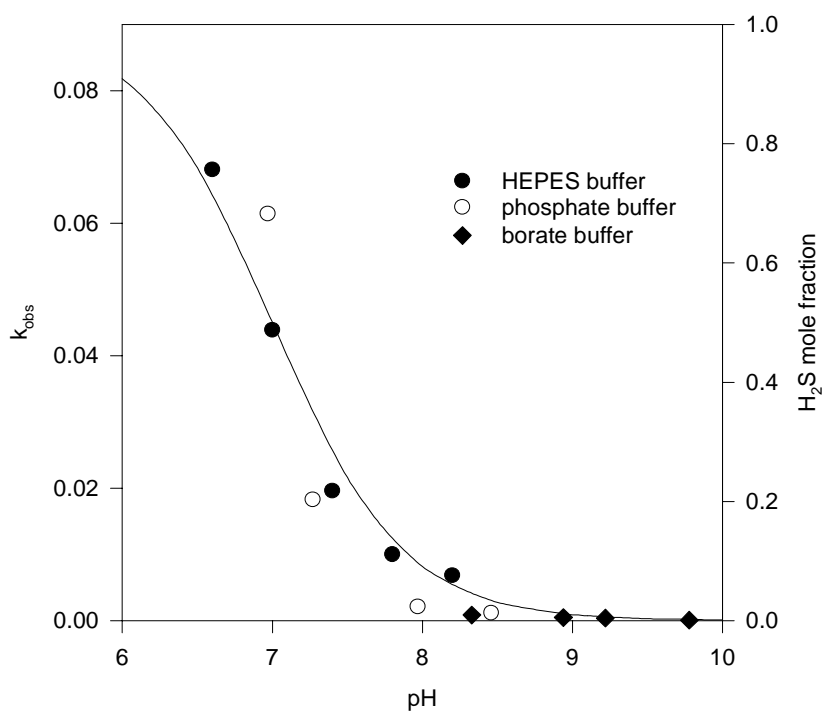

Figure 2-7. The change of $\mathrm{k}_{\mathrm{obs}}$ as a function of $\mathrm{pH}$. The dots are the experimental results and the curve is the mole fraction of $\mathrm{H}_{2} \mathrm{~S}$ species calculated based on the dissociation constants of hydrogen sulfide: $\mathrm{pK}_{1}=7.05$ and $\mathrm{pK}_{2}=19$. 
Reaction Mechanism. The first-order reduction with respect to $\mathrm{Cr}(\mathrm{VI})$ and reductant concentrations are consistent with the previous studies of $\mathrm{Cr}(\mathrm{VI})$ reduction by $\mathrm{H}_{2} \mathrm{~S}$ (Pettine et al., 1994, 1998), ascorbate (Dixon et al., 1995), and thiol compounds (Connett and Wetterhahn, 1985; Shi et al., 1999). The studies on $\mathrm{Cr}(\mathrm{VI})$ reduction by thiols have shown that the reaction begins with the formation of a $\mathrm{Cr}(\mathrm{VI})$ thioester followed by either a redox reaction involving a second molecule of thiol or an unimolecular redox reaction of the thioester (Connett and Wetterhahn, 1985). The $\mathrm{Cr}(\mathrm{VI})$-thioesters have been identified spectroscopically (e.g. with glutathione, cysteine, and thiolactate), suggesting that the reaction take place by an inner-sphere mechanisms.

The electron transfer step could take place faster or slower than the formation of the thioester, depending on the reductant. This thioester formation step limits $\mathrm{Cr}(\mathrm{VI})$ reduction by some reductants (e.g., thiolactate, thiomalate, and penicillamine), since the electron transfer step is faster than the rate of $\mathrm{Cr}(\mathrm{VI})$ ligand exchange, or $\mathrm{Cr}(\mathrm{VI})$-thioester formation (Connett and Wetterhahn, 1985).

We propose that the attack of chromate by hydrogen sulfide also proceeds by the formation of a precursor. A three-step mechanism proposed for the reduction of $\mathrm{Cr}(\mathrm{VI})$ by $\mathrm{H}_{2} \mathrm{~S}$ is illustrated by Eq. 6-12. The first step (Eqs 6 and 7) involves the formation of a chromium-sulfur precursor like $\left\{\mathrm{H}_{2} \mathrm{O}_{4} \mathrm{CrS}\right\}^{2-}$. The attack of chromate ion by a $\mathrm{H}_{2} \mathrm{~S}$ molecule (Eq 6) is most likely, considering the lock of an ionic strength effect on the reaction and the rate dependence on $\mathrm{H}_{2} \mathrm{~S}$ observed in this study (Fig 2-6). The effect of $\mathrm{pH}$ can be alternatively interpreted by a $\mathrm{HS}^{-}$attack of $\mathrm{HCrO}_{4}^{-}$ (Eq 7) since $\mathrm{HS}^{-}$is the main species in most of the $\mathrm{pH}$ range examined, however, this mechanism is not supported by the fact that ionic strength does not affect the reaction. The second step involves either an intra-molecular electron transfer of the precursor complex (Eq 8) or the reaction of the precursor with a second $\mathrm{H}_{2} \mathrm{~S}(\mathrm{Eq} 9)$. A two-electron transfer process is proposed since our experiments indicate the existence of elemental sulfur as a product. The third step accounts for the reactions of $\mathrm{Cr}(\mathrm{IV})$ and/or $\mathrm{Cr}(\mathrm{V})$, which are normally very fast and may not affect the overall reaction kinetics.

Step 1:

$$
\begin{aligned}
& \mathrm{H}_{2} \mathrm{~S}+\mathrm{CrO}_{4}^{2-} \stackrel{k_{1}}{\longleftrightarrow}\left\{\mathrm{H}_{2} \mathrm{O}_{4} \mathrm{Cr}^{V I} \mathrm{~S}\right\}^{2-} \\
& \mathrm{HS}^{-}+\mathrm{CrO}_{4}^{2-}+\mathrm{H}^{+} \stackrel{k_{1}^{\prime}}{\longleftrightarrow}\left\{\mathrm{H}_{2} \mathrm{O}_{4} \mathrm{Cr}^{V I} \mathrm{~S}\right\}^{2-}
\end{aligned}
$$

Step 2:

$$
\begin{aligned}
& \left\{\mathrm{H}_{2} \mathrm{O}_{4} \mathrm{Cr}^{V I} \mathrm{~S}\right\}^{2-} \stackrel{k_{2}}{\longrightarrow} \mathrm{Cr}^{I V} \mathrm{O}_{3}{ }^{2-}+\mathrm{S}^{0}+\mathrm{H}_{2} \mathrm{O} \\
& \left\{\mathrm{H}_{2} \mathrm{O}_{4} \mathrm{Cr}^{V I} \mathrm{~S}\right\}^{2-}+\mathrm{H}_{2} \mathrm{~S} \stackrel{k_{3}}{\longrightarrow} \mathrm{Cr}^{I V} \mathrm{O}_{3}{ }^{2-}+\mathrm{HSSH}+\mathrm{H}_{2} \mathrm{O}
\end{aligned}
$$

Step 3:

$$
\begin{aligned}
& \mathrm{Cr}^{I V}+\mathrm{Cr}^{V I} \stackrel{\mathrm{k}_{4}}{\longrightarrow} 2 \mathrm{Cr}^{V} \\
& 2 \mathrm{Cr}^{I V} \stackrel{k_{5}}{\longrightarrow} \mathrm{Cr}^{I I I}+\mathrm{Cr}^{V} \\
& \mathrm{Cr}^{V}+\mathrm{S}^{-I I} \stackrel{k_{6}}{\longrightarrow} \mathrm{Cr}^{I I I}+S^{0}
\end{aligned}
$$

The precursor formation and the electron transfer proceed sequentially. If the formation of the intermediate thiol compounds is slower than the electron transfer processes and the overall reaction is limited by the slow step, the concentration of the precursor would reach a steady state. A rate law consistent with this mechanism is: 


$$
\frac{d[\mathrm{Cr}(\mathrm{VI})]}{d t}=\frac{-k_{1}\left(k_{3}\left[\mathrm{H}_{2} \mathrm{~S}\right]+k_{2}\right)}{k_{-1}+k_{2}+k_{3}\left[\mathrm{H}_{2} \mathrm{~S}\right]}\left[\mathrm{H}_{2} \mathrm{~S}\right]\left[\mathrm{CrO}_{4}{ }^{2-}\right]
$$

where $k_{2}$ represents the electron transfer by Eq. 8 to form elemental sulfur and $k_{3}\left[\mathrm{H}_{2} \mathrm{~S}\right]$ by Eq. 9 to form polysulfides. Polysulfides such as tetrasulfide and pentasulfide were detected in neutral and slightly basic solutions (O'Brien, and Birkner, 1977). Our experiments with HPLC and UVvisible spectroscopy, however, failed to show the presence of polysulfides, suggesting that the Eq. 8 is more important (i.e., $\left.k_{2}>>k_{3}\left[\mathrm{H}_{2} \mathrm{~S}\right]\right)$. Consequently, Eq. 13 can be simplified as:

$$
\frac{d[\mathrm{Cr}(\mathrm{VI})]}{d t}=\frac{-k_{1} k_{2}}{k_{-1}+k_{2}}\left[\mathrm{H}_{2} \mathrm{~S}\right]\left[\mathrm{CrO}_{4}{ }^{2-}\right]
$$

In this equation, $\left[\mathrm{H}_{2} \mathrm{~S}\right]$ is the concentration of the fully protonated species of sulfide, rather than the total concentration of sulfide $\left[\mathrm{H}_{2} \mathrm{~S}\right]_{\mathrm{T}}$ as monitored analytically as a function of time. $\left[\mathrm{H}_{2} \mathrm{~S}\right]$ can be easily calculated based on the dissociation constants for hydrogen sulfide, $\mathrm{pH}$, and $\left[\mathrm{H}_{2} \mathrm{~S}\right]_{\mathrm{T}}$ as shown in Eq. 15:

$$
\left[H_{2} S\right]=\left[H_{2} S\right]_{T}\left\{\frac{\left[H^{+}\right]^{2}}{\left[H^{+}\right]^{2}+\left[H^{+}\right] K_{1}+K_{1} K_{2}}\right\}
$$

where $\mathrm{K}_{1}$ and $\mathrm{K}_{2}$ are the dissociation constants for $\mathrm{H}_{2} \mathrm{~S}$ and $\mathrm{HS}^{-}$, respectively. Combining Eq. 14 and 15, we have:

$$
\begin{aligned}
\frac{d[\mathrm{Cr}(\mathrm{VI})]}{d t} & =\frac{-k_{1} k_{2}\left[\mathrm{CrO}_{4}{ }^{2-}\right]\left[\mathrm{H}_{2} S\right]_{T}}{k_{-1}+k_{2}}\left\{\frac{\left[\mathrm{H}^{+}\right]}{\left[H^{+}\right]^{2}+\left[H^{+}\right] K_{1}+K_{1} K_{2}}\right\} \\
& =\frac{-k_{1} k_{2} Q\left[\mathrm{CrO}_{4}{ }^{2-}\right]\left[\mathrm{H}_{2} S\right]_{T}}{k_{-1}+k_{2}}
\end{aligned}
$$

where $Q=\left\{\frac{\left[H^{+}\right]^{2}}{\left[H^{+}\right]^{2}+\left[H^{+}\right] K_{1}+K_{1} K_{2}}\right\}$

It is clear that the second order kinetics observed for $\mathrm{Cr}(\mathrm{VI})$ reduction by sulfide can be explained by this reaction scheme, with $k_{1} k_{2} Q /\left(k_{-1}+k_{2}\right)$ in equation 17 corresponding to the second order rate constant, $k$, of the equation 4 . If the electron transfer step is much faster than the reversible step of the intermediate thiol compound $\left(k_{2}>>k_{-1}\right)$, the formation of the intermediate compound would be rate-limiting, resulting in an overall rate constant $k=k_{l} Q$. It should be noted that $Q$ is a function of $\mathrm{pH}(\mathrm{Eq} 18)$. As $\mathrm{pH}$ increases (approximately up to 11), the slope of $\log Q$ versus $\mathrm{pH}$ goes toward -1 due to the ignorable values of the 1 st and 3rd terms at denominator, while as $\mathrm{pH}$ decreases, the slope moves to 0 . Such a $\mathrm{pH}$ dependence agrees well with the current experimental results (Fig. 2-6), i.e., the overall rate constant $k$ of $\mathrm{Cr}(\mathrm{VI})$ reduction by sulfide is proportional to the mole fraction of $\mathrm{H}_{2} \mathrm{~S}$ species in the solution. The result, however, is not in conflict with the observation by Pettine et al (27), where a slope of 1 was obtained from a linear $\log k_{o b s}$ vs. pH plot. The difference is resulted from the different $\mathrm{pH}$ ranges tested. When our data in the comparable $\mathrm{pH}$ range $(\mathrm{pH} 7-9.8)$ are also presented by the $\log k_{o b s}$ vs. $\mathrm{pH}$ plot, we similearly obtain a straight line with a slope of -0.99 . The linear $\log k_{o b s}$ vs. pH plot is only valid under basic condition, not for the whole $\mathrm{pH}$ range tested in this study. Under strongly acidic conditions where sulfide exists mainly as $\mathrm{H}_{2} \mathrm{~S}$, it is expected that $k_{o b s}$ will be $\mathrm{pH}$-independent, but further research, suitable for measuring fast reduction kinetics under acidic condition, is needed to confirm the 
prediction. Additionally, $\mathrm{Cr}(\mathrm{VI}) \mathrm{acid} / \mathrm{base}$ speciation may affect the reaction rate and needs to be assessed.

\section{CONCLUSIONS}

This part of the work was to investigate the reaction stochiometry, kinetics, and mechanism for $\mathrm{Cr}(\mathrm{VI})$ reduction by hydrogen sulfide in the aqueous phase. Batch experiments with excess $[\mathrm{Cr}(\mathrm{VI})]$ over $\left[\mathrm{H}_{2} \mathrm{~S}\right]_{\mathrm{T}}$ indicated that the molar amount of sulfide required for the reduction of one molar of $\mathrm{Cr}(\mathrm{VI})$ was 1.5, suggesting the main product of sulfide oxidation be elemental sulfur. Further study with Transmission Electron Microscopy (TEM) and Energy-Dispersive X-Ray Spectroscopy (EDS) confirmed that chromium hydroxide and elemental sulfur were the stable products. Aqueous $\mathrm{Cr}(\mathrm{VI})$ reduction by sulfide is first order with respect to each of the two reactants. The effect of $\mathrm{pH}$ results from the speciation change of sulfide, since it appears that only the fully protonated sulfide species reacts with $\mathrm{Cr}(\mathrm{VI})$. Elemental sulfur is the main stable product during sulfide oxidation by $\mathrm{Cr}(\mathrm{VI})$. Such understanding provides insights as how to optimize the design of the ISGR approach for the remediation of chromium-contaminated sites and to predict and assess the system performance. 


\title{
III. CHROMIUM(VI) REDUCTION BY SULFIDE UNDER ANAEROBIC CONDITIONS: CATALYSIS BY ELEMENTAL SULFUR PRODUCT
}

\author{
(Yeqing Lan, Chulsung Kim, Baolin Deng, Edward C. Thornton, and Huifang Xu)
}

\section{INTRODUCTION}

Chromium is one of the most frequently detected soil and groundwater contaminants (Riley and Zachara 1992; NRC 1994). In aquatic environments, chromium occurs mainly as species in the oxidation states of $\mathrm{Cr}^{\mathrm{VI}}$ and $\mathrm{Cr}^{\mathrm{III}}$. Since $\mathrm{Cr}^{\mathrm{III}}$ species are normally less mobile, the reduction of $\mathrm{Cr}^{\mathrm{VI}}$ to $\mathrm{Cr}^{\mathrm{III}}$ decreases chromium mobility and bioavailability. As a result, $\mathrm{Cr}^{\mathrm{VI}}$ reduction is used as a main approach for chromium contamination site remediation.

Many chemicals are capable of reducing $\mathrm{Cr}^{\mathrm{VI}}$ by directly providing electrons in the aquatic system, including zerovalent iron (Blowes et al. 1997; Puls et al. 1999), divalent iron (Eary and Rai 1988; Fendorf and Li 1996; Buerge and Hug 1997), hydrogen sulfide (Pettine et al. 1994; Thornton and Amonette 1999), and organic compounds (Elovitz and Fish 1994; Wittbrodt and Palmer 1995; Deng and Stone 1996a; Deng and Stone 1996b). Rates of $\mathrm{Cr}^{\mathrm{VI}}$ reduction depend upon the types of reductants and solution $\mathrm{pH}$. For example, $\mathrm{Cr}^{\mathrm{VI}}$ reduction by $\mathrm{Fe}^{\mathrm{II}}$ takes place rapidly, with the reaction rate decreasing from $\mathrm{pH} 1.5$ to 4.5 and increasing from $\mathrm{pH} 5.5$ to 8.7 (Buerge and Hug 1997; Pettine et al. 1998). The reduction by many organic compounds is slow near neutral $\mathrm{pH}$ but the rate normally increases as $\mathrm{pH}$ is decreased (Deng 1995). Once reduced, $\mathrm{Cr}^{\mathrm{III}}$ species are quite stable. The only compounds known to oxidize $\mathrm{Cr}^{\mathrm{III}}$ to $\mathrm{Cr}^{\mathrm{VI}}$ are manganese oxides in the subsurface environment (Eary and Rai 1987; Fendorf and Zasoski 1992; Banerjee and Nesbitt 1999).

There are many other chemical constituents that may not directly reduce $\mathrm{Cr}^{\mathrm{VI}}$, but can alter the rate of $\mathrm{Cr}^{\mathrm{VI}}$ reduction. Surface-catalyzed $\mathrm{Cr}^{\mathrm{VI}}$ reduction on goethite $(\alpha-\mathrm{FeOOH})$, aluminum oxide $\left(\alpha-\mathrm{Al}_{2} \mathrm{O}_{3}\right)$ and titanium dioxide by various organic reductants has been observed, including $\alpha$ hydroxyl carboxylic acids and their esters, $\alpha$-carbonyl carboxylic acids, and substituted phenols (Deng and Stone 1996; Deng and Stone 1996). The research revealed that the rate of $\mathrm{Cr}^{\mathrm{VI}}$ reduction could be increased by several orders of magnitude in the presence of some metal (hydr)oxides. In another study, Buerge and Hug (Buerge and Hug 1999) found that $\mathrm{Cr}^{\mathrm{VI}}$ reduction by $\mathrm{Fe}^{\mathrm{II}}$ was strongly enhanced by iron minerals including goethite and lepidocrocite. Dissolved metals such as $\mathrm{Mn}^{\mathrm{II}} / \mathrm{Mn}^{\mathrm{III}}$ and $\mathrm{Fe}^{\mathrm{II}} / \mathrm{Fe}^{\mathrm{III}}$ are also able to catalyze $\mathrm{Cr}^{\mathrm{VI}}$ reduction (Huber and Haight 1976).

$\mathrm{Cr}^{\mathrm{VI}}$ reduction by hydrogen sulfide takes place rapidly in a wide range of $\mathrm{pH}$, with elemental sulfur as the main product of sulfide oxidation (Section II). This reaction has been explored as a remediation approach for chromium immobilization in the subsurface (Thornton and Amonette 1999) and may also contribute to $\mathrm{Cr}^{\mathrm{VI}}$ reduction in natural water and sediments (Pettine et al. 1994). The objective of this paper is to evaluate whether the particulate elemental sulfur produced during the reaction can catalyze further $\mathrm{Cr}^{\mathrm{VI}}$ reduction, similar to other mineral surfaces. 


\section{MATERIALS AND METHODS}

Chemicals: Solutions were prepared by deionized Milli-Q water ( $\mathrm{Q}-\mathrm{H}_{2} \mathrm{O}$, with $18.2 \mathrm{M} \Omega$-cm resistivity, Millipore Corp.) after purging with high purity nitrogen gas for at least $20 \mathrm{~min}$. Glassware was cleaned by soaking in $1 \mathrm{M} \mathrm{HCl}$ for at least $3 \mathrm{hrs}$ and then thoroughly rinsed by Q$\mathrm{H}_{2} \mathrm{O}$. Potassium dichromate, elemental sulfur $\left(\mathrm{S}_{8}\right)$, diphenyl carbazide, acetone, and $\mathrm{N}, \mathrm{N}-$ dimethyl-1,4-phenylene-diamine oxalate were purchased from Aldrich Chemical Company and boric acid, sodium phosphate, sodium hydroxide, sodium sulfide $\left(\mathrm{Na}_{2} \mathrm{~S} \bullet 9 \mathrm{H}_{2} \mathrm{O}\right)$, sulfuric acid, ferric chloride, and diammonium hydrogen phosphate were from Fisher Scientific. The chemicals were at least ACS reagent grade and used without further purification, except that sodium sulfide crystals were rinsed with degassed $\mathrm{Q}-\mathrm{H}_{2} \mathrm{O}$ to remove the oxidized surface layer. Stock solutions of chromate and sulfide were stored in amber bottles placed in an anaerobic chamber (Models 855-AC, PLAS-LABS, INC.) prior to use. Elemental sulfur stock was prepared by crystalline elemental sulfur $\left(\mathrm{S}_{8}\right)$ powder dispersed in acetone.

Experimental Systems: Experiments reported in this study were mostly performed in the anaerobic chamber $\left(\mathrm{N}_{2}\right.$, balanced by $\left.10 \% \mathrm{H}_{2}\right)$, including experimental setup and chemical analyses. Solution $\mathrm{pH}$ was controlled by $0.10 \mathrm{M}$ phosphate buffer $(\mathrm{pH} 7.60)$ or $0.10 \mathrm{M}$ borate buffer $(\mathrm{pH} 8.10)$. No strong electrolytes were applied to control ionic strength in this study, since the literature (Pettine et al. 1994; Pettine et al. 1998) and our preliminary experiments all indicated that the reaction was independent of ionic strength when it was between 0.0 and $1.0 \mathrm{M}$. The actual ionic strength in the experimental systems was determined mainly by the buffer solutions, which was less than $0.10 \mathrm{M}$.

To ensure no sulfide loss due to evaporation, adsorption, and oxygenation, we tested the stability of sulfide at $\mathrm{pH}=7.60$ and $25{ }^{\circ} \mathrm{C}$. First, approximately $40 \mathrm{ml}$ of $0.10 \mathrm{M}$ phosphate buffer was added into a $41 \mathrm{ml}$ amber bottle and degassed with high purity $\mathrm{N}_{2}$ for 20 minutes, then the bottle was moved into the anaerobic chamber. After sulfide stock solution was pippeted into the buffer solution, the bottle was closed by a screw cap with Teflon liner and mixed by hand. Samples $(0.50 \mathrm{ml})$ were taken at 30 -min interval with a $0.5 \mathrm{ml}$ glass syringe for sulfide analysis. Sulfide stability was evaluated for 180 minutes at $200 \mu \mathrm{M}$ concentration level and 120 minutes at $800 \mu \mathrm{M}$ concentration level. Most kinetic experiments in this study followed this procedure with a sulfide concentration ranging from 200 to $800 \mu \mathrm{M}$.

Reaction stoichiometry between $\mathrm{Cr}^{\mathrm{VI}}$ and $\mathrm{S}^{-\mathrm{II}}$ was determined by monitoring the consumption of both reactants with different initial concentration ratios. The temperature was maintained at $15 \pm$ $0.5^{\circ} \mathrm{C}$ and $25 \pm 0.5^{\circ} \mathrm{C}$ using a water bath.

Kinetic experiments were conducted by monitoring $\mathrm{Cr}^{\mathrm{VI}}$ concentration as a function of time in excess sulfide over $\mathrm{Cr}^{\mathrm{VI}}$. At $\mathrm{pH} 7.60$, tests were performed with initial $\mathrm{Cr}^{\mathrm{VI}}$ concentrations ranging from 10 to $60 \mu \mathrm{M}$ and initial sulfide concentrations from 300 to $800 \mu \mathrm{M}$. The temperature varied from 5 to $35^{\circ} \mathrm{C}$. At $\mathrm{pH} 8.10,\left[\mathrm{Cr}^{\mathrm{VI}}\right]_{0}$ and $\left[\mathrm{S}^{\mathrm{II}}\right]_{0}$ were $40 \mu \mathrm{M}$ and $800 \mu \mathrm{M}$, respectively.

Several types of experiments were performed to evaluate whether elemental sulfur produced during $\mathrm{Cr}^{\mathrm{VI}}$ reduction by $\mathrm{S}^{-\mathrm{II}}$ could alter the reaction rate. (1). After $40 \mu \mathrm{M} \mathrm{Cr}^{\mathrm{VI}}$ was completely reduced in a system with $800 \mu \mathrm{M}$ total sulfide, another $40 \mu \mathrm{M} \mathrm{Cr}{ }^{\mathrm{VI}}$ was re-spiked into the system. It is hypothesized that if elemental sulfur was involved in the $\mathrm{Cr}^{\mathrm{VI}}$ reduction, the reduction rate of the re-spiked $\mathrm{Cr}^{\mathrm{VI}}$ should be enhanced by the elemental sulfur produced in the earlier reaction. (2) After $40 \mu \mathrm{M} \mathrm{Cr}{ }^{\mathrm{VI}}$ was completely reduced in a system with $800 \mu \mathrm{M}$ total sulfide, the supernatant was collected by centrifugation at $6000 \mathrm{rpm}$ (IEC Clinical Centrifuge, International Equipment Company), followed by filtration through $0.40 \mu \mathrm{m}$ Millipore membrane filters. The 
supernatant was degassed with $\mathrm{N}_{2}$ again and in the anaerobic chamber, spiked with certain amounts of $\mathrm{Cr}^{\mathrm{VI}}$ and $\mathrm{S}^{\mathrm{II}}$. (3). Colloidal elemental sulfur was added into the buffer solution prior to the additions of $\mathrm{Cr}^{\mathrm{VI}}$ and $\mathrm{S}^{-\mathrm{II}}$. Elemental sulfur was prepared in acetone to allow proper dispersion and formation of elemental sulfur colloids. In the reaction systems, acetone concentration was always less than $2 \%$. Control experiments showed that at this concentration level, acetone didn't alter the reaction rate between $\mathrm{Cr}^{\mathrm{VI}}$ and $\mathrm{S}^{\mathrm{II}}$.

Analytical Methods: $\mathrm{Cr}^{\mathrm{VI}}$ concentration was determined by the diphenylcarbazide colorimetric method, using phosphoric buffer to control $\mathrm{pH}$ for the color development (Deng and Stone 1996). The absorbance was measured in a $1-\mathrm{cm}$ cell at $540 \mathrm{~nm}$ on a spectrophotometer (Spectronic 20 Genesys, Spectronic Instruments). The method detection limit was $0.05 \mu \mathrm{M}$ and the precision

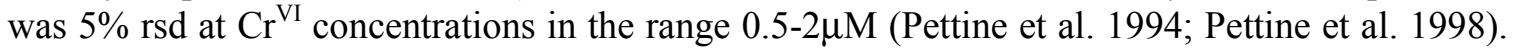
Sulfide concentration in the stock solution was standardized with the standard iodometric titration method (APHA et al. 1998). Sulfide concentration during the reaction was monitored by the methylene blue colorimetric method with the absorbance measured at $664 \mathrm{~nm}$ (Allen et al. 1993; APHA et al. 1998).

To our surprise, the methylene blue method for sulfide analysis was significantly affected by the order of reagent additions (Table 1). If the reagents were added with the sequences of A (sulfide + $5 \mathrm{ml} \mathrm{H} \mathrm{H}_{2} \mathrm{O}+$ amine-sulfuric acid solution + ferric chloride), $\mathrm{B}$ (sulfide $+5 \mathrm{ml} \mathrm{H}_{2} \mathrm{O}+$ mixture of amine-sulfuric acid solution and ferric chloride), and $\mathrm{C}\left(5 \mathrm{ml} \mathrm{H}_{2} \mathrm{O}+\right.$ sulfide + amine-sulfuric acid solution + ferric chloride), the absorbance values were all similar. Adding the amine-sulfuric acid and ferric chloride stock solutions separately or adding the mixture of the two reagents didn't alter the absorbance. If other orders were followed as for $\mathrm{D}, \mathrm{E}$, and $\mathrm{F}$, however, the absorbance values were significantly lower. Thus, following proper order of reagent addition was critical to maintain the sensitivity of the method and avoid erroneous results. In this study, we selected the following sequence for sulfide analysis: (1) adding $5 \mathrm{ml}$ Milli-Q water; (2) injecting sulfide sample into the bottom of the water through a syringe; (3) adding the mixture of amine-sulfuric acid and ferric chloride solution for color development. Using the premixed amine-sulfuric acid and ferric chloride solution decreased time for reagent addition and increased analytic precision. This was similar to the procedure used for the analysis of acid volatile sulfur (AVS) in sediments (Allen et al. 1993). Additionally, it was noticed that the calibration curve for the methylene blue method did not follow a strict straight line for sulfide concentration ranging from 0 to $40 \mu \mathrm{M}$, but two linear segments were observed (data not shown). To minimize the analytical error, a two-segment calibration curve was used for the concentration from 0 to $15 \mu \mathrm{M}$ and from 15 to $40 \mu \mathrm{M}$, respectively.

Solution $\mathrm{pH}$ was measured prior to and after the redox reaction by an Orion $420 \mathrm{~A} \mathrm{pH}$ meter following a 2-point calibration. To evaluate how complete the oxygen was removed by $\mathrm{N}_{2}$ purging, dissolved oxygen was analyzed in selected experiments using the $\mathrm{HACH}$ dissolved oxygen test kit (HACH company, Loveland, $\mathrm{CO}$ ).

Transmission electron microscopy (TEM) was used for the imaging of elemental sulfur particles. A drop of solution containing the $\mathrm{S}$ particles was placed on a holey carbon coated $\mathrm{Cu}$ grid. The $\mathrm{Cu}$ grid was placed on TEM specimen holder after the $\mathrm{Cu}$ grid dried. All TEM observations were carried out with a JEOL 2010 high-resolution transmission electron microscope (HRTEM) with an attached Oxford LINK EDS system (Xu and Wang 2000). 
Table 1. Effect of orders of reagent addition on the absorbance during sulfide analysis by the methylene blue colorimetric method.

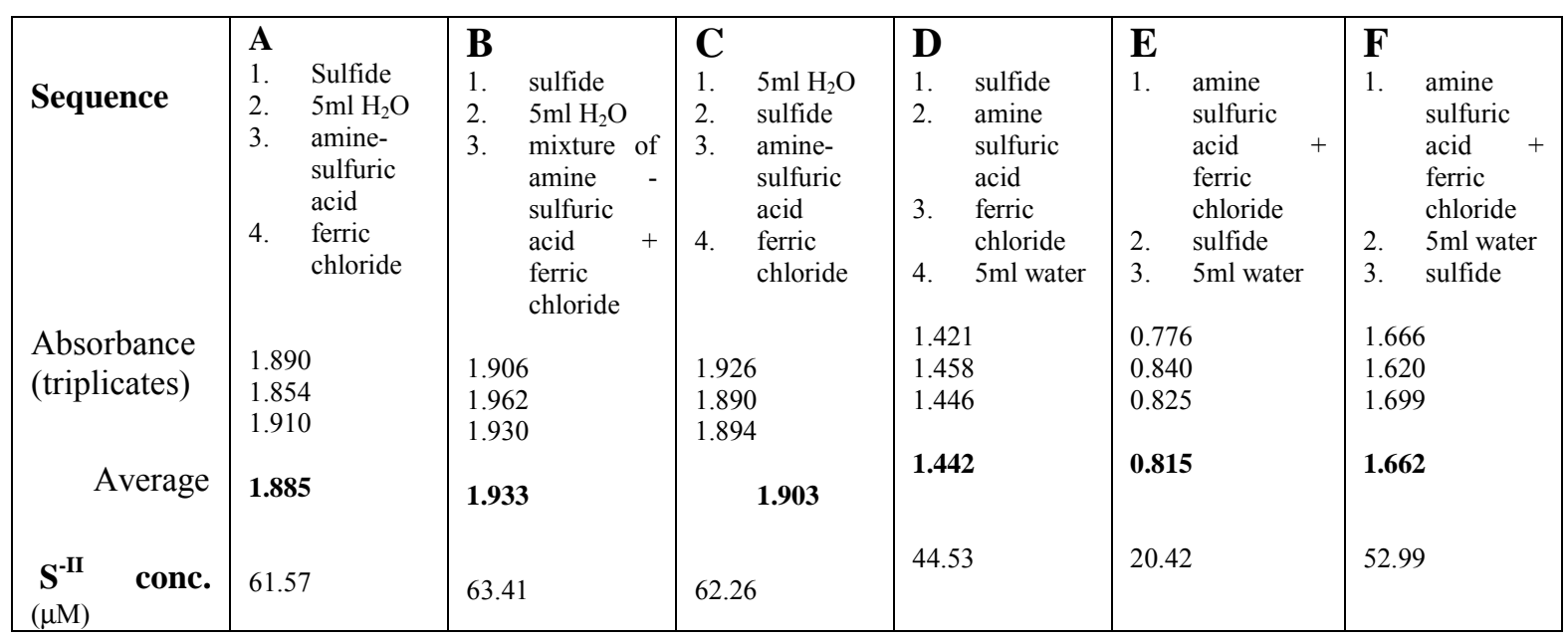

\section{RESULTS AND DISCUSSION}

Sulfide Stability: For the experiments designed to study sulfide oxidation kinetics, potential loss of sulfide due to its evaporation, adsorption, and oxygenation needs to be properly controlled. The stability of sulfide in the phosphate buffered aqueous solution was tested at initial concentrations of 200 and $800 \mu \mathrm{M}\left(\mathrm{pH}=7.60\right.$ and $\left.25^{\circ} \mathrm{C}\right)$, and the results indicated that sulfide was stable during a time period of 2 to $3 \mathrm{hrs}$ (Figure 3-1), following the established experimental procedure. By minimizing the loss of sulfide through evaporation and oxygenation, we were able to investigate the reaction stoichiometry and kinetics by monitoring both $\mathrm{Cr}^{\mathrm{VI}}$ and $\mathrm{S}^{-\mathrm{II}}$.

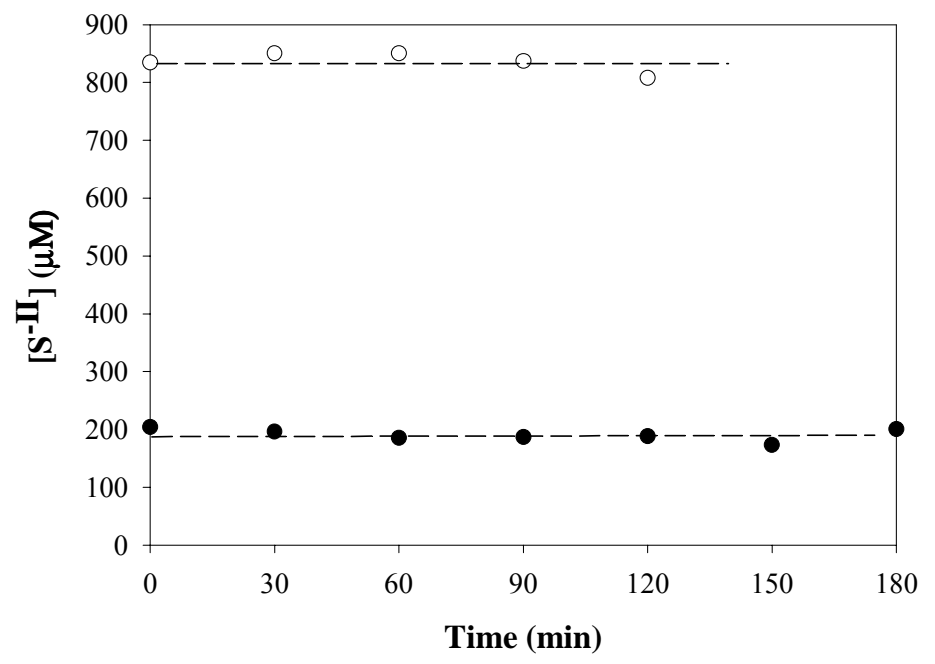

Figure $3-1$. The stability of sulfide in the experimental systems $\left(\mathrm{pH}=7.60\right.$ and $\left.25^{\circ} \mathrm{C}\right)$ 
Reaction Kinetics: Through well-controlled batch experiments performed in an anaerobic chamber, it is observed that while $\mathrm{Cr}(\mathrm{VI})$ reduction by sulfide follows a pseudo first order kinetics with respect to $[\mathrm{Cr}(\mathrm{VI})]$ initially, as described in Section II, and the rate was largely accelerated at the later stage of the reaction (Figure 3-2). This discovery was not expected prior to the start of the project, and to our knowledge, it has not been reported in the literature.

Such acceleration is likely due to the formation of some reaction intermediates and products. Since elemental sulfur and chromium hydroxide are known to form in the experimental system, our working hypothesis was that the acceleration was due to elemental sulfur and chromium hydroxide. We examined $\mathrm{Cr}(\mathrm{VI})$ reduction in the presence of $40 \mu \mathrm{M}$ of $\mathrm{Cr}(\mathrm{III})$ at $\mathrm{pH} 8.10$. The $\mathrm{Cr}(\mathrm{III})$ species, mainly in the form of $\mathrm{Cr}(\mathrm{OH})_{3(\mathrm{~s})}$ under the experimental condition, didn't demonstrate any discernible effect on the reaction kinetics. Thus elemental sulfur produced during the reaction was proposed to be the main compound causing the accelerated $\mathrm{Cr}(\mathrm{VI})$ reduction.

Two types of experiments were conducted to see whether elemental sulfur could be involved in the rate acceleration observed. In the first type, we allowed $40 \mu \mathrm{M} \mathrm{Cr}(\mathrm{VI})$ to be completely reduced by $800 \mu \mathrm{M} \mathrm{S}^{-\mathrm{II}}$, and then additional $\mathrm{Cr}(\mathrm{VI})$ was re-spiked but no additional sulfide was added. To illustrate, the results at $\mathrm{pH} 8.10$ (buffered by borate) are shown in Figure 3-3. Under this $\mathrm{pH}$ condition, it took $210 \mathrm{~min}$ for the complete reduction of the first batch of $\mathrm{Cr}(\mathrm{VI})$ (curve A), and only 56 min for the second batch (curve B). The acceleration was observed under even slightly lower reductant concentration than in the first batch since no sulfide was re-spiked. The results indicate that the products formed during the reaction catalyzed the $\mathrm{Cr}(\mathrm{VI})$ reduction processes.

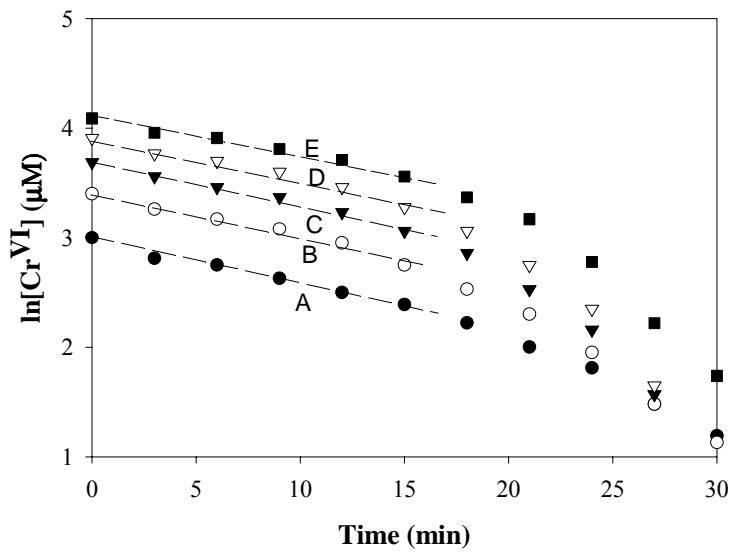

Figure 3-2. $\ln \left[\mathrm{Cr}^{\mathrm{VI}}\right]$ as a function of time in the systems with excess of sulfide $(800 \mu \mathrm{M})$ at $\mathrm{pH}=7.60$ and $25^{\circ} \mathrm{C}$. Reaction rate for $\mathrm{Cr}(\mathrm{VI})$ was accelerated compared to first order kinetics. $\left([\mathrm{Cr}(\mathrm{VI})]_{0}(\mu \mathrm{M}): \mathrm{A}=20 ; \mathrm{B}=30 ; \mathrm{C}=40 ; \mathrm{D}=50 ; \mathrm{E}=60\right.$.) 


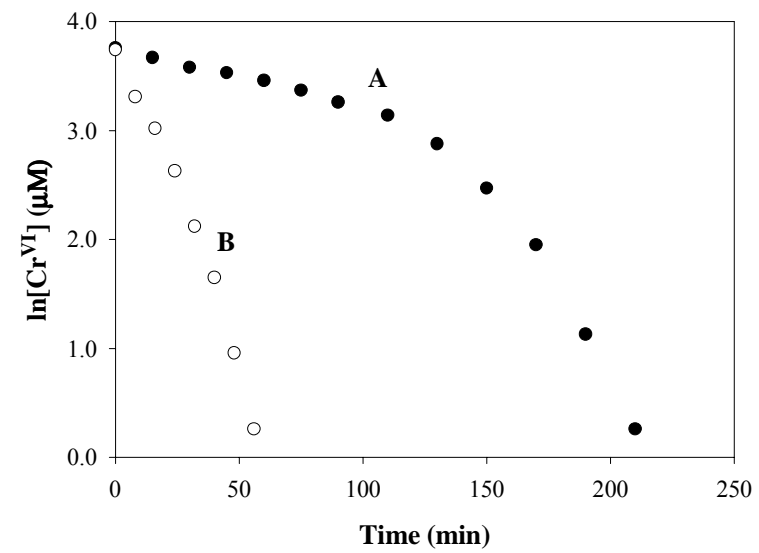

Figure 3-3. Rates of $\mathrm{Cr}(\mathrm{VI})$ reduction by sulfide at $\mathrm{pH}$ 8.10. Curve $\mathrm{A}$ is for the reduction of the first batch of $\mathrm{Cr}(\mathrm{VI})(40 \mu \mathrm{M})$ by $(800 \mu \mathrm{M}$ sulfide $)$; Curve $\mathrm{B}$ is for the re-spiked $\mathrm{Cr}(\mathrm{VI})$ after the first batch is completed.

The second type of testing involved in the addition of various amounts of elemental sulfur into the system before the redox reaction was initiated. The results showed that the presence of elemental sulfur did increase the reaction rate significantly (Figure 3-4). The presence of elemental sulfur greatly decreased the time for complete $\mathrm{Cr}(\mathrm{VI})$ reduction. Higher concentrations of added sulfur particles resulted in faster $\mathrm{Cr}(\mathrm{VI})$ reduction. When the initial concentration of elemental sulfur was raised to $320 \mu \mathrm{M}$, the time needed for completing the reaction was less than $30 \mathrm{~min}$. In addition, in the presence of externally added sulfur colloids, the $\ln \left[\mathrm{Cr}^{\mathrm{VI}}\right]$ vs. t plots are linear, suggesting a first order kinetics.

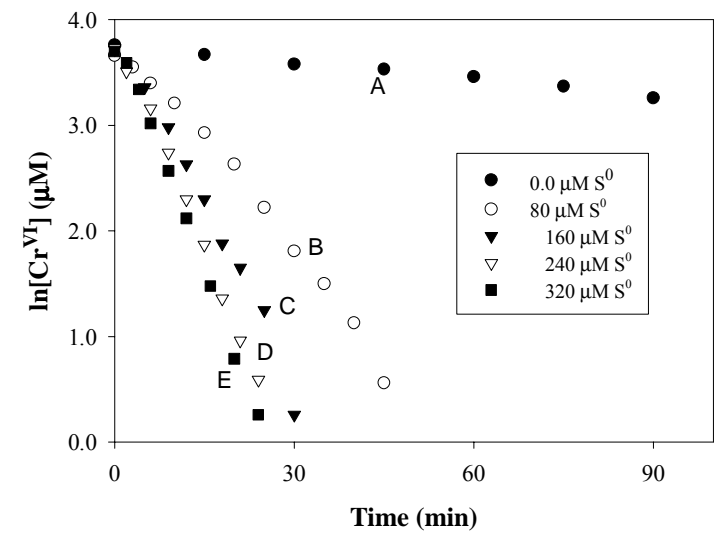

Figure 3-4. Effect of externally added elemental sulfur on $\mathrm{Cr}(\mathrm{VI})$ reduction in the systems with excess of sulfide $(800 \mu \mathrm{M})$ at $25^{\circ} \mathrm{C}$ and $\mathrm{pH} 7.60$ (Externally added [ $\mathrm{S}^{0}$ ] $(\mu \mathrm{M}): \mathrm{A}=0 ; \mathrm{B}=80 ; \mathrm{C}=160 ; \mathrm{D}=240 ; \mathrm{E}=320)$.

During the tests with crystalline sulfur particles, we observed that the colloidal system exhibited a milky white appearance typical of elemental sulfur. When sulfide was also added into the system, however, this milky white appearance disappeared and the colloidal system became almost as clear 
as true solution (Figure 3-5). TEM study showed that without $\mathrm{S}^{-\mathrm{II}}$ in the system, the elemental sulfur particles display an elongated shape, with an averaged width of $10 \mathrm{~nm}$ and length of 50 $100 \mathrm{~nm}$ (Figure 3-6a). With $\mathrm{S}^{\text {-II }}$ being present, the elemental sulfur was in the form of much smaller nano particles with an average size of around $5 \mathrm{~nm}$ (Figure 3-6b). These nano $\mathrm{S}^{0}$ particles were not amorphous, but in crystalline form because sharp diffraction rings in selected-area electron diffraction (SAED) patterns were observed. Apparently, interactions between $\mathrm{S}^{0}$ and $\mathrm{S}^{-\mathrm{II}}$, or the sorption of $\mathrm{S}^{\text {III }}$ onto the surface, have altered the crystalline behavior of the elemental sulfur.

It is believed that the rate acceleration at later stage of the reaction is caused by the $\mathrm{S}^{0}$ produced in the system. Several lines of evidences support this hypothesis. First, re-spiked $\mathrm{Cr}^{\mathrm{VI}}$ is reduced much faster than the $\mathrm{Cr}^{\mathrm{VI}}$ originally present in the system. Between the two main reaction products in the system, $\mathrm{Cr}(\mathrm{OH})_{3(\mathrm{~s})}$ does not affect the reaction, so the other one, $\mathrm{S}^{0}$, is most likely involved. Second, the presence of externally added $\mathrm{S}^{0}$ increases the rate of $\mathrm{Cr}^{\mathrm{VI}}$ reduction, and the higher the $\mathrm{S}^{0}$ concentration, the faster the rate (Fig.3-4).

The catalytic kinetics for $\mathrm{Cr}^{\mathrm{VI}}$ reduction caused by $\mathrm{S}^{0}$ produced in the system is different from typical autocatalytic processes (Cappelos and Bielski 1980; Schwartz 1989). Rate of a typical autocatalytic reaction is slow initially, increases to a maximum, and decreases again due to the depletion of the reactants. For example, oxidation of organic compounds by $\mathrm{MnO}_{4}^{-}$follows this autocatalytic model, in which $\mathrm{Mn}^{2+}$ produced during the reaction acts as a catalyst (Schwartz 1989; Perez-Benito, Arias et al. 1990). The kinetic data on $\mathrm{Cr}^{\mathrm{VI}}$ reduction by sulfide, however, can't be described by the typical autocatalytic model. Instead, the reaction follows first order at the initial stage of the reaction. The acceleration takes place only after a certain time period, e.g., 15 min at $\mathrm{pH} 7.8$, and by that time, the amount of $\mathrm{S}^{0}$ produced can be as high as $40 \mu \mathrm{M}$.

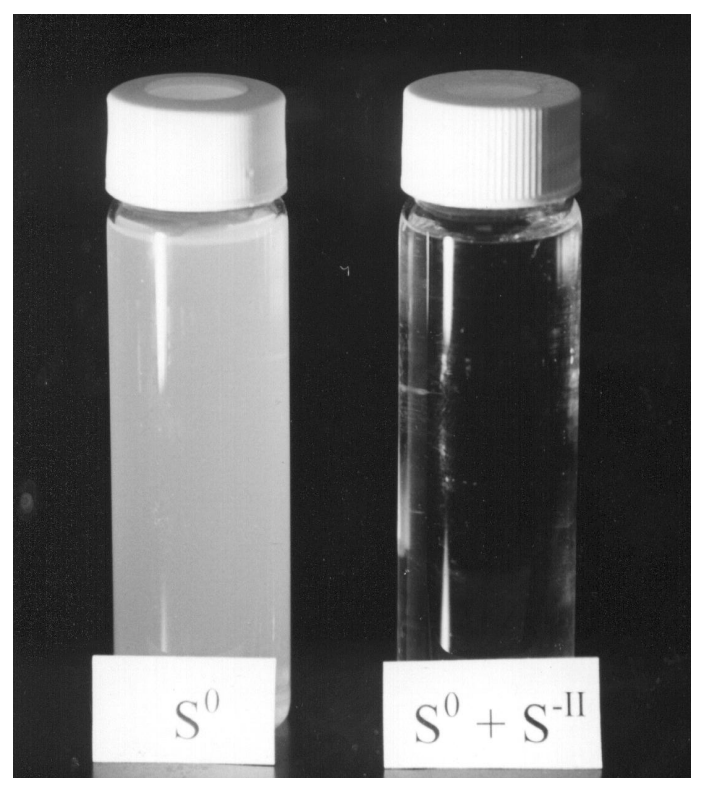

Figure 3-5. Photos of crystalline elemental sulfur particles $\left(\mathrm{S}_{8}\right)$ in the absence and presence of $\mathrm{S}^{-\mathrm{II}}$ 


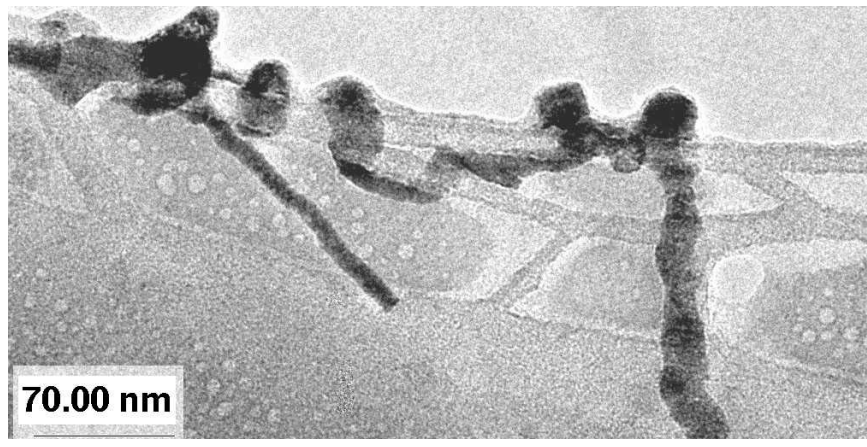

(a)

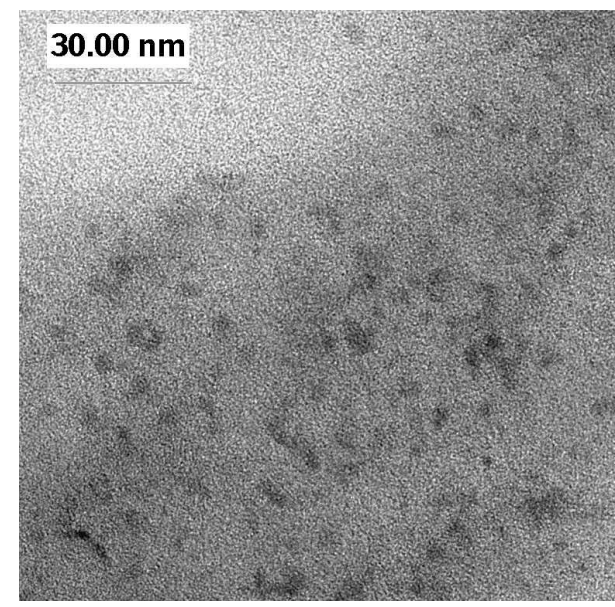

(b)

Figure 3-6. (a) $\mathrm{S}^{0}$ particles from a sample without $\mathrm{H}_{2} \mathrm{~S}$ treatment. Most $\mathrm{S}$ particles display elongated shapes. Average width of the elongated $\mathrm{S}$ particles is about $10 \mathrm{~nm}$. (b) $\mathrm{S}^{0}$ nano particles from a sample with $\mathrm{H}_{2} \mathrm{~S}$ treatment. They are nano crystalline particles. Noise background is amorphous carbon film holding the $\mathrm{S}$ particles. Average size of the $\mathrm{S}$ nano-crystals is about $5 \mathrm{~nm}$.

We propose that particulate form of elemental sulfur or $\mathrm{S}^{0}$ colloids are the catalyst of $\mathrm{Cr}^{\mathrm{Vl}}$ reduction by sulfide. Amorphous $\mathrm{S}^{0}$ molecules, when produced during the reaction, are dispersed in the aqueous system and are not capable of catalyzing the reaction. Only when nucleation occurs that eventually leads to the formation of crystalline $S^{0}$ colloids, the catalytic pathway becomes significant compared to the non-catalytic pathway. Thus, the reaction follows the pseudo first order kinetics at the initial stage when the colloidal form of elemental sulfur is not significant, even though $\mathrm{S}^{0}$ is produced from the very beginning of the reaction. Once colloidal $\mathrm{S}^{0}$ is formed, which provides reactive surface for reactant adsorption, the reaction is accelerated due to the high reactivity of sorbed reactants. Adsorption of $\mathrm{Cr}^{\mathrm{VI}}$ onto amorphous elemental sulfur is insignificant (less than $3 \%$ ). $\mathrm{S}^{-\mathrm{II}}$ sorption onto nano-crystalline $\mathrm{S}^{0}$ colloids, however, is highly likely due to the similar electronic structure of $\mathrm{S}^{0}$ and $\mathrm{S}^{-\mathrm{II}}$. Particle size of elemental sulfur is significantly decreased due to the presence of $\mathrm{S}^{-\mathrm{II}}$ as shown in Fig. 3-6, which indicates the existence of strong interactions between $\mathrm{S}^{0}$ and $\mathrm{S}^{-\mathrm{II}}$. Effort of measuring $\mathrm{S}^{-\mathrm{II}}$ sorption onto the elemental sulfur colloids was not successful because we were unable to separate solids with particle size around 5 $\mathrm{nm}$.

\section{CONCLUSION}

Through well-controlled batch experiments performed in an anaerobic chamber, it is observed that while $\mathrm{Cr}(\mathrm{VI})$ reduction by sulfide follows a pseudo first order kinetics with respect to [Cr(VI)] initially, the rate was largely accelerated at the later stage of the reaction. It was known that elemental sulfur was the product of sulfide oxidation by $\mathrm{Cr}^{\mathrm{VI}}$ under the anaerobic condition. The elemental sulfur produced can form particulate sulfur colloids capable of adsorbing sulfide and such adsorbed sulfide exhibits much higher reactivity towards $\mathrm{Cr}^{\mathrm{VI}}$ reduction than the aqueous phase sulfide and is responsible for the accelerated $\mathrm{Cr}^{\mathrm{VI}}$ reduction observed. 


\title{
IV. EFFECT OF VARIOUS SOIL MINERALS ON Cr(VI) REDUCTION BY SULFIDE
}

\author{
(Yeqing Lan, Chulsung Kim, Baolin Deng)
}

\section{INTRODUCTION}

Release of toxic heavy metals into soils and water has been widespread. Chromium is one of the concerned heavy metals due to its high toxic and carcinogenic properties. Between the two common oxidation states of chromium in the aquatic environment, trivalent chromium usually has lower solubility and stronger affinity to soil components than hexavalent chromium, therefore, reduction of $\mathrm{Cr}(\mathrm{VI})$ to $\mathrm{Cr}(\mathrm{III})$ has been used as an important remediation technology for $\mathrm{Cr}(\mathrm{VI})$ contaminated soils and water. $\mathrm{Cr}(\mathrm{VI})$ species can be reduced by many types of reductants such as zero valent iron (Blowes et al., 1997; Pratt et al., 1997; Ponder et al., 2000), ferrous iron (Eary and Rai, 1988; Fendorf and Li, 1996; Sedlak and Chan, 1997; Pettine et al., 1998; Buerge and Hug, 1997; 1998; 1999; Seaman et al. 1999), and naturally occurring organic compounds (James and Bartlett, 1983; Goodgame and Hayman, 1984; Eary and Rai, 1991; Wittbrodt and Palmer, 1995). The reaction kinetics is strongly dependent upon the nature of the reductants and $\mathrm{pH}$.

Recently, hydrogen sulfide has been applied for reductive $\mathrm{Cr}(\mathrm{VI})$ immobilization that is particularly suitable for vadoze zone remediation. Facile reduction of $\mathrm{Cr}(\mathrm{VI})$ by sulfide in the aqueous phase has been demonstrated by a number of studies (Schroeder and Lee, 1975; Smillie et al., 1981; Saleh et al., 1989; Pettine et al., 1994; 1998; Thornton and Amonette, 1999). Under the anaerobic condition, elemental sulfur was identified as the major product of sulfide oxidation (Section II). The reaction was first order with respect to both $\mathrm{Cr}(\mathrm{VI})$ and $\mathrm{H}_{2} \mathrm{~S}$ and the kinetics was interpreted by a three step mechanism: formation of an inner sphere chromate-sulfide complex formation, intramolecular electron transfer to form $\mathrm{Cr}(\mathrm{IV})$ species, and subsequent fast reactions leading to the formation of $\mathrm{Cr}$ (III). It was further demonstrated that the produced elemental sulfur provided surface sites for sulfide sorption, and the sorbed sulfide possessed substantially higher reactivity towards $\mathrm{Cr}(\mathrm{VI})$ reduction than dissolved sulfide (Section III). Therefore, $\mathrm{Cr}(\mathrm{VI})$ reduction by sulfide in the aqueous phase proceeds through two stages: initial homogeneous reaction followed by a stage with significant contribution by the surface-catalyzed pathway.

To thoroughly assess the efficiency of $\mathrm{Cr}(\mathrm{VI})$ immobilization by $\mathrm{H}_{2} \mathrm{~S}$ treatment, we need to understand how various soil components affect $\mathrm{Cr}(\mathrm{VI})$ reduction and $\mathrm{H}_{2} \mathrm{~S}$ consumption. Important components include clay minerals and metal (hydr)oxides because of their widespread distribution and high specific surface areas. The effects could come from direct $\mathrm{Cr}(\mathrm{VI})$ reduction by the soil components or indirectly by the catalysis of mineral components for $\mathrm{Cr}(\mathrm{VI})$ reduction. Eary and Rai (1989) observed Cr(VI) reduction by hematite and biotite over a wide $\mathrm{pH}$ range from 3.5 to 11 . They proposed that the dissolution of ferrous iron from solid phases into the aqueous phase should take place prior to $\mathrm{Cr}(\mathrm{VI})$ reduction and the redox reaction occurred in the solution phase rather than at surface sites. Dissolution, however, may not be needed for some other minerals. For example, Patterson and Fendorf (1997) demonstrated that freshly prepared ferrous sulfide (FeS) reduced $\mathrm{Cr}(\mathrm{VI})$ quite effectively in the $\mathrm{pH}$ range of $5.0-8.0$ and reaction took place at surfacesolution interface. In addition to $\mathrm{Cr}(\mathrm{VI})$ reduction directly by ferrous species in soils, it is known that minerals such as aluminum oxide $\left(\gamma-\mathrm{Al}_{2} \mathrm{O}_{3}\right)$, goethite $(\alpha-\mathrm{FeOOH})$, and titanium dioxide $\left(\mathrm{TiO}_{2}\right)$ can catalyze $\mathrm{Cr}(\mathrm{VI})$ reduction by many types of organic compounds (Deng and Stone, 1996a; b). Buerge and Hug (1999) showed that the rate of $\mathrm{Cr}(\mathrm{VI})$ reduction by ferrous iron was also increased by some metal oxides. 
In this section, effects of clay minerals (illite, montmorillonite, and kaolinite) and metal oxides $\left(\mathrm{Al}_{2} \mathrm{O}_{3}, \mathrm{SiO}_{2}\right.$ and $\left.\mathrm{TiO}_{2}\right)$ on $\mathrm{Cr}(\mathrm{VI})$ reduction by sulfide were examined.

\section{MATERIALS AND METHODS}

Chemicals: Chemicals were obtained from Aldrich/Sigma (potassium dichromate, elemental sulfur $\left(\mathrm{S}_{8}\right)$, diphenyl carbazide, acetone, $\mathrm{N}, \mathrm{N}$-dimethyl-1,4-phenylene-diamine oxalate, ferrozine, and HEPES) and Fisher Scientific (boric acid, sodium phosphate, sodium hydroxide, sodium sulfide $\left(\mathrm{Na}_{2} \mathrm{~S} \bullet 9 \mathrm{H}_{2} \mathrm{O}\right)$, sulfuric acid, hydrogen chloride, ferric chloride, and diammonium hydrogen phosphate). All chemicals were at least ACS reagent grade and used without further purification, except sodium sulfide crystals that was rinsed with degassed water to remove the oxidized surface layer. Stock solutions of chromate and sulfide were prepared by Milli-Q water $\left(\mathrm{Q}-\mathrm{H}_{2} \mathrm{O}\right.$, with18.2 $\mathrm{M} \Omega-\mathrm{cm}$ resistivity, Millipore Corp.) purged thoroughly with high purity nitrogen gas and stored in amber bottles and placed in an anaerobic chamber (Models 855-AC, PLAS-LABS, INC.) prior to use. Stock solution of elemental sulfur was prepared by dispersing crystalline elemental sulfur $\left(\mathrm{S}_{8}\right)$ powder in acetone. Glassware was cleaned by soaking in $1 \mathrm{M} \mathrm{HCl}$ for at least $3 \mathrm{hrs}$ and then thoroughly rinsed.

Minerals: Kaolin (KGa-2), montmorillonite (STx-1), and illite (IMt-2) were obtained from the Source Clay Minerals Repository, University of Missouri-Columbia (U.S.A), and aluminum oxide, silicon oxide, and titanium oxide, Degussa Corporation. Point of zero charge (PZC) and BET specific surface area (SSA) of minerals is listed in Table 4-1.

Table 4-1. Point of Zero Charge and BET special surface aera of minerals.

\begin{tabular}{|l|l|l|}
\hline Minerals & $\mathrm{pH}$ & $\mathrm{SSAC}$ \\
\hline Aluminum oxide & $\left.8.9^{\mathrm{a}} / \mathrm{g}\right)$ \\
\hline Silicon oxide & $2.3^{\mathrm{a}}$ & $90.1^{\mathrm{a}}$ \\
\hline Titanium oxide & $6.5^{\mathrm{d}}$ & $90.0^{\mathrm{a}}$ \\
\hline Montmorillonite & $5.9^{\mathrm{f}}$ & $40.5^{\mathrm{a}}$ \\
\hline Kaolin & $4.5-5.0^{\mathrm{e}}$ & $99.0^{\mathrm{f}}$ \\
\hline Illite & $3.5^{\mathrm{b}}$ & $22.4^{\mathrm{b}}$ \\
\hline
\end{tabular}

a--Degussa (1991), b--this work, c--, d--Torrents and Stone (1991), e--Zhou (1996), f--Buerge and Hug (1999)

Experimental procedure: Most of experiments reported in this study, including experimental setup and chemical analyses, were performed in an anaerobic chamber $\left(\mathrm{N}_{2}\right.$, balanced by $\left.10 \% \mathrm{H}_{2}\right)$ with a temperature of $24.0 \pm 0.5^{\circ} \mathrm{C}$. Solution $\mathrm{pH}$ was controlled by $0.10 \mathrm{M}$ borate buffer (adjusted with $0.1 \mathrm{M}$ boric acid and sodium hydroxide). No strong electrolytes were applied to control ionic strength in this study, because both earlier studies (Pettine, et al, 1994 and 1998) and our preliminary experiments indicated that the reaction was independent of ionic strength in the range from 0.0 and $1.0 \mathrm{M}$. The actual ionic strength in the experimental systems was controlled largely by the borate buffer, which had a total concentration of $0.10 \mathrm{M}$.

Kinetics experiments examining the effect of minerals on $\mathrm{Cr}(\mathrm{VI})$ reduction began with purging an adequate amount of borate buffer solution in a $40 \mathrm{ml}$ amber bottle with high purity nitrogen gas for $20 \mathrm{~min}$. The vessel was then closed immediately by a screw cap with Teflon/silicon septum and moved into the anaerobic chamber. Variable amounts of minerals and $0.80 \mathrm{ml}$ of $2.00 \mathrm{mM}$ $\mathrm{K}_{2} \mathrm{CrO}_{4}$ stock solution were added into the bottle, followed by hand-mixing for $30 \mathrm{~min}$. Adequate amounts of sulfide stock solution and $\mathrm{Q}-\mathrm{H}_{2} \mathrm{O}$ were introduced afterwards to keep a final slurry 
volume at $40.00 \mathrm{ml}$. The final concentrations of $\mathrm{Cr}(\mathrm{VI})$ and sulfide were $40.0 \mu \mathrm{M}$ and $800 \mu \mathrm{M}$, respectively, and concentrations of minerals were $0,0.5,1.5,3.0,5.0 \mathrm{~g} / \mathrm{L}$. Approximately $1 \mathrm{ml}$ of slurry was periodically withdrawn by a $3 \mathrm{ml}$ plastic syringe and immediately filtered through a 0.22 $\mu \mathrm{m}$ membrane filter and the filtrate was measured for Cr (VI) analysis. Due to the strong effect observed for illite and kaolinite on $\mathrm{Cr}(\mathrm{VI})$ reduction, these two minerals were selected for further study at a $3.0 \mathrm{~g} / \mathrm{L}$ solid loading and $\mathrm{pH}$ from 7.67 to 9.07 . Other conditions were maintained the same.

Several types of experiments were performed at $\mathrm{pH} 8.27$ to evaluate whether ferrous iron produced from illite could alter the reaction rate of $\mathrm{Cr}(\mathrm{VI})$ reduction by sulfide: (1) addition of $5.0 \mu \mathrm{M} \mathrm{Fe}$ (II) into the homogeneous system with $\mathrm{Cr}(\mathrm{VI})$ and sulfide only; (2) addition of phenanthroline into the homogenous system with $\mathrm{Cr}(\mathrm{VI})$ and sulfide; (3) addition of a strong Fe(II) chelating agent, phenanthroline, into the illite system with $\mathrm{Cr}(\mathrm{VI})$, sulfide, and illite. $\mathrm{Fe}(\mathrm{II})$ and phenanthroline were introduced before $\mathrm{Cr}(\mathrm{VI})$ and sulfide were transferred into the reaction system.

$\mathrm{Cr}(\mathrm{VI})$ and sulfide adsorption: The adsorption of $\mathrm{Cr}(\mathrm{VI})$ and sulfide onto illite and kaolin surfaces at $\mathrm{pH} 7.87$ was assessed by monitoring the concentrations of $\mathrm{Cr}(\mathrm{VI})$ and sulfide after solid/solution separation with filtration. Initial concentrations of $\operatorname{Cr}(\mathrm{VI})$ and sulfide were 40.0 and $800 \mu \mathrm{M}$, respectively.

Adsorbed and dissolved $\mathrm{Fe}(\mathrm{II})$ : The adsorbed and dissolved amounts of $\mathrm{Fe}(\mathrm{II})$ in illite suspension at $\mathrm{pH} 8.27$ were monitored in the following three experimental systems: (1) illite + borate buffer; (2) illite + borate buffer + sulfide; (3) illite + borate buffer + sulfide + elemental sulfur. Final concentrations were $800.0 \mu \mathrm{M}$ for sulfide and $50.0 \mu \mathrm{M}$ for elemental sulfur. A $3.0 \mathrm{ml}$ suspension was filtered through a $0.10 \mu \mathrm{m}$ membrane and the filtrate was analyzed for soluble $\mathrm{Fe}(\mathrm{II})$. The solids on the membrane were washed with $3 \mathrm{ml}$ Mill-Q water four times to remove the remaining sulfide on the solid surfaces. Afterwards, the solids and the membrane were soaked in a $3.0 \mathrm{ml}$ of $0.1 \mathrm{M} \mathrm{HCl}$ solution and stirred with a magnetic Teflon bar for $20 \mathrm{~min}$. Then, the suspension was filtered with a $0.22 \mu \mathrm{m}$ membrane filter and the filtrate was analyzed for the adsorbed $\mathrm{Fe}(\mathrm{II})$.

Analytical Methods: $\mathrm{Cr}(\mathrm{VI})$ concentration was determined by the diphenylcarbazide colorimetric method, using phosphoric buffer to control pH for the color development (APHA,1998; Deng et al, 1996). The absorbance was measured in a $1-\mathrm{cm}$ cell at $540 \mathrm{~nm}$ on a spectrophotometer (Spectronic 20 Genesys, Spectronic Instruments) and the method had a detection limit of $0.05 \mu \mathrm{M}$. Sulfide concentration in the stock solution was standardized with the standard iodometric titration method (APHA, 1998). Sulfide concentration during the reaction was monitored by a modified methylene blue method (Section III).

Ferrozine method was adopted for Fe(II) analysis (Amonette et al, 2000 and Lovely et al, 1986). It was noticed that borate buffer and sulfide could affect the analytical procedure. If borate buffer was mixed with Fe(II) followed by ferrozine solution, no color development could be observed. Formation of FeS in the system could increase the time needed for full color development. In this study, we added $1.0 \mathrm{ml}$ of $0.50 \mathrm{M} \mathrm{HCl}$ into the system with borate buffer, sulfide and $\mathrm{Fe}(\mathrm{II})$, followed by ferrozine. This sequence of reagent addition resulted in complete and immediate color development without interference from borate buffer and sulfide. $\mathrm{pH}$ ranging from 3.0 to 7.3 did not appear to affect the analysis.

Solution $\mathrm{pH}$ was measured before and after the reaction by an Orion 420A pH meter after a 2-point calibration. Dissolved oxygen was analyzed using the HACH dissolved oxygen test kit (HACH Company, Loveland, CO), which was used to evaluate how completely the oxygen was removed 
by $\mathrm{N}_{2}$ purging. The dissolved oxygen in borate buffer was decreased to below the detection limit of $6.3 \mu \mathrm{M}$ through purging.

\section{RESULTS}

Effect of minerals on reaction rate: Clay minerals (illite, kaolinite and montmorillonite) and metal oxides $\left(\mathrm{Al}_{2} \mathrm{O}_{3}, \mathrm{SiO}_{2}\right.$ and $\left.\mathrm{TiO}_{2}\right)$ were used to study the effect of mineral surfaces on the reduction of $\mathrm{Cr}(\mathrm{VI})$ by sulfide. The initial concentrations of $\mathrm{Cr}$ (VI) and sulfide were 40 and 800 $\mu \mathrm{M}$, respectively, and the solution $\mathrm{pH}$ was 7.87 (borate buffer). Sulfide concentration was at least 20 times as much as that of $\mathrm{Cr}$ (VI) during the reaction. Since sulfide in our specific experimental setup was near constant and the overall reaction was pseudo first-order with respect to $\mathrm{Cr}$ (VI) (Sections II and III), the kinetic data were expressed by $\ln [\mathrm{Cr}(\mathrm{VI})]$ versus time plots as shown in Figure 4-1(a-f).

In the presence of illite, the reduction of Cr (VI) by sulfide was faster than the control system without mineral and was increased with increasing amount of illite from 0.5 to $5.0 \mathrm{~g} / \mathrm{L}$ (Fig. 4-1a). For example, with $5.0 \mathrm{~g} / \mathrm{L}$ of illite, the time needed to complete the reaction was about $50 \%$ of the reaction time in the control system. The plots of $\ln [\mathrm{Cr}(\mathrm{VI})]$ versus time were not linear, however, indicating that overall reaction did not follow a first order kinetics. Instead, a slower initial reaction was followed by a faster one, a trend similarly observed in the homogeneous systems (Section III).

For $\mathrm{Al}_{2} \mathrm{O}_{3}$, no obvious difference was observed between the systems with and without the solid (Fig. 4-1b). Overall, the kinetic data were characterized by a slow initial reaction step, followed by a fast one. In the stage of slow reaction, $\ln [\mathrm{Cr}(\mathrm{VI})]$ v.s. $t$ plots were linear.

Unlike illite and $\mathrm{Al}_{2} \mathrm{O}_{3}$, all other minerals including kaolin (Fig. 4-1c), montmorillonite (Fig. 41d), $\mathrm{SiO}_{2}$ (Fig. 4-1e) and $\mathrm{TiO}_{2}$ (Fig. 4-1f) decreased the rate of $\mathrm{Cr}(\mathrm{VI})$ reduction by sulfide as compared to the system without mineral. The effect was more dramatic at higher mineral concentrations. Better linear plots of $\ln [\mathrm{Cr}(\mathrm{VI})]$ versus time were obtained with higher concentrations of these minerals. The results indicated that these minerals did not catalyze, but inhibit the reaction between $\mathrm{Cr}$ (VI) and sulfide. In addition, by comparing the specific surface area (SSA) listed in table 4-1 with the kinetic results shown in Fig.4-1(a-f), it was clear that the large SSA provided by minerals was not the key factor in accelerating the reduction of $\mathrm{Cr}(\mathrm{VI})$ by sulfide. For example, illite, with the lowest SSA of the minerals examined, can accelerate the reaction rate, while $\mathrm{Al}_{2} \mathrm{O}_{3}$ and $\mathrm{SiO}_{2}$, both with high SSA, displayed different roles in affecting the reaction rates.

Effect of $\boldsymbol{p H}$ : Illite and kaolin were selected for further study because these two minerals exhibited quite different effects on the $\mathrm{Cr}(\mathrm{VI})$ reduction reaction, which might provide some insight into the reaction mechanism. The experiments were conducted in the systems initially containing $40 \mu \mathrm{M}$ of $\mathrm{Cr}(\mathrm{VI}), 800 \mu \mathrm{M}$ of sulfide, and $3.0 \mathrm{~g} / \mathrm{L}$ of illite or $3.0 \mathrm{~g} / \mathrm{L}$ of kaolin, and the solution $\mathrm{pH}$ was controlled at six levels $(\mathrm{pH} 7.67,7.87,8.07,8.27,8.67$ and 9.07. The results (figure 4-2(a-f)) indicated that: (1) the reduction rates in various systems followed the order: illite $>$ homogeneous system> kaolin; (2) in illite and homogeneous systems, overall reaction was characterized by a slower initial step, followed by a faster one, while in the kaolin system, all plots 

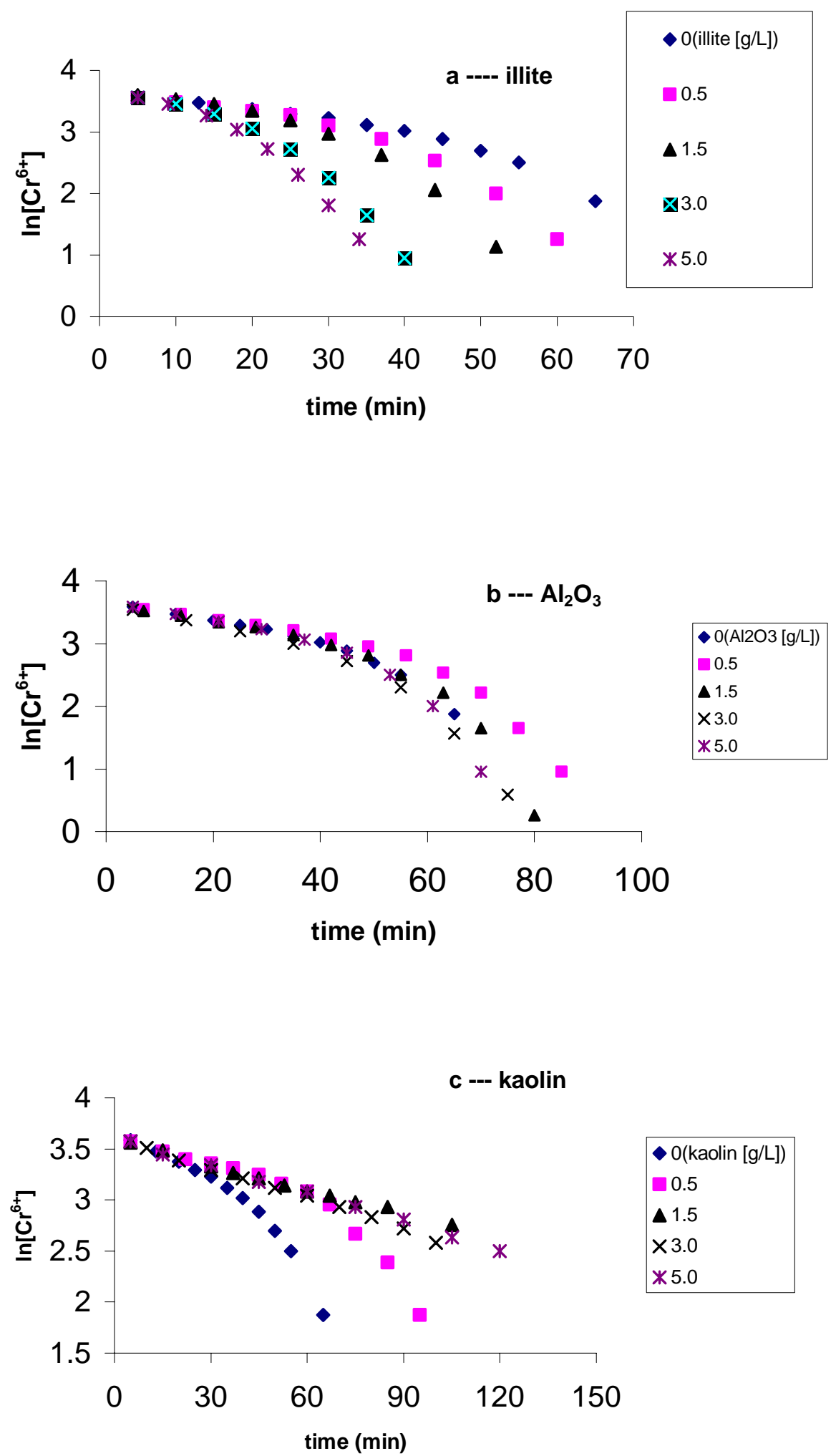

Figure 4-1. Effects of minerals on the reaction between $40 \mu \mathrm{M}$ of $\mathrm{Cr}(\mathrm{VI})$ and $800 \mu \mathrm{M}$ of sulfide, with a $=$ illite, $\mathrm{b}=\mathrm{Al}_{2} \mathrm{O}_{3}, \mathrm{c}=$ kaolin, $\mathrm{d}=$ montmorillonite, $\mathrm{e}=\mathrm{SiO}_{2}$, and $\mathrm{f}=\mathrm{TiO}_{2}$. 

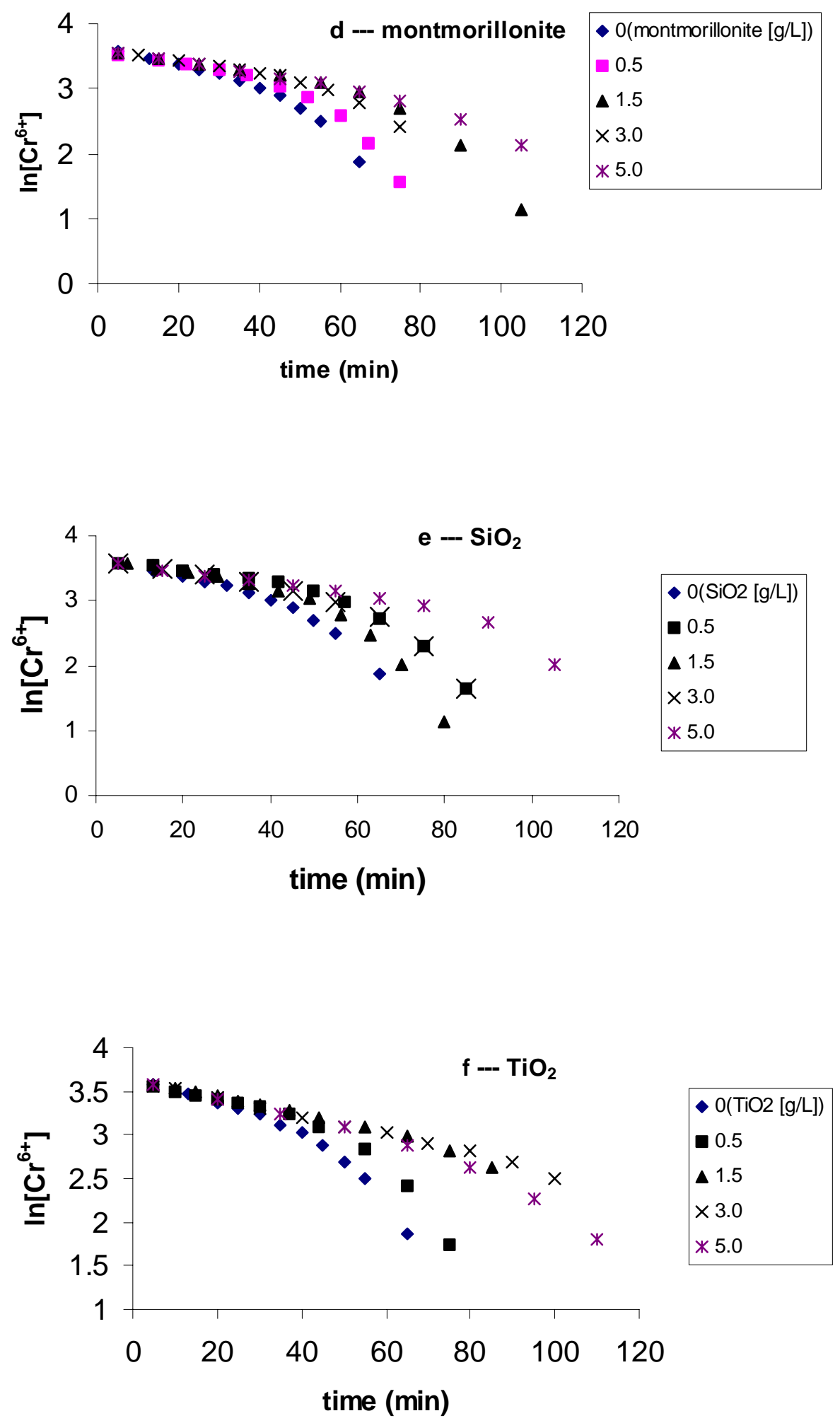

Figure 4-1 (Continued) 
of $\ln [\mathrm{Cr}(\mathrm{VI})$ versus time were linear; (3) in homogeneous system, $\ln [\mathrm{Cr}(\mathrm{VI})]$ v.s. $t$ in the initial stage displayed a linear trend, but deviated the linear line downwards, representing an accelerated reaction compared to the first order kinetics. If the data before the point of deviation were used in the $\ln [\mathrm{Cr}(\mathrm{VI})]$ v.s. t plots, which corresponded to about $35 \%$ to $50 \%$ (i.e., 15 to $20 \mu \mathrm{M}$ ) of the initial $\mathrm{Cr}(\mathrm{VI})$ was reduced, the derived rate constants for the homogeneous system were almost the same as those in the kaolin system (Figure 4-3). It was clear that with $\mathrm{pH}$ increase, the reaction rate was significantly decreased for both types of systems. The relationship between $\ln k_{\mathrm{obs}}$ and $\mathrm{pH}$ was linear with a slope of 2.13 for the kaolin system and 2.05 for the homogeneous system, suggesting the overall reaction order with respect to $\mathrm{H}^{+}$was probably 2 .

Adsorption of $\boldsymbol{C r}(\boldsymbol{V I})$ and Sulfide: In the systems with $40.0 \mu \mathrm{M} \mathrm{Cr}(\mathrm{VI})$ and $3.0 \mathrm{~g} / 1$ of illite or kaolin, no adsorption of $\mathrm{Cr}(\mathrm{VI})$ was observed as tested at $\mathrm{pH}$ 7.87. This agreed with previous studies (Buerge et al, 1999). Surfaces of illite and kaolin carried negative charges at this $\mathrm{pH}$ (much higher than PZC in Table 1), which reduced the adsorption of anionic $\mathrm{Cr}(\mathrm{VI})$ species (mainly $\left.\mathrm{CrO}_{4}{ }^{2-}\right)$ due to the unfavorable electronic interaction. In addition, borate might inhibit $\mathrm{Cr}(\mathrm{VI})$ adsorption because its concentration $(0.10 \mathrm{M})$ was 2500 times as high as $\mathrm{Cr}(\mathrm{VI})$ concentration $(40 \mu \mathrm{M})$. Sulfide adsorption $\mathrm{pH} 7.87$ was shown in Figure 4-4. It was clear that sulfide did not adsorb on kaolin, but soluble sulfide decreased approximately $13 \%$ or $104 \mu \mathrm{M}$ in the illite system.

Adsorption of $\mathbf{F e}($ II $)$ on illite: The amount of adsorbed Fe(II) onto illite was assessed in the systems with and without sulfide being present (Figure 4-5). In the control with borate buffer solution but without any sulfide, ferrous iron associated with illite was about $7 \mu \mathrm{M}$ and was constant during a 90 min of testing. In the presence of $800 \mu \mathrm{M}$ of sulfide, the adsorbed $\mathrm{Fe}(\mathrm{II})$ was increased by about $4 \mu \mathrm{M}$ in the first $30 \mathrm{~min}$ when compared to the control, then leveled off. The trend was somewhat similar to the adsorption of sulfide on illite. Comparing to the amount of sulfide adsorption of around $105 \mu \mathrm{M}$ (Fig. 4-4b), this $4 \mu \mathrm{M}$ of Fe(II), likely produced from the reduction of $\mathrm{Fe}$ (III) by sulfide, accounted for any a very small fraction of the sulfide adsorbed on illite. When a $50 \mu \mathrm{M}$ of elemental sulfur was added into the mixture of illite and sulfide, even more adsorbed $\mathrm{Fe}(\mathrm{II})$ was produced than in the system with sulfide alone. The increased amount was about 1.5 to $2 \mu \mathrm{M}$. It was likely that the externally added elemental sulfur increased the activity of sulfide, which led to more Fe(III) reduced from the reaction between illite and sulfide.

No dissolved $\mathrm{Fe}(\mathrm{II})$ in the filtrate could be detected in all experiments, which indicated that $\mathrm{Fe}(\mathrm{II})$ was strongly adsorbed on the surface of illite at pH8.27.

Effect of $\mathrm{Fe}$ (II) on the reaction: To investigate whether Fe(II) from illite leads to catalysis of $\mathrm{Cr}(\mathrm{VI})$ reduction by sulfide, two types of experiments were designed: (i) addition of Fe(II) into the homogeneous system with $\mathrm{Cr}(\mathrm{VI})$ and sulfide and (ii) addition of phenanthroline into the system with $\mathrm{Cr}(\mathrm{VI})$, sulfide, and also illite. Phenanthroline is a strong chelating agent for Fe(II) and thus expected to the activities involving Fe(II). The effects of Fe(II) and phenanthroline were assessed against the homogeneous control system with $\mathrm{Cr}(\mathrm{VI})$ and sulfide. As shown in Fig. 4-6, addition of low concentration of $\mathrm{Fe}(\mathrm{II})(5.0 \mu \mathrm{M})$ into the homogeneous system dramatically accelerated the $\mathrm{Cr}(\mathrm{VI})$ reduction reaction as compared to the control. Kinetic behavior for $\mathrm{Cr}(\mathrm{VI})$ reduction was similar to the system with $3.0 \mathrm{~g} / \mathrm{L}$ illite, where about 7 to $11 \mu \mathrm{M} \mathrm{Fe}(\mathrm{II})$ in the adsorbed form was produced during the time period. Phenanthroline did not affect the reduction of $\mathrm{Cr}$ (VI) by sulfide in homogeneous system. It was interesting to notice that in the illite system, phenanthroline could 

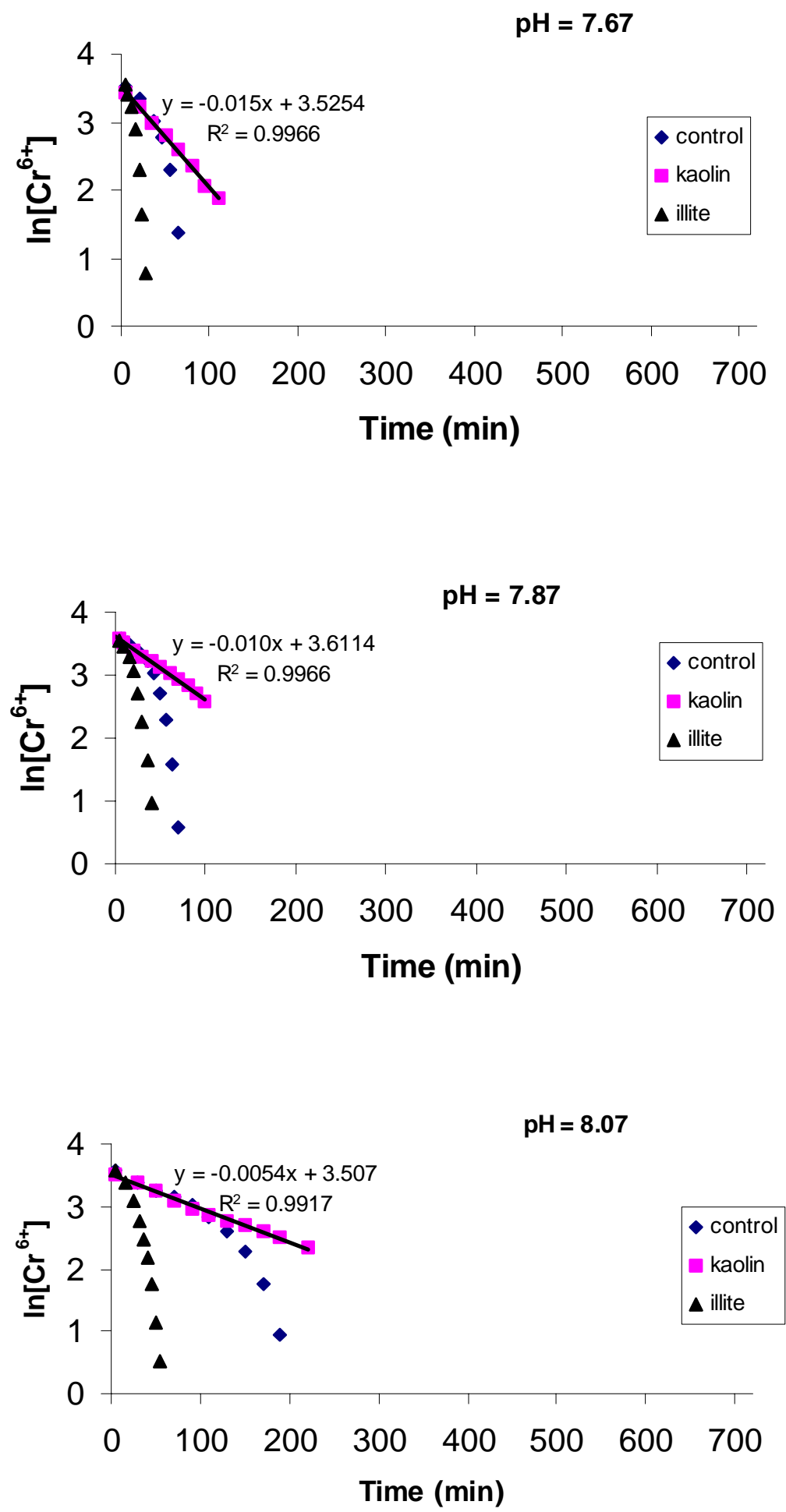

Figure 4-2. Kinetics of $\mathrm{Cr}(\mathrm{VI})$ reduction with and without solid surfaces at various $\mathrm{pHs}$ $\left([\mathrm{Cr}(\mathrm{VI})]_{0}=40.040 \mu \mathrm{M} \text {; [sulfide }\right]_{0}=800 \mu \mathrm{M}$; [illite or kaolin $]_{0}=3.0 \mathrm{~g} / \mathrm{L} ; \mathrm{pH}$ levels: 7.67 , $7.87,8.07,8.27,8.67$ and 9.07). 

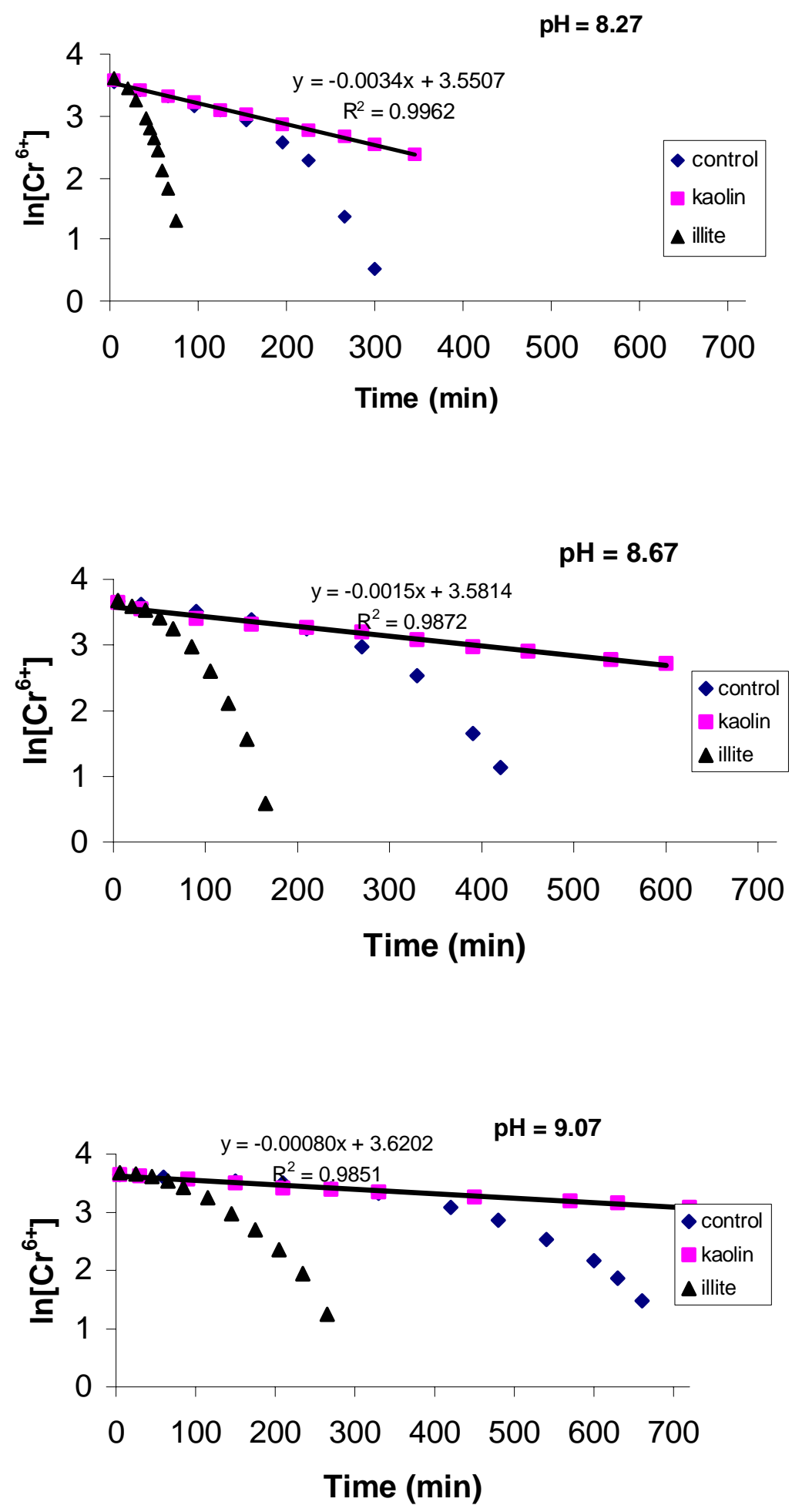

Figure 4-2 (Continued) 


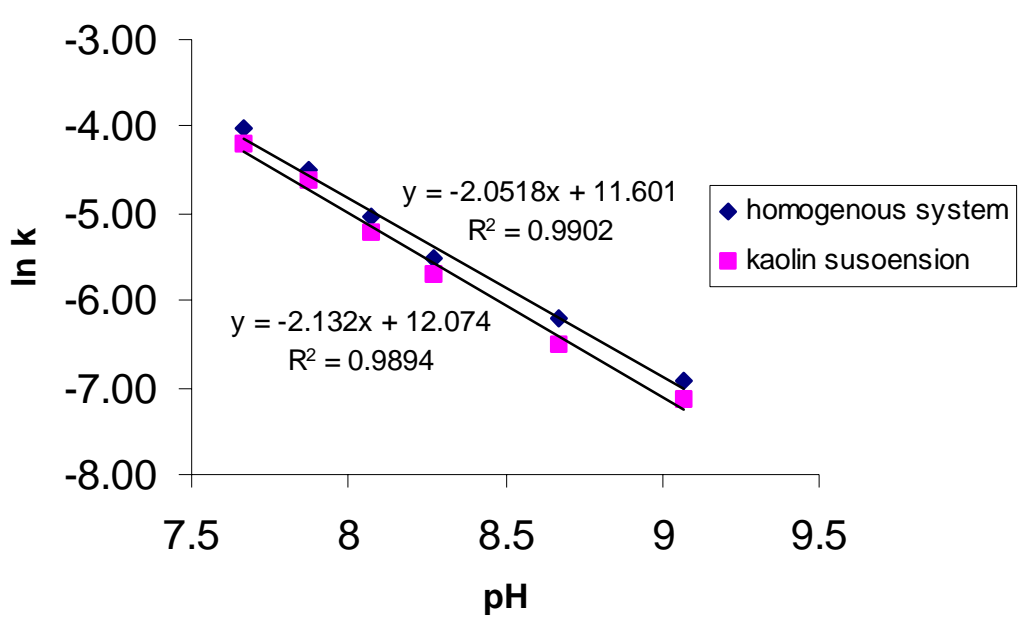

Figure 4-3. $\ln k_{\text {obs }}$ V.s. $\mathrm{pH}$ plots in the homogeneous system and kaolin systems. $k_{\mathrm{obs}}$ in the homogeneous system was obtained using the data collected in the initial stage of the reaction, where 35 to $50 \%$ of original $\mathrm{Cr}(\mathrm{VI})$ was reduced.

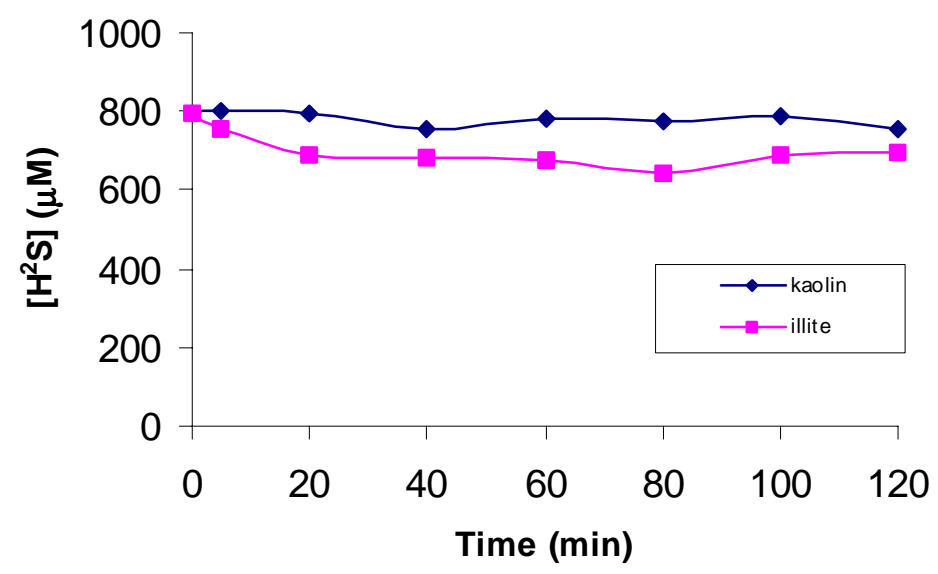

Figure 4-4. Adsorption of sulfide in the illite and kaolin systems at $\mathrm{pH} 7.87$. The initial sulfide concentration is $800.0 \mu \mathrm{M}$. 


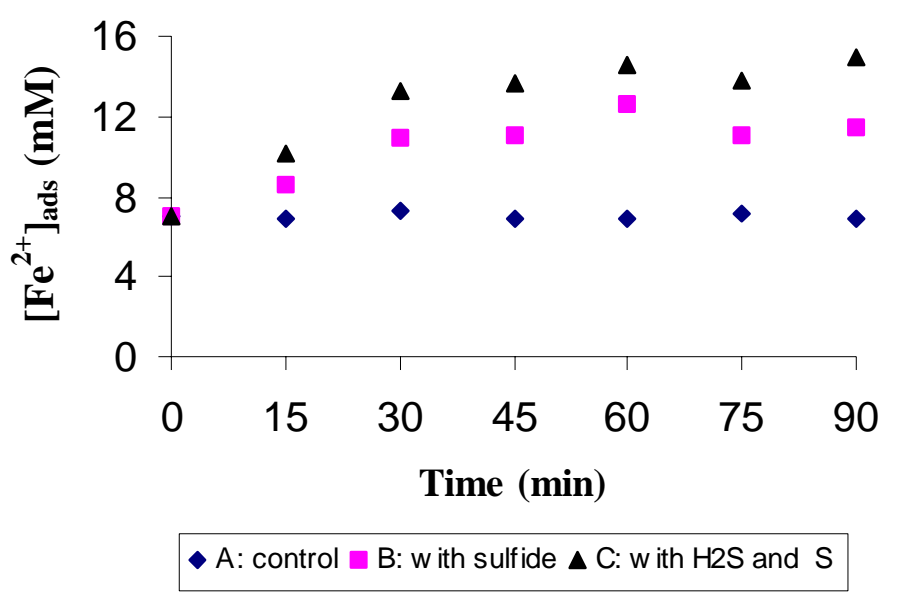

Figure 4-5. Adsorbed amounts of Fe(II) measured in the illite systems at pH8.27 (borate buffer). (A) control, (B) with $800 \mu \mathrm{M}$ sulfide, (C) with $800 \mu \mathrm{M}$ sulfide and $50 \mu \mathrm{M}$ added elemental sulfur.

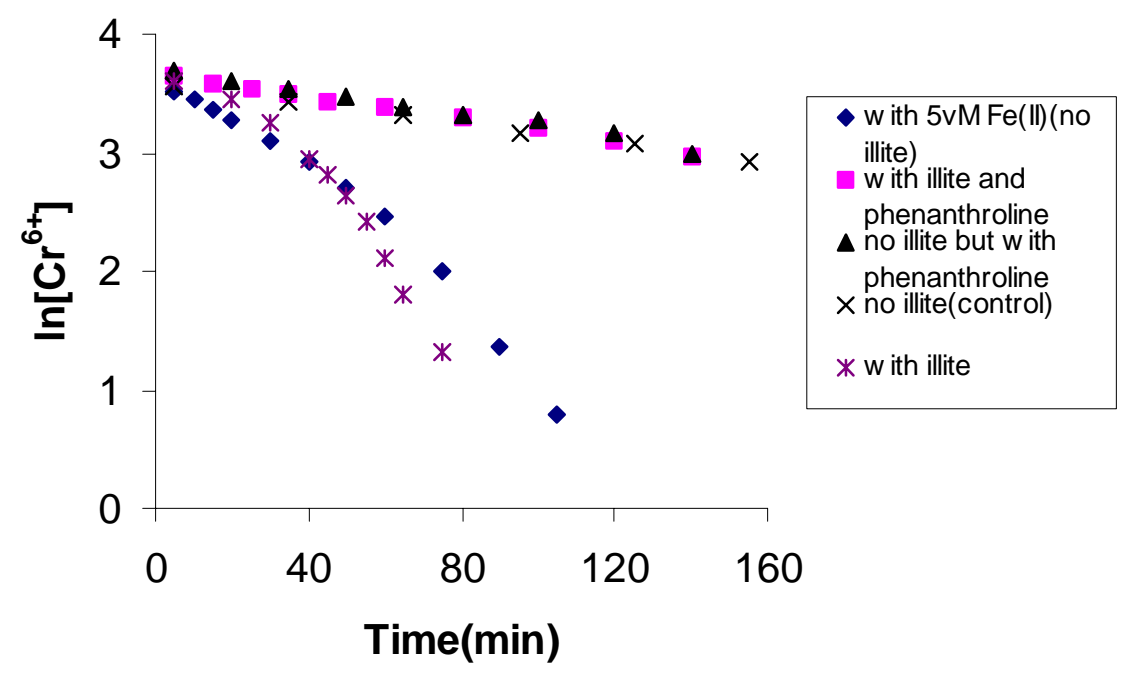

Figure 4-6. Effect of ferrous iron on the reduction of $\mathrm{Cr}(\mathrm{VI})$ by sulfide at $\mathrm{pH} 8.27$

completely block the effect of illite on the reduction of $\mathrm{Cr}(\mathrm{VI})$. In fact, in the following three

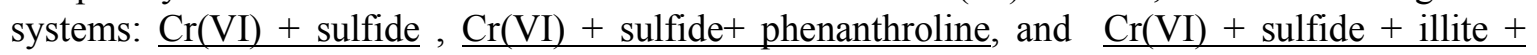
phenanthroline, the $\ln [\mathrm{Cr}(\mathrm{VI})]$ versus time plots were all linear with almost the same rate constant. The results suggested that both dissolved Fe(II) and absorbed Fe(II) could catalyze catalyze $\mathrm{Cr}(\mathrm{VI})$ reduction by sulfide, but once $\mathrm{Fe}(\mathrm{II})$ is in the chelated form with phenanthroline, it's catalytic capability disappeared. 


\section{CONCLUSIONS}

Experiments in this section showed that the minerals could be categorized into three groups in terms of their effects on $\mathrm{Cr}(\mathrm{VI})$ reduction by sulfide. Illite exhibited dramatic catalytic effect on the reduction of $\mathrm{Cr}(\mathrm{VI})$ by sulfide. $\mathrm{Al}_{2} \mathrm{O}_{3}$ showed no obvious effect on the reaction. The third group, which included kaolin, montmorillonite, $\mathrm{SiO}_{2}$ and $\mathrm{TiO}_{2}$, inhibited the reduction of $\mathrm{Cr}(\mathrm{VI})$ as compared to the control without minerals being present. In the illite suspension, ferrous iron produced from the mineral dissolution, although at low concentration, was likely responsible for the rate acceleration by serving as an electron shuttle. The reaction rate increased with increasing $\mathrm{Fe}$ (II) concentration and at the later stage, the effect of elemental sulfur product could also be observed. When a strong Fe(II) chelating agent such as phenanthroline was added into the system, the effect of illite on $\mathrm{Cr}(\mathrm{VI})$ disappeared, suggesting Fe(II) bound to the strong ligand could not act as a catalyst. The inhibitive behavior observed for the third group was likely due to the uptake of elemental sulfur product on the mineral surfaces, so the catalytic effect from elemental sulfur was hindered. 
(Kirk J. Cantrell, Steven B.Yabusaki, Mark H. Engelhard, Alexandre H. Mitroshkov and Edward C. Thornton)

\section{$\underline{\text { INTRODUCTION }}$}

In situ gaseous reduction (ISGR) has been demonstrated to be an effective remediation technology for in situ immobilization of chromate in vadose zone sediments/soils (Thornton et al.1999). This gas phase approach for vadose zone treatment offers significant benefits over liquid phase in situ treatment approaches and excavation methods. For liquid phase in situ treatment, control of the treatment liquid within the desired volume of the vadose zone is difficult and has the potential to cause unintentional mobilization of the contaminants. Excavation is typically expensive, requiring ex-situ treatment, disposal and backfilling. Excavation also can also have practical limitations when the depth of contamination is great. The approach taken with the ISGR technology is to mix $\mathrm{H}_{2} \mathrm{~S}$ with a carrier gas (typically air or nitrogen) and pump the mixture through a central injection well installed within the contaminated volume of the vadose zone. Surrounding the injection well are a series of extraction wells that use vacuum pumps to draw gas through and treat the desired volume of the contaminated vadose zone. The primary reaction of interest for chromate immobilization is generalized as follows:

$2 \mathrm{CrO}_{4}^{2-}+3 \mathrm{H}_{2} \mathrm{~S}(\mathrm{~g})+2 \mathrm{H}_{2} \mathrm{O}=2 \mathrm{Cr}(\mathrm{OH})_{3}(\mathrm{~s})+3 \mathrm{~S}^{0}+4 \mathrm{OH}^{-}$

It is assumed that the chromate is adsorbed or precipitated onto soil surfaces. In this process, the highly mobile chromate anion is reduced to $\mathrm{Cr}^{3+}$ that precipitates as the hydroxide with a solubility that is generally less than the drinking water standard for $\mathrm{pH}$ values between 6 and 12 (Rai et al. 1987).

At room temperature, the rate of gas phase oxidation of $\mathrm{H}_{2} \mathrm{~S}$ by oxygen is negligible; however, iron oxides are well-known oxidizing reagents and oxidation catalysts for $\mathrm{H}_{2} \mathrm{~S}$ (Davydov et al., 1998; Wieckowska, 1995). For most soils the quantity of iron oxides that can act to oxidize $\mathrm{H}_{2} \mathrm{~S}$ will greatly exceed the quantity of the reducible target contaminants. As a result, it expected that the quantity of $\mathrm{H}_{2} \mathrm{~S}$ required to remediate a site and the rate of treatment will typically be dependent upon the quantity and form of the iron oxides in the soils and not on the amount of contaminants present. For example at the White Sands Missile Range pilot demonstration, the average $\mathrm{Fe}^{3+}$ concentration in the sediments was approximately $1,300 \mathrm{mg} / \mathrm{kg}$, whereas the maximum $\mathrm{Cr}(\mathrm{VI})$ concentration was $85 \mathrm{mg} / \mathrm{kg}$ (Thornton et al., 1999).

The objective of this work is to develop a mechanistic understanding of the important reactions that occur between $\mathrm{H}_{2} \mathrm{~S}$ and iron oxides and to determine the reaction rates between $\mathrm{H}_{2} \mathrm{~S}$ and iron oxides. These reaction rates are required for the development of design and simulation models that can accurately predict the effectiveness of ISGR technology for environmental remediation applications.

\section{BACKGROUND}

Interactions between iron oxides or hydroxides $\mathrm{H}_{2} \mathrm{~S}$ for removal of $\mathrm{H}_{2} \mathrm{~S}$ from fuel gases such as natural gas and coal gas have been studied for well over a century. Davydov et al. (1998) recently summarized the stoichiometries for reaction of $\mathrm{H}_{2} \mathrm{~S}$ with ferric hydroxide as follows: 
$2 \mathrm{Fe}(\mathrm{OH})_{3}(\mathrm{~s})+3 \mathrm{H}_{2} \mathrm{~S}(\mathrm{~g}) \rightarrow 2 \mathrm{FeS}(\mathrm{s})+1 / 8 \mathrm{~S}_{8}(\mathrm{~s})+6 \mathrm{H}_{2} \mathrm{O}$

$2 \mathrm{Fe}(\mathrm{OH})_{3}(\mathrm{~s})+3 \mathrm{H}_{2} \mathrm{~S}(\mathrm{~g}) \rightarrow 2 \mathrm{Fe}_{2} \mathrm{~S}_{3}(\mathrm{~s})+6 \mathrm{H}_{2} \mathrm{O}$

It was indicated that others have proposed that the initial reaction of $\mathrm{Fe}_{2} \mathrm{O}_{3}$ with $\mathrm{H}_{2} \mathrm{~S}$ produces $\mathrm{Fe}_{2} \mathrm{~S}_{3}$ (Kattner et al. 1988)

$\mathrm{Fe}_{2} \mathrm{O}_{3}(\mathrm{~s})+3 \mathrm{H}_{2} \mathrm{~S}(\mathrm{~g}) \rightarrow \mathrm{Fe}_{2} \mathrm{~S}_{3}(\mathrm{~s})+3 \mathrm{H}_{2} \mathrm{O}$

and that $\mathrm{Fe}_{2} \mathrm{~S}_{3}$ is thermodynamically unstable and reacts to form pyrite and $\mathrm{Fe}_{3} \mathrm{~S}_{4}$

$2 \mathrm{Fe}_{2} \mathrm{~S}_{3}(\mathrm{~s}) \rightarrow \mathrm{FeS}_{2}(\mathrm{~s})+\mathrm{Fe}_{3} \mathrm{~S}_{4}(\mathrm{~s})$

As the process proceeds, the iron (hydr)oxides become depleted. To regenerate the iron (hydr)oxides, the sulfides are reacted with oxygen to produce iron (hydr)oxides and sulfur as a byproduct (Kohl and Riesefedl, 1985, Wieckowska, 1995, and Kattner et al, 1988)

$$
\begin{aligned}
& 4 \mathrm{FeS}(\mathrm{s})+6 \mathrm{H}_{2} \mathrm{O}+3 \mathrm{O}_{2}(\mathrm{~g}) \rightarrow 4 \mathrm{Fe}(\mathrm{OH})_{3}(\mathrm{~s})+1 / 2 \mathrm{~S}_{8}(\mathrm{~s}) \\
& 2 \mathrm{Fe}_{2} \mathrm{~S}_{3}(\mathrm{~s})+6 \mathrm{H}_{2} \mathrm{O}+3 \mathrm{O}_{2}(\mathrm{~g}) \rightarrow 4 \mathrm{Fe}(\mathrm{OH})_{3}(\mathrm{~s})+3 / 4 \mathrm{~S}_{8}(\mathrm{~s}) \\
& 2 \mathrm{Fe}_{2} \mathrm{~S}_{3}(\mathrm{~s})+3 \mathrm{O}_{2}(\mathrm{~g}) \rightarrow 2 \mathrm{Fe}_{2} \mathrm{O}_{3}(\mathrm{~s})+3 / 4 \mathrm{~S}_{8}(\mathrm{~s})
\end{aligned}
$$

It should be noted that these equations represent the net stoichiometry of the reactions, other intermediate reaction steps may occur and therefore these reactions may not represent the complete reaction mechanisms, but represent the overall reaction pathways.

\section{EXPERIMENTAL METHODS}

Column experiments were conducted by mixing $1 \% \mathrm{H}_{2} \mathrm{~S}$ in nitrogen with a carrier gas to produce a final influent $\mathrm{H}_{2} \mathrm{~S}$ concentration of approximately $200 \mathrm{ppm}_{\mathrm{v}}$. Three carrier gases were used: dry nitrogen, dry air (21\% oxygen) and $100 \%$ oxygen. Electronic gas mass flow controllers/ flowmeters (Aalborg, Orangeburg, New York) were used to control the flow rates of both gas streams. Electronic gas mass flowmeters were used to measure the influent and effluent flow and to verify that no significant leaks occurred in the system. The experiments were conducted at room temperature $\left(20^{\circ} \mathrm{C}\right.$ to $\left.24^{\circ} \mathrm{C}\right)$. The substrate used for most experiments was ferrihydrite coated quartz sand. The procedure used to make the ferrihydrite coated quartz sand is detailed elsewhere (Szecsody et al. 1994). Briefly, acid washed Fisher silica (approximately $1.0 \mathrm{~mm}$ to 0.3 $\mathrm{mm}$ ) was coated with iron oxide gel previously synthesized by hydrolysis of a $0.24 \mathrm{~mol} \mathrm{~L}^{-1}$ ferric chloride solution. The ferric oxyhydroxide gel was equilibrated approximately $24 \mathrm{~h}$ at $\mathrm{pH} 7.5$ before mixing with the sand. The mixture was aged for approximately 4 days with $\mathrm{pH}$ adjustment to maintain the $\mathrm{pH}$ between 6.5 and 7.0 , and was washed daily with $0.1 \mathrm{mmol} \mathrm{L}^{-1} \mathrm{NaCl}$. The coated material was then filtered in a large Buchner funnel and air-dried. Some darker iron oxide material that did not attach to the sand was removed by rinsing with deionized water over a \#45 sieve $(354 \mu \mathrm{m})$. The final iron concentration of this material was approximately $0.27 \% \mathrm{Fe}^{3+}$ by weight. Additional substrates included $1 \%$ goethite and $1 \%$ hematite coated sand and a $<2 \mathrm{~mm}$ Hanford sediment.. Preparation of the $1 \%$ goethite and $1 \%$ hematite coated sands involved adding $1 \%$ by weight of dry goethite or hematite powder to dry sand, placing the sand mix in a glass sample jar and rotating overnight. The goethite $(\alpha-\mathrm{FeO}(\mathrm{OH}))$ was obtained from Afla Aesar as a powder. The hematite was from Ironton, $\mathrm{MN}$ and was crushed to $<106 \mu \mathrm{m}$. XRD analysis 
of these mineral indicated that the goethite was essentially pure, while the hematite had a minor amount of quartz impurity. The Hanford sediment was sieved to less than $2 \mathrm{~mm}$ and contained $0.29 \%$ ferric iron as determined by $0.5 \mathrm{M} \mathrm{HCl}$ extraction. The experiments were conducted in $30.0 \mathrm{~cm}$ long x $0.9 \mathrm{~cm}$ ID Spectra/Chrom Glass columns. Teflon tubing was used to deliver the gas to and from the columns. Three flowrates were used 102, 204, and 510 standard cubic centimeters per minute $\left(17.6,35.2,87.9\right.$ pore volumes per minute). $\mathrm{H}_{2} \mathrm{~S}$ was measured in the influent and effluent with electrochemical gas sensors (EIT, Exton, PA). The sensors were calibrated with certified standards containing $100 \mathrm{ppm}_{\mathrm{v}} \mathrm{H}_{2} \mathrm{~S}$ in nitrogen. EIT sensors were also used to verify that no $\mathrm{SO}_{2}(\mathrm{~g})$ formed during the experiments.

Once the $\mathrm{H}_{2} \mathrm{~S}$ in the effluent exceeded approximately $90 \%$ of the influent concentration, flow to the column was stopped and the column was transferred to an anaerobic chamber. The iron oxide coated sand was removed from the column and homogenized. Three separate extractions were conducted to determine reaction products. Extractions for sulfate, thiosulfate, and sulfite were conducted by adding $10.0 \mathrm{mls}$ of oxygen free deionized water to 2.00 grams of sand in a centrifuge tube. The tube was placed on a rotator for approximately 24 hours in the anaerobic chamber. The extracts were analyzed by ion chromatography (Dionex, DX-120). An IonPac AS9-HC analytical column and an IonPac AG9-HC guard column were used. The eluent was 9.0 $\mathrm{mM}$ solution of $\mathrm{Na}_{2} \mathrm{CO}_{3}$ with a flow rate of $1.0 \mathrm{~mL} / \mathrm{min}$. Complete separation of all observed anions including sulfur-containing anions such as sulfate, sulfite, and thiosulfate was routinely achieved. Elemental sulfur was determined by extracting $1.00 \mathrm{gm}$ of sand with $5.00 \mathrm{mls}$ of benzene followed by Gas Chromatography - Mass Spectrometry (GC-MS) analysis using an HP5890/5970 system. In this procedure, an HP-1 capillary column $(\mathrm{L}=30 \mathrm{~m}, 0.32 \mathrm{~mm}$ i.d., 0.17 $\mu \mathrm{m}$ film) was used. The temperature program was $50^{\circ} \mathrm{C}$ to $250^{\circ} \mathrm{C} @ 15^{\circ} \mathrm{C} / \mathrm{min}$., with a $5 \mathrm{~min}$. hold time. Each analysis included a four level calibration was conducted using an SV Internal Standard Mix (RESTEK, \#31006). Ferrous and ferric iron extractions were conducted by adding 2.00 grams of sand to $10.0 \mathrm{mls}$ of oxygen free $0.5 \mathrm{M} \mathrm{HCl}$ and rotating the mixture in tubes in the anaerobic chamber for approximately 24 hours. The iron was analyzed colorimetrically with the phenathroline method (Loeppert and Inskeep, 1996).

Surface analysis of the reacted iron oxide coated sand was conduced with X-ray photoelectron spectroscopy (XPS) to identify reaction products. XPS measurements were made on a Physical Electronics Quantum 2000 Scanning ESCA Microprobe. This system uses a focused monochromatic Al Ka x-ray $(1486.7 \mathrm{eV})$ source for excitation and a spherical section analyzer. The instrument has a 16 element multichannel detection system. The X-ray beam used was a $100 \mathrm{~W}, 100 \mathrm{um}$ diameter beam that is rastered over a $1.4 \mathrm{~mm}$ by $0.2 \mathrm{~mm}$ rectangle on the sample. The x-ray beam is incident normal to the sample and the $\mathrm{x}$-ray detector is at $45^{\circ}$ away from the normal. The survey scans were collected using a pass energy of $117.4 \mathrm{eV}$. For the $\mathrm{Ag} \mathrm{3d} \mathrm{5/2}$ these conditions produce FWHM of better than $1.6 \mathrm{eV}$. The high-energy resolution data was collected using a pass energy of $23.5 \mathrm{eV}$. For the $\mathrm{Ag} 3 \mathrm{~d} 5 / 2$ these conditions produce FWHM of better than $0.75 \mathrm{eV}$. The collected data were referenced to an energy scale with binding energies for $\mathrm{Cu} 2 \mathrm{p} 3 / 2$ at $932.67 \pm 0.05 \mathrm{eV}$ and $\mathrm{Au} 4 \mathrm{f}$ at $84.0 \pm 0.05 \mathrm{eV}$. Low energy electrons and argon ions were used for specimen neutralization.

\section{RESULTS AND DISCUSSION}

$\boldsymbol{H}_{2} \mathrm{~S}$ Reaction with Ferrihydrite: $\mathrm{H}_{2} \mathrm{~S}$ breakthrough curves for three column experiments with the ferrrihydrite coated sand, using three different carrier gases, conducted at a flowrate of $102 \mathrm{sccm}$ are shown in Figure 5-1. These curves are plotted as the ratio of effluent concentration over influent concentration vs. time. The influent $\mathrm{H}_{2} \mathrm{~S}$ concentration in each case was approximately 
$200 \mathrm{ppm}_{\mathrm{v}}$. The carrier gases used were nitrogen, air (21\% oxygen), and $100 \%$ oxygen. The fastest breakthrough occurs when the carrier gas is $100 \%$ oxygen. The second fastest breakthrough occurs when air is the carrier gas and the slowest breakthrough occurs when $\mathrm{N}_{2}$ is the carrier gas.

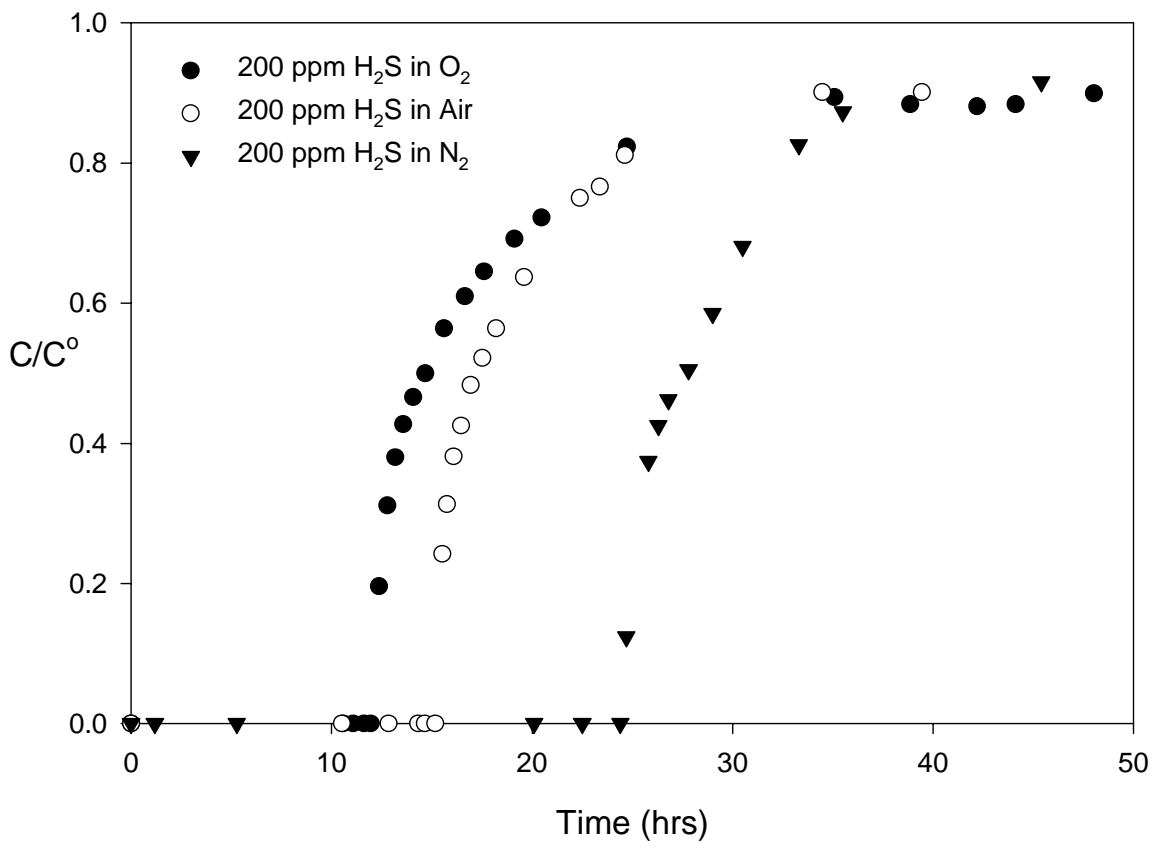

Figure 5-1. $\mathrm{H}_{2} \mathrm{~S}$ breakthrough curves for ferrihydrate coated sand $\left(0.27 \% \mathrm{Fe}^{3+}\right)$ in various carrier gases $\left(200 \mathrm{ppm} \mathrm{H}_{2} \mathrm{~S}\right)$ at a flowrate of $102 \mathrm{sccm}$.

Column breakthrough curves for three different flowrates, where $\mathrm{N}_{2}$ was used as the carrier gas, are plotted in Figure 5-2. In this case, the ratio of effluent concentration over influent concentration is plotted against the ratio of the total moles of $\mathrm{H}_{2} \mathrm{~S}$ reacted over the total moles of $\mathrm{Fe}^{3+}$ in the column. The breakthrough curves are shifted to lower $\mathrm{H}_{2} \mathrm{~S} / \mathrm{Fe}^{3+}$ ratios at the flowrate increases. This is consistent with a rate-controlled process. If the reactions occurred as an equilibrium process, these breakthrough curves would be expected to be coincident. 


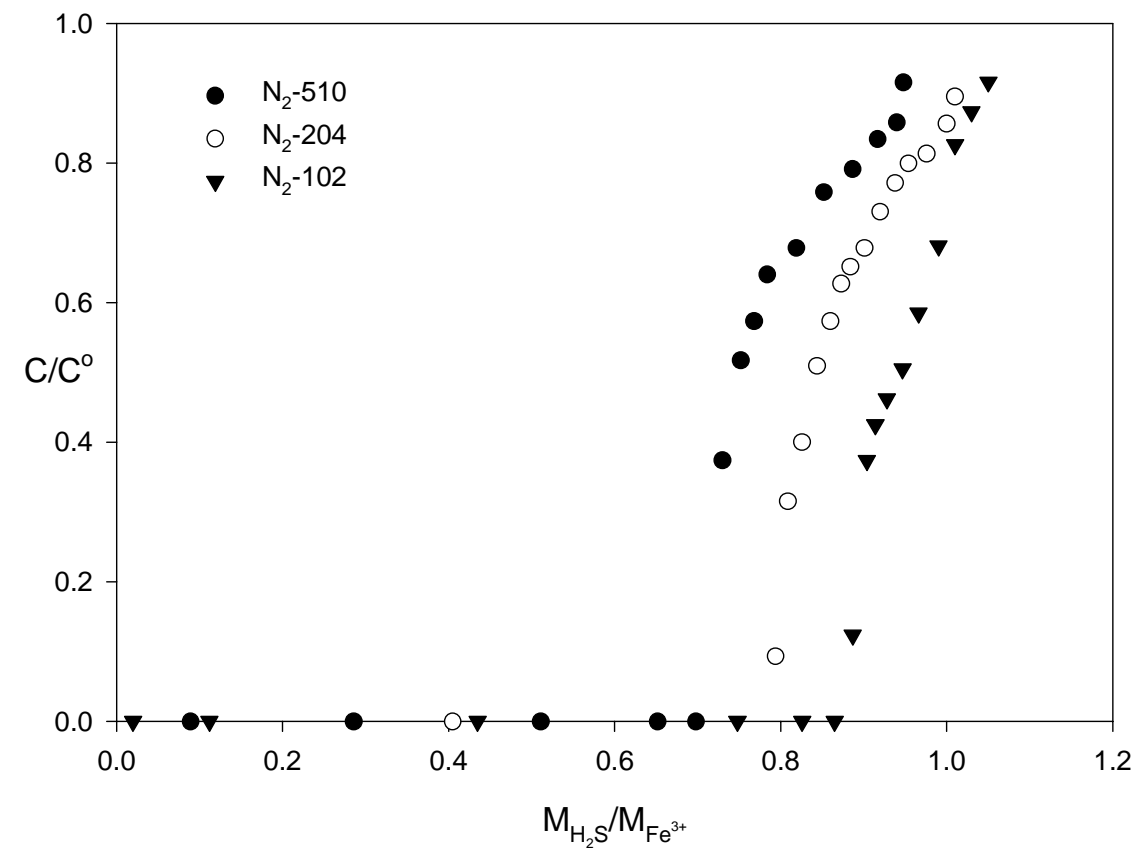

Figure 5-2. $\mathrm{H}_{2} \mathrm{~S}$ breakthrough curves for ferrihydrite coated sand $\left(0.27 \% \mathrm{Fe}^{3+}\right)$ in nitrogen $\left(200 \mathrm{ppm}_{2} \mathrm{~S}\right)$ at various flowrates.

Mass balance results (on a molar basis) for each of the column experiments are presented in Table 1. Included in the table is the column name (determined from the carrier gas and flowrate in standard cubic centimeters per minute), the initial (unreacted) ferric iron content determined from the $0.5 \mathrm{M} \mathrm{HCl}$ extracts, quantity of $\mathrm{H}_{2} \mathrm{~S}$ that reacted within the column, the ferrous iron ( $\left.\mathrm{FeS}\right)$, sulfur, moles of thiosulfate-sulfur, moles of sulfate-sulfur and moles of $\mathrm{FeS}_{2}$-sulfur. The $0.5 \mathrm{M}$ $\mathrm{HCl}$ extraction will dissolve $\mathrm{FeS}$ but not $\mathrm{FeS}_{2}$ (Heron et al., 1994); therefore, $\mathrm{FeS}_{2}$ sulfur was determined by assuming that the difference between the total iron before and after the experiment was $\mathrm{FeS}_{2}$. A breakthrough experiment conducted on the silica sand (with no ferrihydrate) indicated that $\mathrm{H}_{2} \mathrm{~S}$ adsorption onto the silica surfaces was negligible.

Table 1. Mole balance for column experiments (n.m. - not measured, n.d. - not detected).

\begin{tabular}{|l|l|l|l|l|l|l|l|l|}
\hline Column & $\begin{array}{l}\text { Init. } \\
\text { Fe }^{3+}\end{array}$ & $\begin{array}{l}\mathbf{H}_{2} \mathbf{S} \\
\text { Used }\end{array}$ & $\mathbf{F e}^{2+}(\mathbf{F e S})$ & $\begin{array}{l}\text { Sulfur- } \\
\text { S }\end{array}$ & Thio-S & $\begin{array}{l}\text { Sulfate- } \\
\text { S }\end{array}$ & FeS $_{2}-\mathbf{S}$ & $\begin{array}{l}\text { Total-S } \\
\text { Products }\end{array}$ \\
\hline $\mathrm{N}_{2}-102$ & $1.67 \mathrm{e}-3$ & $1.95 \mathrm{e}-3$ & $1.33 \mathrm{e}-3$ & $6.60 \mathrm{e}-4$ & $7.40 \mathrm{e}-6$ & $2.60 \mathrm{e}-6$ & n.d. & $2.00 \mathrm{e}-3$ \\
\hline $\mathrm{N}_{2}-204$ & $1.70 \mathrm{e}-3$ & $1.85 \mathrm{e}-3$ & $1.33 \mathrm{e}-3$ & $4.90 \mathrm{e}-4$ & n.m. & n.m. & n.d. & $1.82 \mathrm{e}-3$ \\
\hline $\mathrm{N}_{2}-510$ & $1.69 \mathrm{e}-3$ & $1.60 \mathrm{e}-3$ & $1.43 \mathrm{e}-3$ & $5.30 \mathrm{e}-4$ & n.m. & n.m. & n.d. & $1.96 \mathrm{e}-3$ \\
\hline $\mathrm{O}_{2}-102$ & $1.70 \mathrm{e}-3$ & $1.31 \mathrm{e}-3$ & $8.32 \mathrm{e}-5$ & $5.89 \mathrm{e}-4$ & $3.64 \mathrm{e}-5$ & $3.70 \mathrm{e}-5$ & $4.02 \mathrm{e}-4$ & $1.15 \mathrm{e}-3$ \\
\hline Air-102 & $1.64 \mathrm{e}-3$ & $1.24 \mathrm{e}-3$ & $1.05 \mathrm{e}-4$ & $6.30 \mathrm{e}-4$ & $3.28 \mathrm{e}-5$ & $4.75 \mathrm{e}-5$ & $3.91 \mathrm{e}-4$ & $1.21 \mathrm{e}-3$ \\
\hline
\end{tabular}


For easier comparisons, these values are converted to a percentage basis, relative to the quantity of $\mathrm{H}_{2} \mathrm{~S}$ (Table 2). For the $\mathrm{N}_{2}$ experiments, thiosulfate and sulfate were measured in just one experiment because it was determined that these reaction products account for a very small fraction of the total $\mathrm{H}_{2} \mathrm{~S}$ oxidation products. Note that if equation 2 is the only reaction of significance, the mole balance of $\mathrm{FeS}$ and $\mathrm{S}^{0}$ relative to the moles of $\mathrm{H}_{2} \mathrm{~S}$ consumed should be $67 \%$ and $33 \%$ respectively. The results for the $\mathrm{N}_{2}$ experiments are very close to these theoretical values and indicate that equation 2 is the primary reaction that occurs between $\mathrm{H}_{2} \mathrm{~S}$ and ferrihydrate in the absence of $\mathrm{O}_{2}$.

Table 2. Mass balances (percent $\mathrm{H}_{2} \mathrm{~S}$ basis) for column experiments (n.m. - not measured).

\begin{tabular}{|l|l|l|l|l|l|l|l|}
\hline Column & $\begin{array}{l}\mathbf{H}_{2} \mathbf{S} \\
\text { Used }\end{array}$ & $\mathbf{F e}^{2+}(\mathbf{F e S})$ & Sulfur-S & Thio-S & Sulfate-S & $\mathbf{F e S}_{2}-\mathbf{S}$ & $\begin{array}{l}\text { Total-S } \\
\text { Products }\end{array}$ \\
\hline $\mathrm{N}_{2}-102$ & 100 & 68 & 34 & 0.4 & 0.1 & 0 & 103 \\
\hline $\mathrm{N}_{2}-204$ & 100 & 72 & 26 & n.m. & n.m. & 0 & 98 \\
\hline $\mathrm{N}_{2}-510$ & 100 & 89 & 33 & n.m. & n.m. & 0 & 122 \\
\hline $\mathrm{O}_{2}-102$ & 100 & 6.3 & 45 & 2.7 & 2.8 & 31 & 88 \\
\hline Air-102 & 100 & 8.5 & 51 & 2.6 & 3.8 & 32 & 98 \\
\hline
\end{tabular}

XPS analyses were conducted on some of the reacted materials to identify the reaction products. Sulfur species results for the $\mathrm{N}_{2}-102$ column are shown in Figure 5-3. Regression analysis of these results, indicate that the reaction products are consistent with $\mathrm{FeS}$, and $\mathrm{S}^{0}$, with a small amount of sulfate. The XPS results indicate $60 \% \mathrm{FeS}$ (mackinawite, $\mathrm{Fe}_{1+\mathrm{x}} \mathrm{S}(\mathrm{x}=0.01-0.08)$ ), and $34 \% \mathrm{~S}^{0}$, and are very close to the theoretical values. The formation of mackinawite is consistent with results obtained in low temperature aqueous systems. Lennie and Vaughan (1996) indicate that the iron monosulfides mackinawite and amorphous FeS are the first formed iron sulfides in aqueous systems at low temperature and amorphous $\mathrm{FeS}$ is rapidly converts to mackinawite. The XPS results also indicated a sulfate concentration of $4.5 \%$. This value is significantly higher than that determined by analysis of the water extracts. The likely explanation for this discrepancy is that a small amount of FeS oxidation at the surface occurred as a result of brief exposure to air that occurred during the transfer of the sample from the inert atmosphere storage to the XPS sample chamber. Because XPS is a surface technique (sensitive to a depth of approximately 5 to $50 \AA$ ), the measured concentration of sulfate in this surface zone is likely to be elevated relative to the bulk sulfate content determined from the water extracts.

The results of the experiments in which oxygen and air were used as carrier gases (Tables 1 and 2) indicate that equation 2 alone cannot explain these results. A significantly higher degree of oxidation is apparent in the reaction products. For example, FeS makes up only a small fraction of the reaction products (6-9\%). Although the amount of $\mathrm{H}_{2} \mathrm{~S}$ consumed in the experiments that had oxygen in the carrier gas was about $70 \%$ of that consumed in the nitrogen carrier gas experiments, the quantity of sulfur that was produced was nearly the same or slightly higher. This suggests that reaction 6 is important when oxygen is in the carrier gas. When oxygen is in the carrier gas, a small fraction of thiosulfate and sulfate were also produced. Although the concentrations of these reaction products make up only a relatively small fraction of the total sulfur balance, they are significantly higher than observed in the nitrogen carrier gas experiments. A number of possible reaction pathways are possible for these two oxidation products; however, because of the dominance of reaction 2 in the absence of oxygen, the following reaction pathways are assumed: 


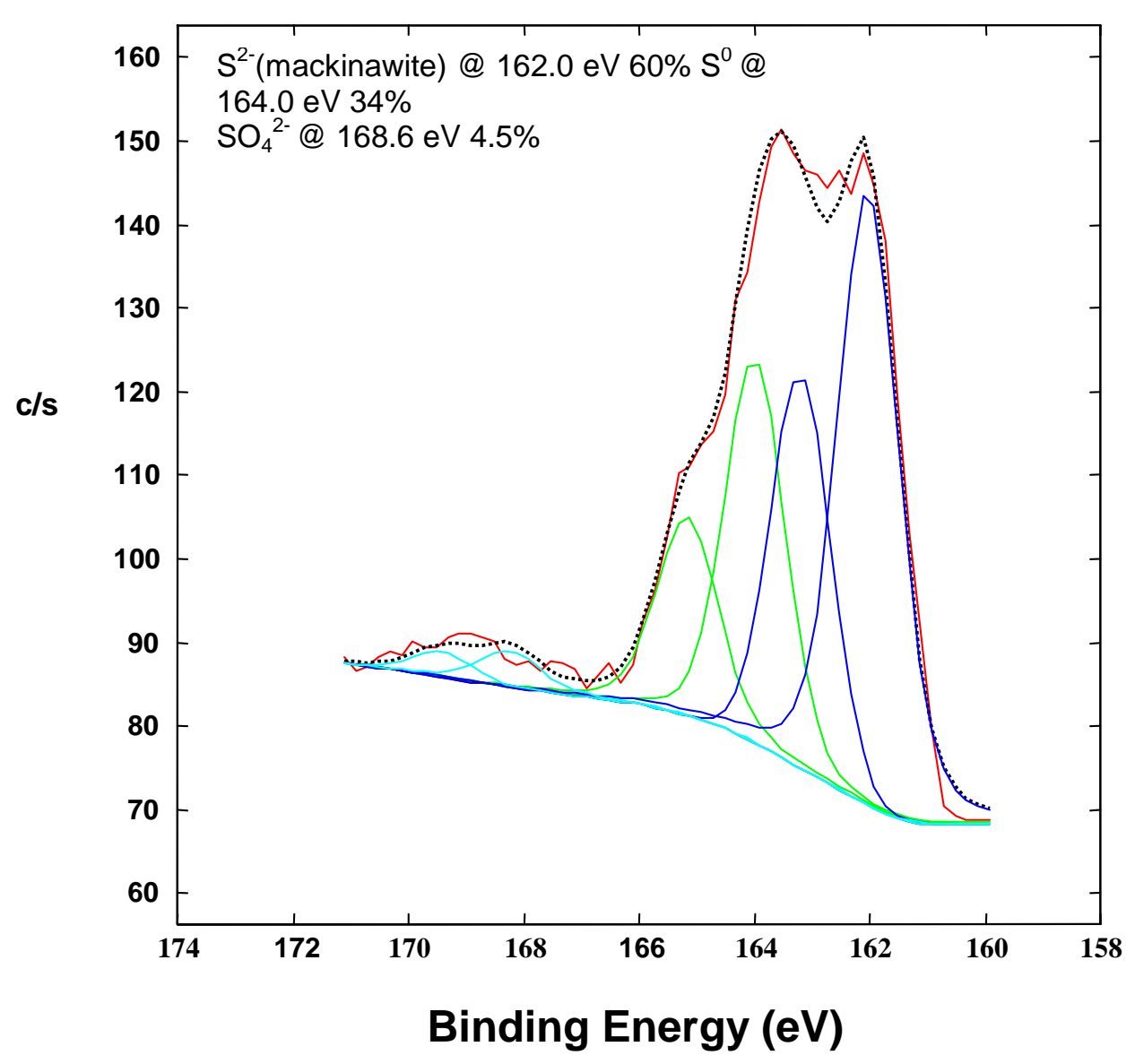

Figure 5-3. XPS spectra (dotted line) and best fit (red) for sample from column $\mathrm{N}_{2}-102$. The best fit was determined using $\mathrm{S}^{2-}$ (blue), $\mathrm{S}^{\mathrm{o}}$ (green), and $\mathrm{SO}_{4}{ }^{2-}$ (aqua).

$$
\begin{aligned}
& \mathrm{FeS}(\mathrm{s})+9 / 4 \mathrm{O}_{2}(\mathrm{~g})+5 / 2 \mathrm{H}_{2} \mathrm{O} \rightarrow \mathrm{H}_{2} \mathrm{SO}_{4}+\mathrm{Fe}(\mathrm{OH})_{3}(\mathrm{~s}) \\
& \mathrm{FeS}(\mathrm{s})+5 / 2 \mathrm{O}_{2}(\mathrm{~g})+4 \mathrm{H}_{2} \mathrm{O} \rightarrow \mathrm{H}_{2} \mathrm{~S}_{2} \mathrm{O}_{3}+\mathrm{Fe}(\mathrm{OH})_{3}(\mathrm{~s})
\end{aligned}
$$

The most significant reaction product, for the experiments that had oxygen in the carrier gas, besides sulfur, is $\mathrm{FeS}_{2}$. As indicated earlier, previous workers have indicated that $\mathrm{FeS}_{2}$ could be produced through the reaction pathway shown in equation 3 , followed by equation 5 . If this were true, it would be expected that these reactions would also occur in the absence of oxygen; however, no $\mathrm{FeS}_{2}$ is produced under these circumstances in our experiments. It should be pointed out that it is possible that not all of the reactions pathways that have been put forth in the 
literature for reaction of $\mathrm{H}_{2} \mathrm{~S}$ with iron (hydr)oxides (equations 2 though 8) are necessarily applicable to our low temperature conditions. Based on reasoning suggested earlier for the formation of thiosulfate and sulfate, it is suggested that $\mathrm{FeS}_{2}$ is produced through oxidation of FeS as follows:

$$
\mathrm{FeS}(\mathrm{s})+1 / 2 \mathrm{O}_{2}(\mathrm{~g})+\mathrm{H}_{2} \mathrm{~S}(\mathrm{~g}) \rightarrow \mathrm{FeS}_{2}(\mathrm{~s})+\mathrm{H}_{2} \mathrm{O}
$$

A variety of alternative reaction pathways could be suggested, for example, mackinawite is known to readily oxidize to greigite $\left(\mathrm{Fe}_{3} \mathrm{~S}_{4}(\mathrm{~s})\right.$ ) (Lennei et al, 1997). In our system this could occur as follows;

$$
3 \mathrm{FeS}(\mathrm{s})+1 / 2 \mathrm{O}_{2}(\mathrm{~g})+\mathrm{H}_{2} \mathrm{~S}(\mathrm{~g}) \rightarrow \mathrm{Fe}_{3} \mathrm{~S}_{4}(\mathrm{~s})+\mathrm{H}_{2} \mathrm{O}
$$

Greigite might then dissociate as proposed by Hallberg (1972);

$$
\mathrm{Fe}_{3} \mathrm{~S}_{4}(\mathrm{~s}) \rightarrow 2 \mathrm{FeS}(\mathrm{s})+\mathrm{FeS}_{2}(\mathrm{~s})
$$

this reaction is known to be thermodynamically favorable (Berner, 1967). The net reaction of equations 12 and 13; however, is equation 11. Work conducted in aqueous systems suggests that FeS reacts rapidly with sulfur to produce $\mathrm{FeS}_{2}$ (Rickard, 1975; Luther, 1991; Lennie et al., 1997):

$$
\mathrm{FeS}(\mathrm{s})+1 / 8 \mathrm{~S}_{8}(\mathrm{~s}) \rightarrow \mathrm{FeS}_{2}(\mathrm{~s})
$$

however, if equation 14 was significant for the conditions of our experiments, then it should have also occurred in the absence of oxygen (nitrogen carrier gas experiments), which it did not.

Based on this analysis it is concluded that the primary reactions of interest, for $\mathrm{H}_{2} \mathrm{~S}$ in a carrier gas containing oxygen, with ferrihydrate are equations 2, 6, and 11 . Equations 9 and 10 will play a minor role. The mass balance results of Table 2 indicate that the majority of the FeS that forms in the oxygen containing carrier gas experiments is further oxidized and that both reactions 6 and 11 are important. For example, if all the sulfur that was formed occurred only as a result of equation 2, then a percent sulfur of 33\% would be expected; however, from Table 2 it is apparent that the fraction of $\mathrm{H}_{2} \mathrm{~S}$ that becomes oxidized to sulfur is significantly higher. XPS analysis was conducted on a sample from column Air-102 in an attempt to confirm the mole balance results shown in Table 1. The results indicated that the distribution of sulfur species at the surface was 55 mole $\%$ sulfate, 34 mole $\%$ sulfur, 7 mole $\%$ sulfite, and 5 mole $\% \mathrm{~S}_{2}{ }^{2-}$ (probably marcasite). When air is in the gas phase, it can be expected that greatest degree of oxidation would occur at the surface relative to the bulk. Therefore, these results do not provide useful quantitative results to confirm the mass balance data in Tables 1 and 2 , but it does confirm that a $\mathrm{S}_{2}{ }^{2-}$ phase (presumably marcasite) does form.

$\mathrm{H}_{2} \mathrm{~S}$ Reaction with Other Iron Oxides and Natural Sediments: A comparison of $\mathrm{H}_{2} \mathrm{~S}$ column breakthrough results for one-percent goethite coated sand $\left(0.63 \% \mathrm{Fe}^{3+}\right)$ and one-percent hematite coated sand $\left(0.70 \% \mathrm{Fe}^{3+}\right)\left(200 \mathrm{ppm} \mathrm{H}_{2} \mathrm{~S}\right.$ in $\mathrm{N}_{2}$ at a flowrate of $\left.102 \mathrm{sscm}\right)$ is shown in Figure 5-4. By comparing these results with the results for ferrihydrite coated sand (containing only about half as much ferric iron) in Figure 5-1, it is clear that goethite and hematite are much less reactive than ferrihydrite. In addition, hematite is much less reactive than goethite, with very little reactivity at all. Mass balance results for these two experiments indicate that only $11 \%$ of the available ferric iron in the goethite and $0.6 \%$ of the available iron in the hematite were reduced in 
these experiments. This is sharp contrast to the ferrihydrite $\left(\mathrm{N}_{2}\right.$ carrier gas) experiments, in which approximately $80 \%$ of the available ferric iron was reduced.

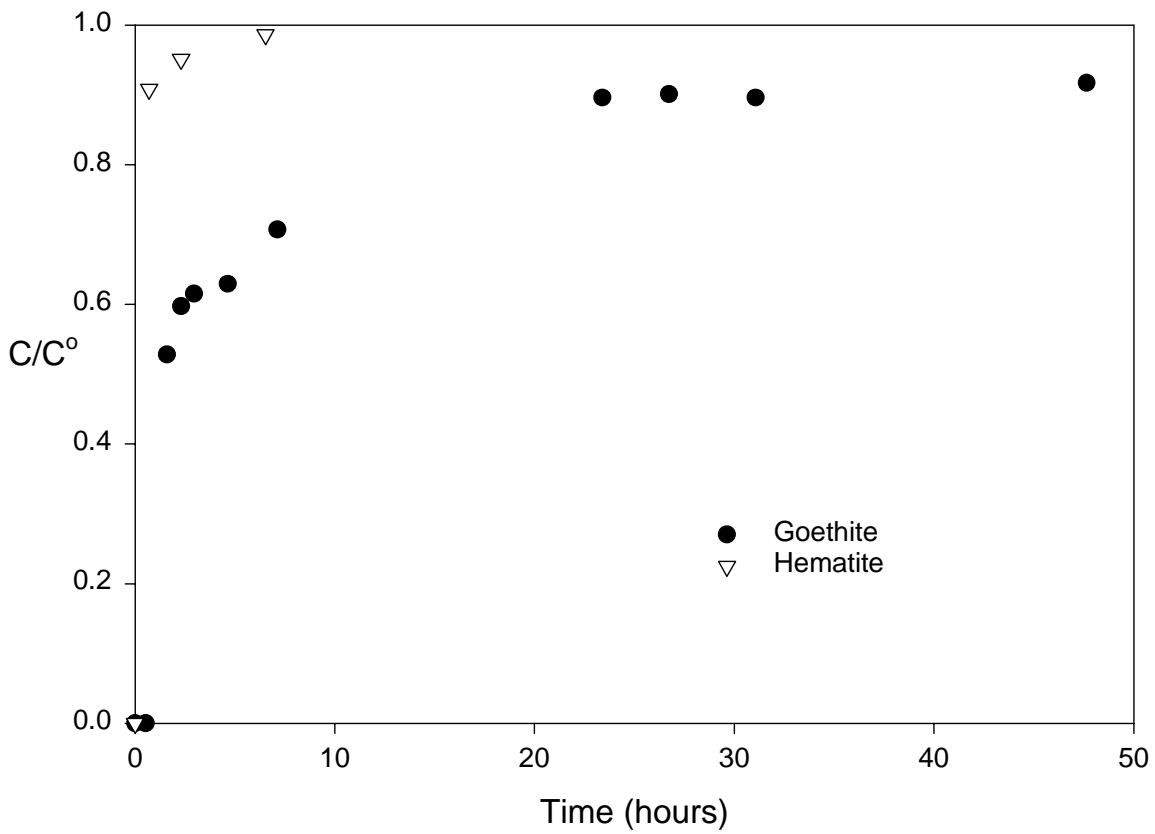

Figure 5-4. $\mathrm{H}_{2} \mathrm{~S}$ breakthrough curves for $1 \%$ goethite $\left(0.63 \% \mathrm{Fe}^{3+}\right)$ and $1 \%$ hematite $\left(0.70 \% \mathrm{Fe}^{3+}\right)$ coated sand in nitrogen $\left(200 \mathrm{ppm} \mathrm{H}_{2} \mathrm{~S}\right)$ at a flowrate of $102 \mathrm{sccm}$.

Figure 5-5 shows results for two $\mathrm{H}_{2} \mathrm{~S}$ column breakthrough curves for Hanford sediments. Both experiments were conducted at a flowrate of $102 \mathrm{sscm}$ and an $\mathrm{H}_{2} \mathrm{~S}$ concentration of $200 \mathrm{ppm}$; however, one experiment was conducted using $\mathrm{N}_{2}$ as the carrier gas and the other using air as the carrier gas. Similar to the ferrihydrite experiments shown in Figure 5-1, the experiment in which air was used for the carrier gas broke through before the experiment using $\mathrm{N}_{2}$ as the carrier gas. No significant delay prior to breakthrough occurs in these experiments. This behavior is more consistent with that observed for the goethite experiments than the ferrihydrite experiments. In the experiment in which $\mathrm{N}_{2}$ was used as the carrier gas, $64 \%$ of the available ferric iron was reduced during the experiment. These results indicate that oxidation of $\mathrm{H}_{2} \mathrm{~S}$ by iron oxides in Hanford sediments has characteristics that are similar to both ferrihydrite coated sand and goethite. The amount of available ferric iron that actually gets reduced is more similar to ferrihydrite coated sand, but the characteristics of the breakthrough curve is more similar to goethite coated sand. Further studies are required to determine the mechanism responsible for these differences in behavior. 


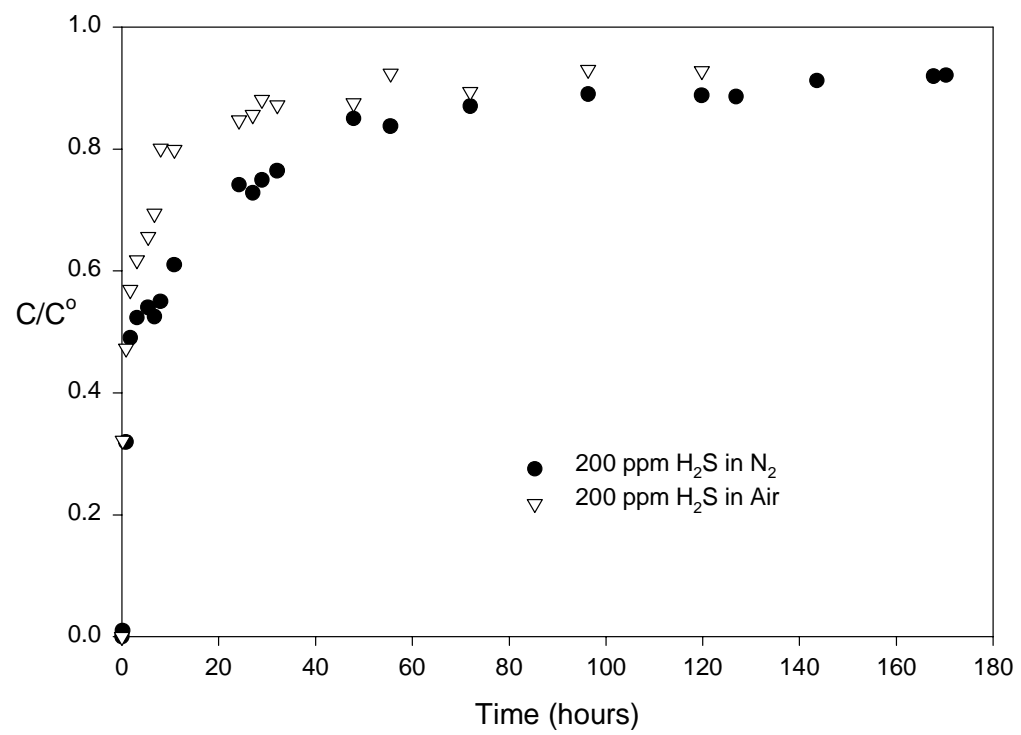

Figure 5-5. $\mathrm{H}_{2} \mathrm{~S}$ breakthrough curves for Hanford sediment $\left(0.29 \% \mathrm{Fe}^{3+}\right)$ in nitrogen and

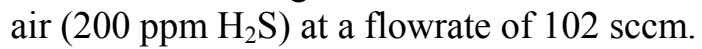

Determination of Reaction Rates and Transport Modeling: Based on the postulated sets of reactions for the nitrogen and oxygen cases, our conceptual model is based on the initial availability of $\mathrm{Fe}(\mathrm{OH})_{3}$ that can react instantaneously with $\mathrm{H}_{2} \mathrm{~S} . \mathrm{H}_{2} \mathrm{~S}$ entering the column reacts with the first $\mathrm{Fe}(\mathrm{OH})_{3}$ it encounters to form $\mathrm{FeS}$ and $\mathrm{S}$. Without any constraints on the reactivity of the $\mathrm{Fe}(\mathrm{OH})_{3}$, a reaction "front" with $\mathrm{FeS}$ and $\mathrm{S}$ behind it and unreacted $\mathrm{Fe}(\mathrm{OH})_{3}$ ahead would slowly propagate down the column with eventual breakthrough at 1.6 days. Because it is known that the actual $\mathrm{H}_{2} \mathrm{~S}$ breakthrough is considerably earlier in both nitrogen and air experiments, our conceptual model must account for the reduction in iron oxide reactivity due to the formation of secondary minerals at the surface, specifically sulfur.

The ferrihydrite precipitated on the surfaces of the quartz sand contained an average concentration of $0.269 \%$. Visually, the ferrihydrite appeared to coat the sand grains but the SEM images (Fig. 5-6) show that the ferrihydrite does not uniformly coat the sand and, in fact, exists as "patches" of varying sizes. The interpretation here is that the surfaces of these ferrihydrite "patches" are initially directly accessible to the $\mathrm{H}_{2} \mathrm{~S}$ gas and account for the bulk of the initial ferrihydrite reactivity. While the formation of secondary minerals on the ferrihydrite surfaces can eventually limit the transport of $\mathrm{H}_{2} \mathrm{~S}$ to the underlying active ferrihydrite, it is the larger and/or thicker patches with lower surface area to volume ratios that will be more susceptible to this surface "suffocation." Over time, in this conceptual model, bulk ferrihydrite reaction rates will range from essentially instantaneous down to nearly zero. 

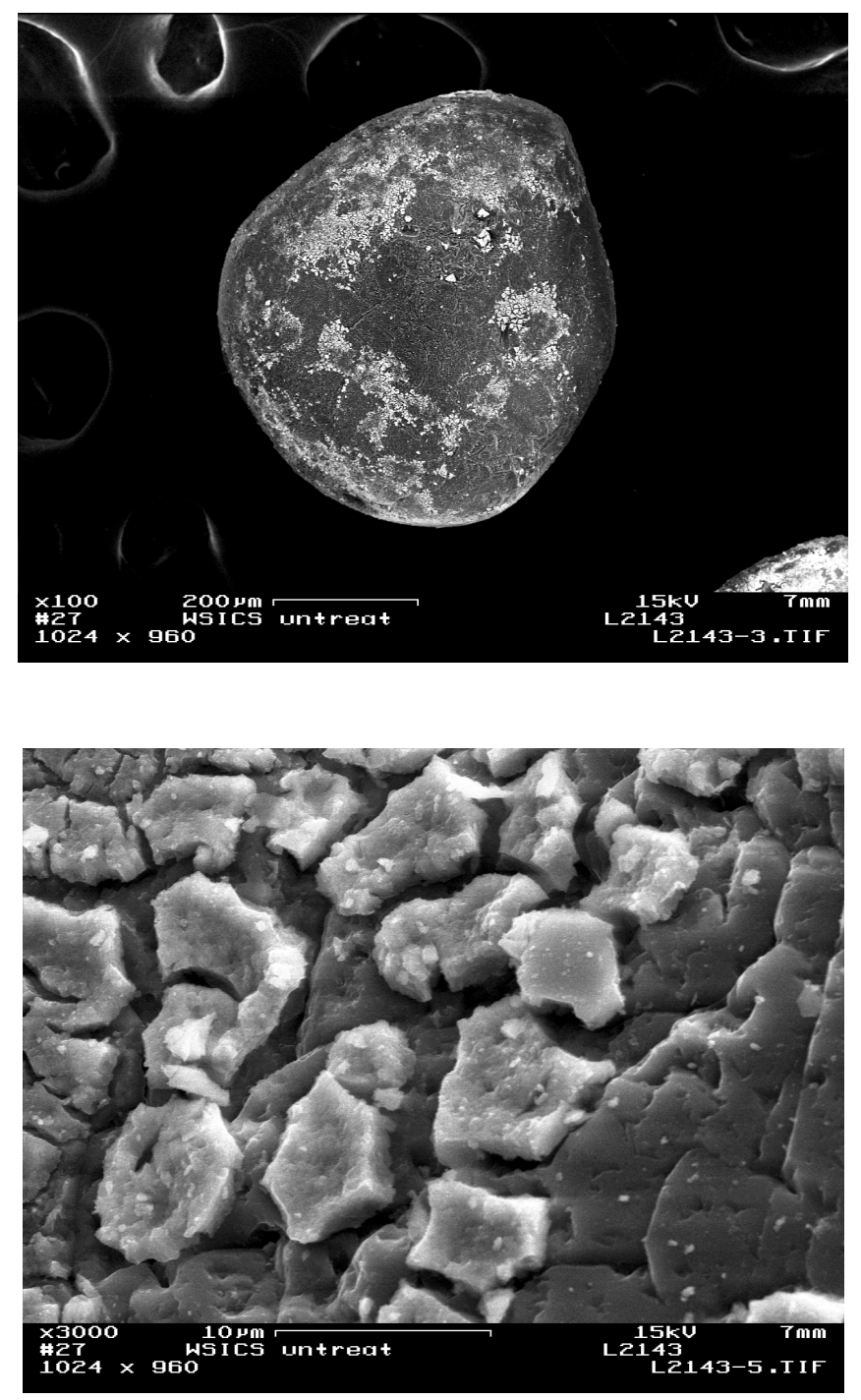

Figure 5-6. SEM Images of the Ferrihydrite Coated Sand.

The multiple reaction rates can be modeled in many ways. Two general approaches were explored: 1) parallel reactions with different reaction rates for different ferrihydrite fractions, and 2) evolving ferrihydrite reactivity dependent on the sulfur mineral volume. Testing of the different conceptual models was performed with the RAFT simulator (Chilakapati, 1995, Chilakapati, et al. 1998, 2000). In this case, RAFT was used to model transport and reactions in the 1-D column experiments. RAFT uses an operator split, sequential, non-iterative approach based on second-order total variation diminishing transport and a differential algebraic equation solution of the system of equilibrium and kinetic reactions. Estimation of reaction rates and ferrihydrite fractions to fit the column breakthrough behavior was performed with UCODE (Poeter and Hill, 1999).

Actual measured influent $\mathrm{H}_{2} \mathrm{~S}$ concentrations were modeled for all experiments to capture the effects of variability that were observed. The $30-\mathrm{cm}$ columns were treated as initially 
homogeneous soils (uniform porosity and initial ferrihydrite distributions) resolved with 251.2 $\mathrm{cm}$ grid cells.

\section{Nitrogen Carrier Gas Case}

Initial modeling and testing of parallel ferrihydrite reactions with first-order kinetics indicated that reaction 2 would have to be assigned to four ferrihydrite fractions with different rates to match the breakthrough behavior. While the dominant fraction would be the ferrihydrite associated with the instantaneous reaction rate, three additional first-order kinetic mass action reactions were necessary to match the breakthrough behavior of $\mathrm{H}_{2} \mathrm{~S}$ effluent concentrations.

With the knowledge that the $\mathrm{H}_{2} \mathrm{~S}$ breakthrough could not be addressed simply with one or two first-order kinetic reactions, we began investigating more mechanistic approaches consistent with our conceptual model of evolving reactivity. The first approach tested was the shrinking core model (Levenspiel, 1998), which accounts for diffusion-limited $\mathrm{H}_{2} \mathrm{~S}$ access to the active ferrihydrite surface through formation of secondary minerals on the idealized spherical particles. In this case, an increasing volume of reaction products continually increases the diffusion length, which effectively decreases the transport rate of $\mathrm{H}_{2} \mathrm{~S}$ to the reactive iron surfaces. The diffusive length between the particle surface and the active iron surface continually increases with time as the ferrihydrite is reacted. In this approach, the reaction rate gradually evolves from instantaneous to slower diffusion-limited rates.

It was found that additional particle sizes would have to be introduced to capture the postbreakthrough $\mathrm{H}_{2} \mathrm{~S}$ behavior. This is because once the particle surface diffusion coefficient is specified, the particle size is the only remaining parameter that can significantly alter the transport-limited reaction rate. It also became apparent that the initial breakthrough of $\mathrm{H}_{2} \mathrm{~S}$ could be effectively controlled by the specification of a fixed fraction of the iron that reacts instantaneously with $\mathrm{H}_{2} \mathrm{~S}$ gas.

To gain better control of the diminishing ferrihydrite reactivity, we investigated a surface poisoning rate law that inhibits reactivity as the formation of reaction products approaches a critical concentration/volume (Perry and Chilton, 1973).

$$
\frac{d\left[H_{2} S\right]}{d t}=-k_{f 1}\left(1-k_{s 1}\left[S^{0}\right]\right)\left[H_{2} S\right]
$$

where

$k_{f 1}=$ forward rate $\left(s^{-1}\right)$

$k_{s 1}=$ inhibition cons $\tan t\left(\mathrm{~cm}^{3} /\right.$ Moles $)$

In this rate law, the irreversible reaction rate of $\mathrm{H}_{2} \mathrm{~S}$ with ferrihydrite is dependent on the $\mathrm{H}_{2} \mathrm{~S}$ and sulfur $\left(\mathrm{S}^{0}\right)$ concentrations. As the sulfur concentration at a given location in the column increases from zero, the rate is linearly reduced until the sulfur concentration approaches the inverse of the inhibition constant, $\mathrm{k}_{\mathrm{s} 1}$, whereupon the rate goes to zero. Note that although $\mathrm{Fe}(\mathrm{OH})_{3}$ is not explicitly included in the rate law, reaction 2 will not proceed when either reactant [i.e., $\mathrm{H}_{2} \mathrm{~S}$ and $\left.\mathrm{Fe}(\mathrm{OH})_{3}\right]$ is not present.

To accommodate this conceptual model, we employ two quantities of $\mathrm{Fe}(\mathrm{OH})_{3}$ that sum to the total ferrihydrite in the system: highly reactive "fast" ferrihydrite and diffusion-limited iron. The 
fast ferrihydrite reaction is reaction 2 treated as an equilibrium reaction with an arbitrarily high stability constant $(\log K=12)$ that essentially drives the reaction to completion (i.e., until one of the reactants is depleted). For the diffusion-limited ferrihydrite, reaction 2 is treated as a kinetic reaction using the surface poisoning rate law to dynamically account for the increasing elemental sulfur volume fraction that limits the transport of $\mathrm{H}_{2} \mathrm{~S}$ to the reactive surface.

The UCODE parameter estimation framework was used to fit 1) initial distribution between "fast" and diffusion-limited iron, 2) inhibition constant, $\mathrm{k}_{\mathrm{s}}$, and 3) intrinsic rate, $\mathrm{k}_{\mathrm{f}}$. The approach was to fit these parameters for the two parallel reactions in the slowest of the three nitrogen experiments, $102 \mathrm{sccm}$, and test the fit against the faster experiments at 204 and $510 \mathrm{sccm}$. The result was a reasonably good simulation of the reactive transport behavior (Fig. 5-7) under a range of flow rates. The model simulations were also in general agreement with measurements at the end of the three nitrogen column experiments for moles of $\mathrm{H}_{2} \mathrm{~S}$ consumed and moles of $\mathrm{FeS}$ and $\mathrm{S}^{0}$ produced (Fig. 5-8). Most simulated components were within $10 \%$ of the observed. It was concluded that the prevailing dynamics of reaction and transport had been adequately captured for this case. The fitted parameters were: $8.07 \times 10^{-5}$ moles/cc of fast ferrihydrite, $1.96 \times 10^{-4}$ moles/cc of diffusion-limited ferrihydrite, and $9.57 \times 10^{3} \mathrm{cc} / \mathrm{mole}$ sulfur inhibition $\left(\mathrm{k}_{\mathrm{s} 1}\right)$.

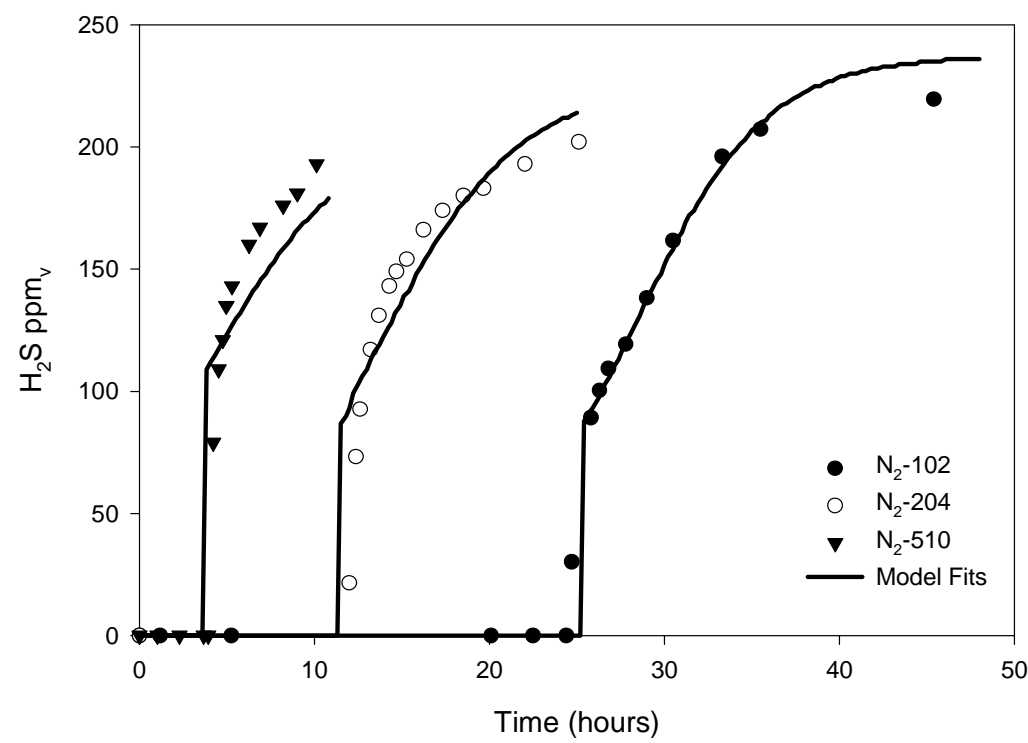

Figure 5-7. Comparison of Measured Effluent Concentrations of $\mathrm{H}_{2} \mathrm{~S}$ with Model Fits for Columns $\mathrm{N}_{2}-102, \mathrm{~N}_{2}-202$, and $\mathrm{N}_{2}-510$. 


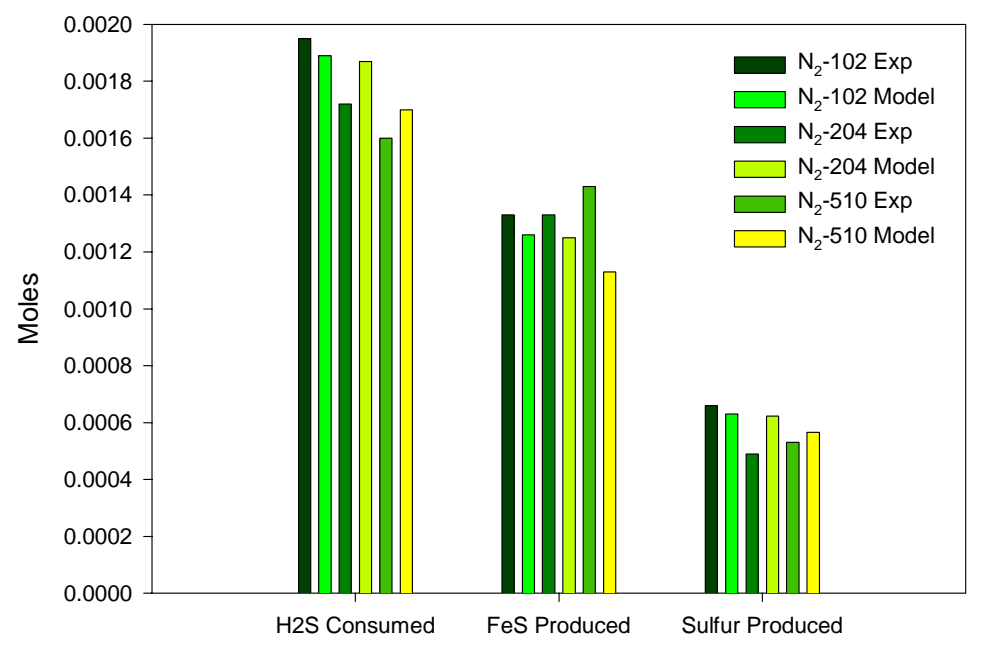

Figure 5-8. Comparison of Measured Values for $\mathrm{H}_{2} \mathrm{~S}$ Consumed, FeS Produced and $\mathrm{S}^{0}$ Produced with Model Determined Values for Columns $\mathrm{N}_{2}-102, \mathrm{~N}_{2}-202$, and $\mathrm{N}_{2}-510$.

\section{Air Carrier Gas Case}

The modeling approach to the air case builds on the two parameterized parallel reactions from the nitrogen case and adds in the two oxidation reactions (reactions 6 and 11). From the standpoint of controlling the initial breakthrough of $\mathrm{H}_{2} \mathrm{~S}$, reaction 6 is critical to the enhanced production of elemental sulfur (as compared to the nitrogen case) that reduces the reactivity of the available ferrihydrite and results in the $\mathrm{H}_{2} \mathrm{~S}$ breakthrough at 0.65 days compared with 1.03 days for the nitrogen case. The amount of fast ferrihydrite determined from the nitrogen experiments is still consistent with the earlier breakthrough; i.e., if fast ferrihydrite alone controlled the breakthrough, it would occur at 0.47 days. Consequently, we continued to use the initial fast ferrihydrite mole fraction as well as the intrinsic rate and inhibition constant from the iron surface poisoning reaction rate law.

Our initial application of UCODE to the air case focused only on identifying reaction rates for the oxygen reactions (reactions 6 and 11). The modeling provided considerable insight on the interplay between the reactions. The enhanced production of elemental sulfur in reaction 6 must be fast enough to accumulate enough sulfur in addition to sulfur created by reaction 2 to inhibit ferrihydrite reactivity leading to early $\mathrm{H}_{2} \mathrm{~S}$ breakthrough. Additionally, the pool of $\mathrm{FeS}$ provided by the equilibrium (i.e., fast ferrihydrite) reaction 2 will eventually lead to three times the sulfur produced in the nitrogen case, which is not consistent with the experimental measurement. It was clear that simple mass action kinetics for reaction 6 was not sufficient to describe the observed behavior. Once again we invoked the surface poisoning rate law, this time for reaction 6 . Nominally, the reaction rate should be dependent on the oxygen concentration; however, the relatively high concentration of oxygen $(210,000 \mathrm{ppm})$ remains essentially constant during the reactions. Consequently, we eliminated oxygen dependence from the rate laws for reactions 6 and 11, essentially incorporating the constant concentration into the intrinsic rate constant. 
$\frac{d[\mathrm{FeS}]}{d t}=-k_{f 2}\left(1-k_{s 2}\left[S^{0}\right]\right)[\mathrm{FeS}]$

where

$k_{f 2}=$ forward rate $\left(s^{-1}\right)$

$k_{s 2}=$ inhibition constan $t\left(\mathrm{~cm}^{3} /\right.$ Moles $)$

$\frac{d[\mathrm{FeS}]}{d t}=-k_{f 3}\left[\mathrm{H}_{2} \mathrm{~S}\right][\mathrm{FeS}]$

where

$k_{f 3}=$ forward rate $\left(s^{-1}\right)$

UCODE was subsequently applied to the air case to identify the intrinsic rate constants for reactions 6 and 11, as well as an additional sulfur inhibition constant for reaction 6 . The comparison of the model and observed concentrations for the Air-102 experiment are shown in Fig. 5-9. While the model simulation of the initial $\mathrm{H}_{2} \mathrm{~S}$ gas breakthrough was 1.8 hours later than the experimental observation at 15.5 hours, much of the general behavior was captured. Furthermore, the comparison between simulated and measured moles of consumed and produced components at the end of the experiment were very good (Figure 5-10). The principal discrepancy was that 1.57E-4 moles of FeS were predicted to be produced compared with the $8.32 \mathrm{E}-5$ moles

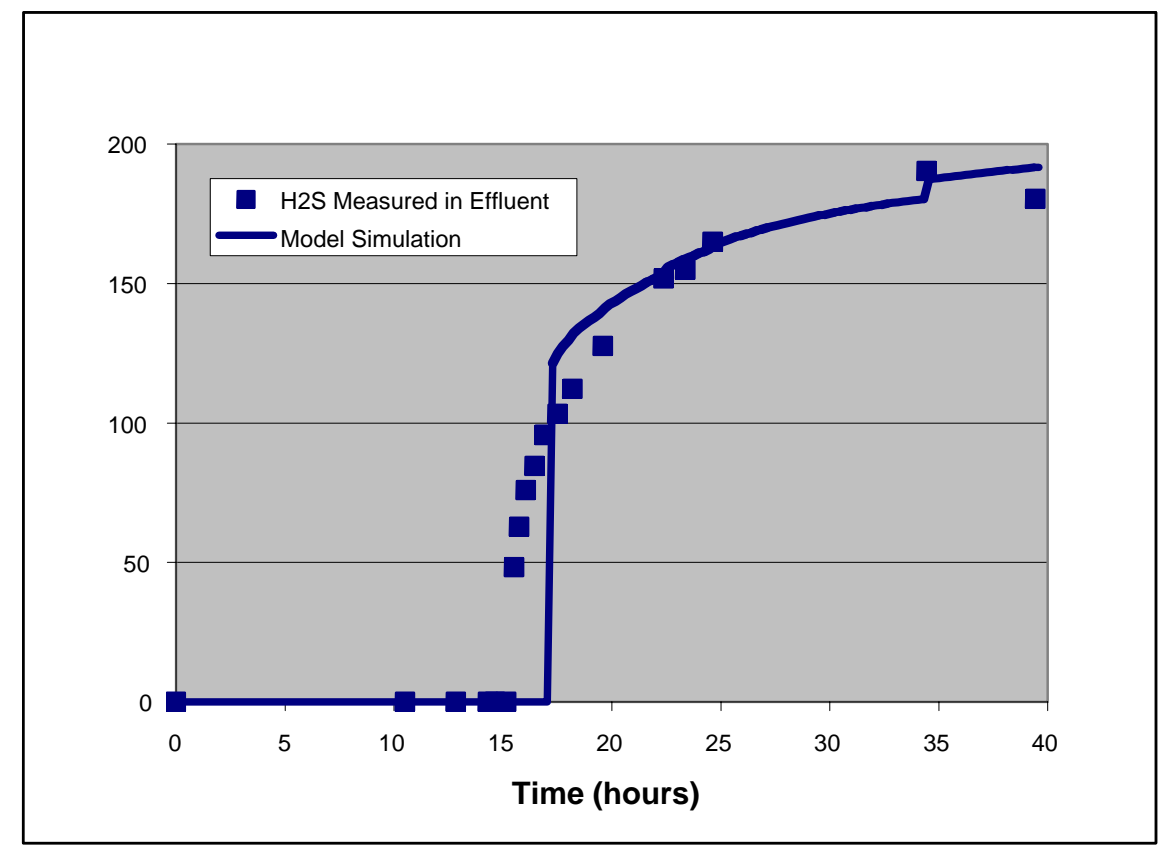

Figure 5-9. Comparison of Measured Effluent Concentrations of $\mathrm{H}_{2} \mathrm{~S}$ with Model Fits for Air-102 Experiment. 


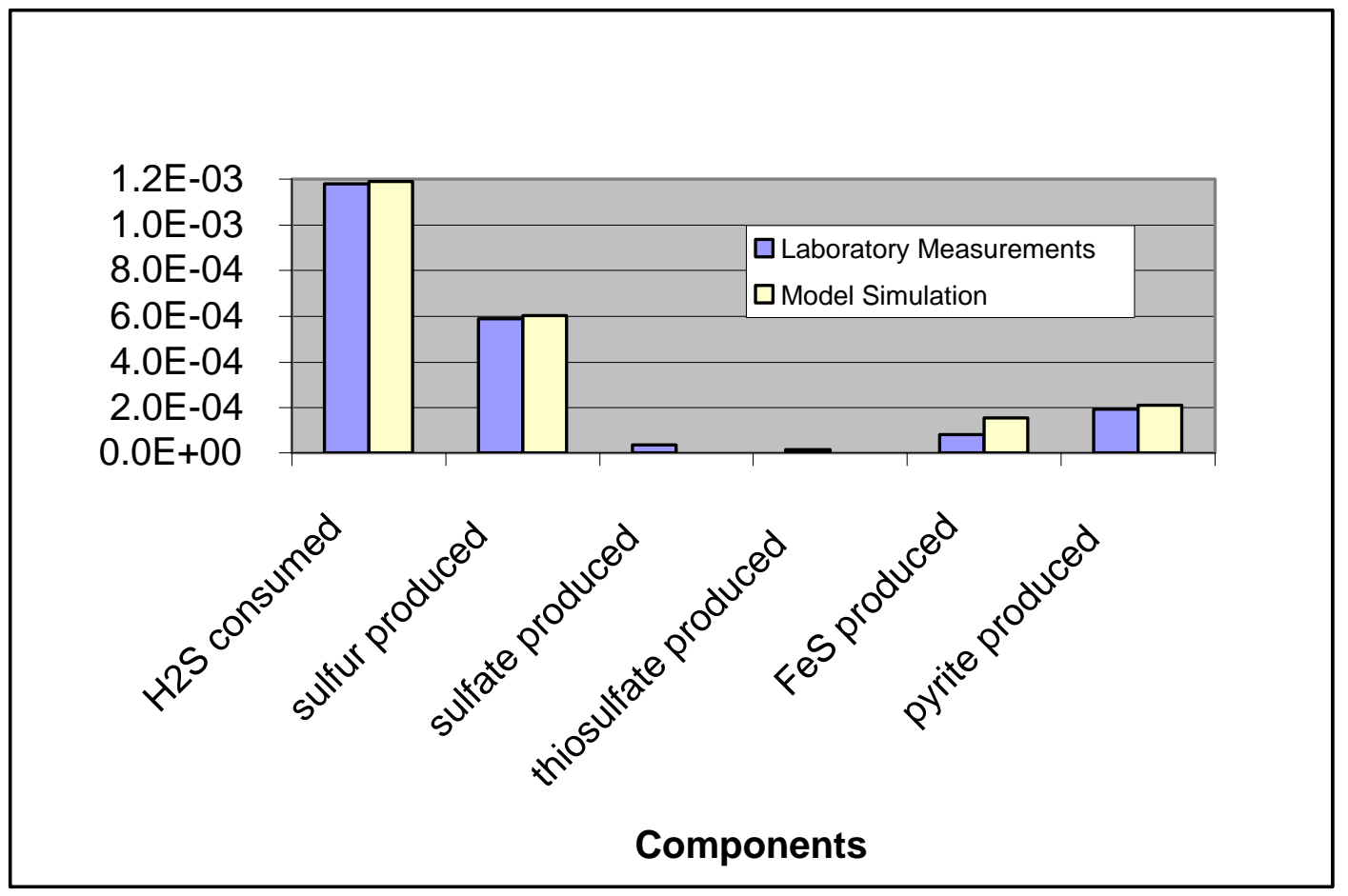

Figure 5-10. Measured and Simulated Component Moles at Experiment End.

that were measured. This might be explained by our omission of reactions 9 and 10 which produce sulfate and thiosulfate, respectively, from the oxidation of FeS. The 3.70E-5 moles of sulfate and the $1.82 \mathrm{E}-5$ moles of thiosulfate measured at the end of the experiment represent the oxidation of 7.34E-5 moles of FeS that are not captured in the model. This is essentially the discrepancy between the simulated and measured FeS.

As mentioned previously, the calibration of the oxygen reaction rates and inhibition contant was performed while maintaining the rates and contant for reaction 2 determined from the nitrogen carrier gas experiment. The fitted parameters were:

intrinsic irreversible rate for reaction $6\left(\mathrm{k}_{\mathrm{f} 2}\right)=8.75 \times 10^{1}(1 /$ day $)$

intrinsic irreversible rate for reaction $11\left(\mathrm{k}_{\mathrm{f} 3}\right)=8.72 \times 10^{7}(1 /$ day $)$

FeS inhibition constant $\left(\mathrm{k}_{\mathrm{s} 2}\right)=1.07 \times 10^{4}(\mathrm{cc} / \mathrm{mole})$

The model appears to capture the salient features of the $\mathrm{H}_{2} \mathrm{~S}$ breakthrough. More importantly the model provided significant insights on the processes controlling the $\mathrm{H}_{2} \mathrm{~S}$ breakthrough.

- The fast (equilibrium reaction 2) iron fraction must be completely depleted before $\mathrm{H}_{2} \mathrm{~S}$ breakthrough takes place.

- $\mathrm{Fe}(\mathrm{OH})_{3}$ reactivity, which regulates the $\mathrm{H}_{2} \mathrm{~S}$ breakthrough behavior through kinetic reaction 2 , is ultimately inhibited by the formation of elemental sulfur 
- The rate of elemental sulfur formation in reaction 6 must be sufficiently fast to accelerate the inhibition of the $\mathrm{Fe}(\mathrm{OH})_{3}$ reactivity that results in the earlier $\mathrm{H}_{2} \mathrm{~S}$ breakthrough in the air case; however, the production of sulfur through reaction 6 must diminish significantly prior to $\mathrm{H}_{2} \mathrm{~S}$ breakthrough to allow kinetic reaction 2 to control the shape of the breakthrough.

- Reaction 11 provides a slow but continuous conversion of the available FeS to pyrite in the presence of $\mathrm{H}_{2} \mathrm{~S}$ and $\mathrm{O}_{2}$. Post-breakthrough $\mathrm{H}_{2} \mathrm{~S}$ behavior is also regulated by the consumption of $\mathrm{H}_{2} \mathrm{~S}$ in this reaction.

\section{CONCLUSIONS}

An understanding of the processes determining the consumption of $\mathrm{H}_{2} \mathrm{~S}$ during interaction with sediments is important with regard to the design of ISGR field remediation activities. The primary sediment component involved in these interactions is ferric (hydr)oxides, which are reduced by $\mathrm{H}_{2} \mathrm{~S}$. The results of the study presented here illustrate that the reactions involving the ferric oxide ferrihydrite with $\mathrm{H}_{2} \mathrm{~S}$ under anaerobic and aerobic conditions are largely understood from a mechanistic standpoint. Future work will focus on extending this work to develop a better understanding of the reaction and diffusional processes determining $\mathrm{H}_{2} \mathrm{~S}$ consumption by sediments under natural conditions. 


\section{Influences of Water Vapor on Cr(VI) Reduction by Gaseous Hydrogen Sulfide}

(B. Hua and B. Deng)

\section{INTRODUCTION}

Chromium contamination has been found in many industrial and federal sites in the United States, due to accidental leakages and improper disposals associated with its widespread usage (Nriagu and Nieboer, 1988; Thornton and Amonntte, 1999). Since hexavalent chromium chemicals are known to be toxic and carcinogenic (Costa, 1997), site remediation is often needed to reduce its risk to humans and ecosystems. Chromium exists as either $\mathrm{Cr}(\mathrm{VI})$ or $\mathrm{Cr}$ (III) species in natural water and soil and is redox active. The mobility of chromium in the environment largely depends on its oxidation states. Generally, $\mathrm{Cr}(\mathrm{VI})$ is quite mobile in soils and aquifers, whereas $\mathrm{Cr}(\mathrm{III})$ is mostly precipitated as hydroxides and/or adsorbed onto mineral surfaces. As a result, $\mathrm{Cr}(\mathrm{VI}) \mathrm{can}$ be immobilized when reduced to $\mathrm{Cr}$ (III) and becomes less bioavailable.

$\mathrm{Cr}(\mathrm{VI})$ reduction can be coupled with both organic reductants, such as soil humic and fulvic substances, and inorganic reductants, such as Fe(II)-bearing minerals and $\mathrm{H}_{2} \mathrm{~S} / \mathrm{HS}^{-} / \mathrm{S}^{2-}$. The reduction by natural organic matter occurs under acidic condition (Bartlett and Kimble, 1976; Wittbrodt and Palmer, 1995). The reduction rate is strongly $\mathrm{pH}$ dependent (Elovitz and Fish, 1994; Wittbrodt and Palmer, 1995; Deng, 1995) and can be catalyzed by mineral surfaces (Deng and Stone, 1996a, b) and dissolved metals (Baldea, 1989). Reduction of $\mathrm{Cr}(\mathrm{VI})$ by Fe(II)-bearing minerals occurs over time scales of several to hundreds of hrs (Eary and Rai, 1991; Jardine et al., 1999). Reactions with zero-valent and divalent irons are even faster (Blowes et al., 1997; Fruchter, 2002). Recently, gaseous reductants, including hydrogen $\left(\mathrm{H}_{2}\right)$, methane $\left(\mathrm{CH}_{4}\right)$, and hydrogen sulfide $\left(\mathrm{H}_{2} \mathrm{~S}\right)$, have been tested for $\mathrm{Cr}(\mathrm{VI})$ reduction in contaminated soils, among which $\mathrm{H}_{2} \mathrm{~S}$ is found to be most effective under ambient environment conditions (Thronton and Amonette, 1997, 1999).

In-situ reduction and immobilization is one of the most important remediation techniques for $\mathrm{Cr}(\mathrm{VI})$-contaminated groundwater and soil. The benefits of in-situ soil remediation include (i) a reduction of risks associated with excavation activities, (ii) an elimination of the need to relocate wastes for treatment and disposal, and (iii) being much more cost-effective in certain situations. For groundwater, in-situ remediation can be accomplished with treatment agents in liquid or solid forms. Zero-valent iron permeable reactive barrier (Blowes et al., 1997) and dithionite barrier (Frutcher 2002), for example, are efficient at remediating $\mathrm{Cr}$ (VI) contaminated groundwaters. For contamination in the vadose-zone, however, mixing a reactive agent in solid form is difficult at the best in the subsurface, and using a liquid reductant possess risks of spreading the contaminants deeper and wider into formerly uncontaminated zones. Employing a reductant in gaseous phase has advantages of easy control of the reductant delivery, high diffusion velocity, quick access to the contaminated site with different features, and efficient removal of residual agent after the completion of treatment (Thornton and Amonette, 1999). In-Situ Gas Reduction (ISGR) is a technology for reductive immobilization of $\mathrm{Cr}(\mathrm{VI})$ and other contaminants in the vadose zone using hydrogen sulfide (Thornton and Amonette, 1997, 1999). Laboratory investigations showed that $\mathrm{H}_{2} \mathrm{~S}$ treatment decreased water-leachable $\mathrm{Cr}(\mathrm{VI})$ in the soils by $90 \%$ to nearly $100 \%$. It was proposed that the immobilization was through both $\mathrm{Cr}(\mathrm{VI})$ reduction and sequestration by the reaction products produced during the treatment. Synchrotron-based X-ray absorption (XANES) data showed that not all $\mathrm{Cr}(\mathrm{VI})$ was in the reduced form post to the treatment (Thornton and Amonette, 1997, 1999). A field demonstration at the White Sand Missile 
Range, New Mexico, resulted in over $70 \%$ of chromium immobilization (Thornton and Amonette, 1997). The field demonstration further shgwed that $\mathrm{H}_{2} \mathrm{~S}$ gas could be handled safely for field application with no secondary contamination.

To design the ISGR system for reductive Cr(VI) immobilization in soils, the reaction kinetics between $\mathrm{Cr}(\mathrm{VI})$ and gaseous $\mathrm{H}_{2} \mathrm{~S}$ must be investigated. $\mathrm{Cr}(\mathrm{VI})$ reduction in the aqueous phase has been well documented (Pettine et al., 1994; Pettine et al., 1998; Kim et al., 2001). The overall reaction was second-order, i.e., first-order with respect to $\mathrm{Cr}(\mathrm{VI})$ and first-order to sulfide. $\mathrm{Cr}(\mathrm{III})$ and elemental sulfur were the stable products (Kim et al., 2001). Information on the kinetics and mechanism for $\mathrm{Cr}(\mathrm{VI})$ reduction in soils, however, is limited. Previous studies had mostly used $\mathrm{H}_{2} \mathrm{~S}$ breakthrough curve to examine whether soil treatment was completed or not (Thornton and Amonette, 1999). The amount of $\mathrm{Cr}(\mathrm{VI})$ reduced in soils was not analyzed so its reduction kinetics by $\mathrm{H}_{2} \mathrm{~S}$ is unknown. It is also unclear whether the kinetics observed in the aqueous phase is relevant to the $\mathrm{Cr}(\mathrm{VI})$ reduction in soils, and whether insoluble or moderately soluble $\mathrm{Cr}(\mathrm{VI})$ compounds, such as $\mathrm{PbCrO}_{4}, \mathrm{BaCrO}_{4}$ and $\mathrm{CaCrO}_{4}$, were reduced by gaseous $\mathrm{H}_{2} \mathrm{~S}$. These less soluble compounds have been identified at some contamination sites (Thornton and Amonette, 1999; James et al., 1995).

As part of our overall effort to better understand the interactions among $\mathrm{Cr}(\mathrm{VI}), \mathrm{H}_{2} \mathrm{~S}$ and soil minerals in the vadose zone, this study aims to (i) investigate the effect of humidity on $\mathrm{Cr}(\mathrm{VI})$ reduction, (ii) examine whether insoluble or moderately soluble chromate compounds (e.g., $\mathrm{PbCrO}_{4}, \mathrm{BaCrO}_{4}$ and $\mathrm{CaCrO}_{4}$ ) can be reduced by $\mathrm{H}_{2} \mathrm{~S}$, and (iii) measure the kinetics of $\mathrm{Cr}(\mathrm{VI})$ reduction by gaseous $\mathrm{H}_{2} \mathrm{~S}$ under various reductant and potassium chromate concentrations. Glass beads were used as solid matrices for various Cr(VI) compounds because of their known particle size distribution and inert-redox characteristics, and a shallow packed bed reactor was chosen in this study for all testing.

\section{MATERIALS AND METHODS}

Chemicals: All solutions were prepared with $18 \mathrm{M} \Omega \cdot \mathrm{cm}$ resistivity deionized and distilled water (DDW, Millpore Co.). Glassware was cleaned with $1 \mathrm{~N} \mathrm{HCl}$ and rinsed with DDW prior to use. Three glass bead and a silica samples were used as surrogates in the study for soils. The glass beads with an average diameter of $0.600 \mathrm{~mm}$ (designated as GA) (Ferro Co.) were used in most of the experiments. The others with diameters of 0.212-0.300 mm (GB) and $0.106 \mathrm{~mm}$ (GC) (Sigma-Aldrich Co.), as well as the silica with a diameter of $0.075-0.150 \mathrm{~mm}$ (SA) (Fisher Scientific Co.), were used to investigate the effect of water moisture content on $\mathrm{Cr}(\mathrm{VI})$ reduction. Potassium dichromate $\left(\mathrm{K}_{2} \mathrm{Cr}_{2} \mathrm{O}_{7}\right)$, diphenylcarbazide (DPC), lead chromate $\left(\mathrm{PbCrO}_{4}\right)$, and iodine $\left(\mathrm{I}_{2}\right)$ were obtained from Sigma-Aldrich Co. Nitric acid $\left(\mathrm{HNO}_{3}\right)$, sodium carbonate $\left(\mathrm{Na}_{2} \mathrm{CO}_{3}\right)$, sodium hydroxide $(\mathrm{NaOH})$, sodium thiosulfate $\left(\mathrm{Na}_{2} \mathrm{~S}_{2} \mathrm{O}_{3}\right)$, potassium biphosphate $\left(\mathrm{K}_{2} \mathrm{HPO}_{4}\right)$, potassium diphosphate $\left(\mathrm{KH}_{2} \mathrm{PO}_{4}\right)$, calcium chloride $\left(\mathrm{CaCl}_{2}\right)$, and barium chloride $\left(\mathrm{BaCl}_{2}\right)$ were purchased from Fisher Scientific. All reagents were at least reagent grade and used as received. Hydrogen sulfide gas (Scott Specialty Gases Co, $1 \pm 0.05 \%$ ), balanced with $\mathrm{N}_{2}$, was used as gas source.

\footnotetext{
* An independent panel review of the technology by the American Society of Mechanical Engineers (ASME) has arrived the conclusion that "the health and safety issues regarding ISGR technology using $\mathrm{H}_{2} \mathrm{~S}$ gas are resolved" (ASME, 1999)
} 
Preparation of Cr(VI)-Contaminated Samples: The glass beads (GA, GB, GC) and silica (SA) with deposited potassium chromate were individually prepared by cleaning 50-100 g of glass beads with $100 \mathrm{~mL}$ DDW three times in a $250-\mathrm{mL}$ flask, followed by addition of a predetermined amount of stock $\mathrm{K}_{2} \mathrm{CrO}_{4}$ solution to the flask. The suspension was then diluted by DDW to a total volume of $200 \mathrm{~mL}$. After $2.0 \mathrm{hrs}$ of mixing, the supernatant was removed and glass beads contaminated with $\mathrm{Cr}(\mathrm{VI})$ were dried at $80^{\circ} \mathrm{C}$ in an oven for $24 \mathrm{hrs}$ and stored at room temperature prior to use. To test whether the prepared material was homogeneous in terms of $\mathrm{Cr}(\mathrm{VI})$ content, four samples, each with $2.50 \pm 0.02 \mathrm{~g}$ of the glass beads, were analyzed for $\mathrm{Cr}(\mathrm{VI})$ contents. The maximum variation in $\mathrm{Cr}(\mathrm{VI})$ content was within $5 \%$ in these samples.

For samples contaminated with $\mathrm{BaCrO}_{4}\left(\mathrm{~K}_{\mathrm{sp}}=1.2 \times 10^{-10}\right.$ (Dean, 1992)) and $\mathrm{CaCrO}_{4}\left(\mathrm{~K}_{\mathrm{sp}}=\right.$ $7.12 \times 10^{-4}$ (James et al., 1994)), the preparation began with adding a $25.0 \mathrm{~g}$ of washed GA into $100 \mathrm{~mL}$ DDW, followed by additions of a $10.0 \mathrm{~mL}$ of $0.20 \mathrm{M} \mathrm{BaCl}_{2}$ or $0.20 \mathrm{M} \mathrm{CaCl}_{2}$ and a 10.00 $\mathrm{mL}$ of $0.10 \mathrm{M} \mathrm{K}_{2} \mathrm{CrO}_{4}$ solution. $\mathrm{BaCl}_{2}$ reacted with $\mathrm{K}_{2} \mathrm{CrO}_{4}$ to form $\mathrm{BaCrO}_{4(\mathrm{~s})}$, and the formation of $\mathrm{BaCrO}_{4(\mathrm{~s})}$ precipitates was easily observable. After $1.0 \mathrm{hr}$, the supernatant was removed and the $\mathrm{BaCrO}_{4}$-contaminated GA was washed three times with $50 \mathrm{~mL}$ DDW and dried at $80^{\circ} \mathrm{C}$. The solution containing $0.10 \mathrm{M} \mathrm{CaCl}_{2}$ and $0.05 \mathrm{M} \mathrm{K}_{2} \mathrm{CrO}_{4}$ was under saturation with respect to $\mathrm{CaCrO}_{4(\mathrm{~s})}$. Nevertheless, since the last step involved drying in the oven, suitable amounts of $\mathrm{CaCrO} 4$ (s) could still form on the glass beads, likely with $\mathrm{K}_{2} \mathrm{CrO}_{4}$ impurities. For $\mathrm{PbCrO}_{4}$ $\left(\mathrm{K}_{\mathrm{sp}}=2.8 \times 10^{-13}\right.$ (James et al., 1994)), the reagent is easily available from commercial sources, so the $\mathrm{PbCrO}_{4}$-contamianted sample was prepared by thoroughly mixing $25 \mathrm{~g}$ of GA and $25 \pm 0.2 \mathrm{mg}$ of $\mathrm{PbCrO}_{4}$ powder.

Experimental Systems: Experiments were conducted to investigate the effects of various parameters on $\mathrm{Cr}(\mathrm{VI})$ reduction, including gaseous properties (i.e., total flow rate of the gas stream, $\mathrm{H}_{2} \mathrm{~S}$ concentration, relative humidity), solid characteristics (i.e., the types of chromate compounds used, initial $\mathrm{Cr}(\mathrm{VI})$ concentration, particle size distribution of glass bead particles), and treatment time. A schematic diagram of the experimental setup is illustrated in Figure 6-1. Reaction between chromate and gaseous $\mathrm{H}_{2} \mathrm{~S}$ took place in a shallow packed bed reactor made of a $10 \mathrm{~mL}$ plastic syringe (i.d. $1.5-\mathrm{cm}$, Fisher Scientific). A thin layer of glass fiber was set at the gas inlet to hold glass beads and for better distribution of gas flow. The amount of glass bead samples was fixed at $2.50 \pm 0.02 \mathrm{~g}$ for all testing. The gaseous concentration of $\mathrm{H}_{2} \mathrm{~S}$ ranged from 0 to 800 parts per million $(\mathrm{v} / \mathrm{v})$, or $\mathrm{ppm}_{\mathrm{v}}$, prepared by dilution of $1.00 \%$ of $\mathrm{H}_{2} \mathrm{~S}$ source gas with high purity nitrogen. To control the water moisture content (relative humidity) in the reactor, the dilution gas was split into two streams: one was mixed directly with the source $\mathrm{H}_{2} \mathrm{~S}$ and the other was allowed to pass through a $200 \mathrm{~mL}$ water bottle to acquire moisture prior to mixing. By setting the flow rate ratio of the two nitrogen streams by separate flowmeters (Fisher Scientific, Gilmont), the relative humidity could be controlled from $0 \%$ to $97 \%$. Nitrogen gas with different relative humidity was introduced into the column 5 min prior to the initiation of $\mathrm{H}_{2} \mathrm{~S}$ flow. This allowed the system to reach equilibrium with the selected humidity condition before $\mathrm{Cr}(\mathrm{VI})$ reduction. The final relative humidity was measured with a hygrometer (Fisher Scientific).

$\mathrm{Cr}(\mathrm{VI})$ reduction was assessed by analyzing extractable $\mathrm{Cr}(\mathrm{VI})$ in $2.50 \mathrm{~g}$ solid sample before and after $\mathrm{H}_{2} \mathrm{~S}$ treatment. Because the samples were consumed during the extraction for $\mathrm{Cr}(\mathrm{VI})$ analysis, one column test had to be conducted for each time point in the kinetic study and under each condition. All tests were conducted at a temperature of $23 \pm 2^{\circ} \mathrm{C}$. Most experiment were run in duplicates, including the ones with various humidities and $\mathrm{Cr}(\mathrm{VI})$ concentrations. The reported data were the average values. The maximum variation between the duplicates was less than $12 \%$. The whole experimental system was setup in a fume hood because proper ventilation was needed 
for lab studies involving gaseous $\mathrm{H}_{2} \mathrm{~S}$. Outlet gaseous stream was scraped for $\mathrm{H}_{2} \mathrm{~S}$ by $0.50 \mathrm{M}$ $\mathrm{NaOH}$ solution.

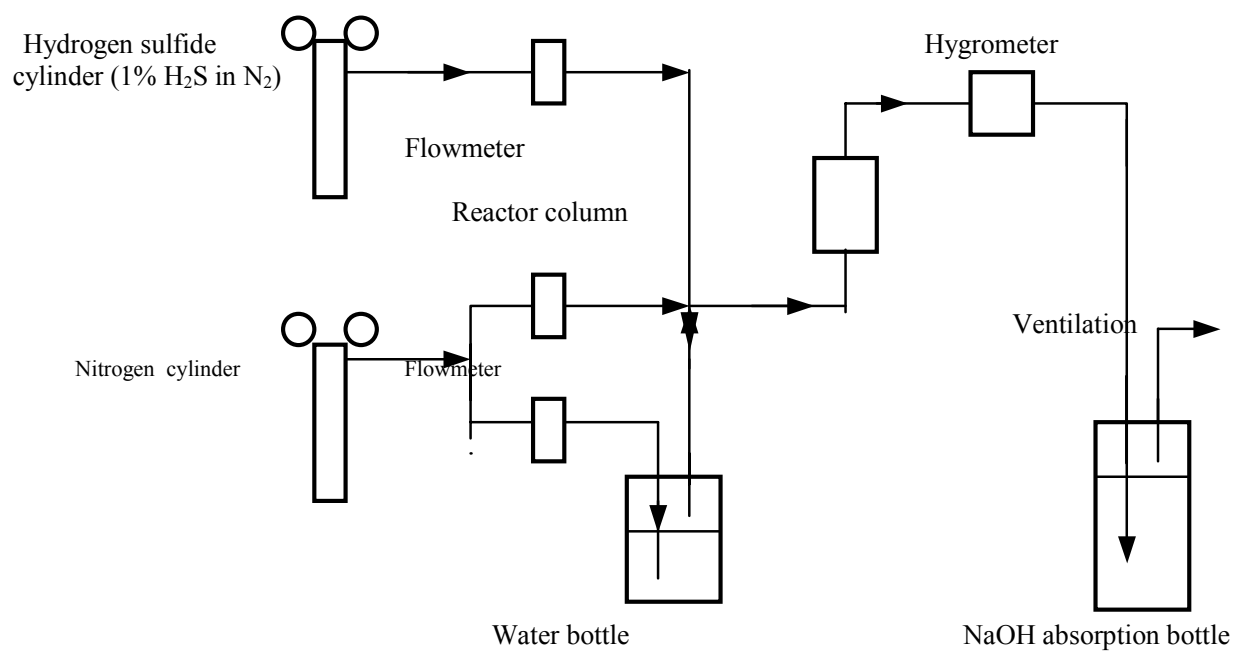

Figure 6-1. Schematic diagram of the experimental setup

Extraction: To monitor the degree of $\mathrm{Cr}(\mathrm{VI})$ reduction by gaseous $\mathrm{H}_{2} \mathrm{~S}$, tests were conducted to select appropriate methods for $\mathrm{Cr}(\mathrm{VI})$ extraction from treated samples. The methods should be able to completely extract $\mathrm{Cr}(\mathrm{VI})$, while at the same time, minimize any chromium redox transformations. Common extraction procedures reported in the literature include the use of distilled water (DW), phosphate buffer ( $\mathrm{PB}$, a solution of $5.0 \mathrm{mM} \mathrm{K} \mathrm{HPO}_{4}$ and $5.0 \mathrm{mM} \mathrm{KH}_{2} \mathrm{PO}_{4}$ with $\mathrm{pH} 7.0)$, alkali solution at ambient temperature $(\mathrm{CH} 25$, a solution containing $0.28 \mathrm{M}$ $\left.\mathrm{Na}_{2} \mathrm{CO}_{3}-0.50 \mathrm{M} \mathrm{NaOH}\right)$ and the alkali solution heated to $90-95^{\circ} \mathrm{C}(\mathrm{CH} 90$, a solution containing $0.28 \mathrm{M} \mathrm{Na}_{2} \mathrm{CO}_{3}-0.5 \mathrm{M} \mathrm{NaOH}$ ) (James et al., 1994, 1995, USEPA, 1994, Vitale et al., 1997). For soluble chromate compounds (e.g., $\mathrm{K}_{2} \mathrm{CrO}_{4}$ ), all of these procedures can quantitatively extract $\mathrm{Cr}(\mathrm{VI})$. Among sparingly soluble chromate compounds, $\mathrm{BaCrO}_{4}$ could be recovered by cold alkali solution $(\mathrm{CH} 25)$ in the absence of a soil matrix, while $\mathrm{PbCrO}_{4}$ could only be completely recovered by hot alkaline solution (CH90) (James et al., 1995). Vitale et al. (1997) found that the hot alkali solution was superior to other four methods (DW, PB, CH25, and $0.10 \mathrm{M}$ of $\mathrm{NaOH}$ hydroxide solution ( $\mathrm{pH} \mathrm{13}$, with sonication)) in extracting greater than $90 \%$ of the spiked $\mathrm{PbCrO}_{4}$ from redox-inert quartz sand and other three soil matrices.

For glass beads contaminated with chromate compounds, our preliminary tests indicated that $\mathrm{K}_{2} \mathrm{CrO}_{4}$ could be completely recovered by all of the four extraction procedures. As a result, DW was selected as the extraction reagent for tests involving $\mathrm{K}_{2} \mathrm{CrO}_{4}$. Because elemental sulfur is known to be a stable product of sulfide oxidation by $\mathrm{Cr}(\mathrm{VI})$ (Kim et al., 2001), its effects on the extraction procedures need to be examined. Tests showed that up to $0.60 \mathrm{~g}$ of the spiked elemental sulfur had no effects on the DW extraction procedure and $\mathrm{Cr}(\mathrm{VI})$ analysis. For the system with $\mathrm{PbCrO}_{4}, \mathrm{BaCrO}_{4}$ or $\mathrm{CaCrO}_{4}$, the hot alkali solution $(\mathrm{CH} 90)$ was used in this study. The procedure involved mixing of a $50.0 \mathrm{~mL}$ extraction solution with $2.50 \mathrm{~g}$ sample in $250-\mathrm{mL}$ Pyrex beaker. The suspension was stirred for $5 \mathrm{~min}$ at room temperature, and then heated to 90 to $95{ }^{\circ} \mathrm{C}$ with a hot plate and constantly stirred for $60 \mathrm{~min}$. After gradually cooling to room 
temperature, the digestion solution was filtered through $0.45-\mu \mathrm{m}$ cellulosic or polycarbonate membrane filters, adjusted to $\mathrm{pH} 7.5 \pm 0.5$ using concentrated fresh $\mathrm{HNO}_{3}$, and diluted with DDW to a final volume of $100 \mathrm{~mL}$ (James et al., 1995; Vitale et al., 1997).

Analytical Methods: $\mathrm{Cr}(\mathrm{VI})$ concentration in solution was determined by a modified DPC colorimetric method (Deng and Stone, 1996a; APHA, 1989), in which stoichiometric oxidation of the DPC reagent yielded a product with an absorption peak at $540 \mathrm{~nm}$. The method has a detection limit of $0.10 \mu \mathrm{M}$. $\mathrm{Cr}(\mathrm{VI})$ concentration determined in the solution was converted to $\mathrm{Cr}(\mathrm{VI})$ concentration on the surface of glass beads, defined as microgram of chromium per gram of glass beads $(\mu \mathrm{g} \mathrm{Cr} / \mathrm{g})$.

Sulfide was analyzed with absorption by a $0.50 \mathrm{M} \mathrm{NaOH}$ solution, followed by determination with the iodometric titration method (APHA, 1989; Allen et al., 1989). The concentration of $\mathrm{H}_{2} \mathrm{~S}$ in the source gas was determined to be $1.04 \%$, the same as reported by the supplier.

Scanning electron microscope (SEM, AMRAY 1600) and video microscope (Cal-Ed Optical) were used to examine the particle size of glass beads and the patterns of chromate compounds deposited onto the surfaces.

\section{$\underline{\text { RESULTS }}$}

Effects of Dilution Gas $\left(\mathrm{N}_{2}\right)$ Flow and Gaseous Reductant $\left(\mathrm{H}_{2} \mathrm{~S}\right)$ Concentration. The effect of $\mathrm{N}_{2}$ flow rate was tested under fixed time period of treatment, aiming to clarify the role of mass transfer at the gas/solid boundary layer on $\mathrm{Cr}(\mathrm{VI})$ reduction. The $\mathrm{N}_{2}$ flow rate was changed from 500 to $1500 \mathrm{~mL} / \mathrm{min}$ (the gas flow rates in this study were all measured at $23{ }^{\circ} \mathrm{C}$ and ambient atmospheric pressure), while the flow of source $\mathrm{H}_{2} \mathrm{~S}$ was fixed as $41 \mathrm{~mL} / \mathrm{min}$. The corresponding concentration of $\mathrm{H}_{2} \mathrm{~S}$ in the mixed gas stream, therefore, was changed from 788 to $277 \mathrm{ppm}_{\mathrm{v}}$, as the $\mathrm{N}_{2}$ flow rate was increased. The time allowed for the reaction between the $\mathrm{Cr}(\mathrm{VI})$ deposited onto glass beads (GA, $127.3 \mu \mathrm{g}$ of $\mathrm{Cr} / \mathrm{g}$ of glass beads) and $\mathrm{H}_{2} \mathrm{~S}$ was $20 \mathrm{~min}$. The relative humidity of the gas stream was approximately $96.7 \%$. The results, to our surprise, showed that the amount of $\mathrm{Cr}(\mathrm{VI})$ reduced was near constant when the dilution gas flow rate was tripled from 500 to $1500 \mathrm{~mL} / \mathrm{mim}$ (data not shown). It appeared that neither the mass transfer at the gas/solid boundary layer, nor the concentration change of gaseous $\mathrm{H}_{2} \mathrm{~S}$ in the range of $277-788 \mathrm{ppm}_{\mathrm{v}}$, has an impact on $\mathrm{Cr}(\mathrm{VI})$ reduction under the experimental conditions. As a result, the flow rate of $\mathrm{N}_{2}$ was set at $800 \mathrm{~mL} / \mathrm{min}$ for all of the subsequent experiments.

Further studies were conducted to examine the effect of gaseous $\mathrm{H}_{2} \mathrm{~S}$ concentration starting at a much lower $\mathrm{H}_{2} \mathrm{~S}$ concentration while maintaining the dilution gas flow rate at $800 \mathrm{~mL} / \mathrm{min}$. The tests still used the glass beads (GA) with $127.3 \mu \mathrm{g} / \mathrm{g}$ of deposited $\mathrm{Cr}(\mathrm{VI})$ and $20 \mathrm{~min}$ of treatment time. As shown in Figure 6-2, as $\mathrm{H}_{2} \mathrm{~S}$ concentration was increased from zero to $100 \mathrm{ppm}_{\mathrm{v}}$, the reduced fraction of $\mathrm{Cr}(\mathrm{VI})$ was increased from 0 to approximately $70 \%$. Further increase of $\mathrm{H}_{2} \mathrm{~S}$ concentration from 100 to $800 \mathrm{ppm}_{\mathrm{v}}$, however, all resulted in approximately $70 \%$ of $\mathrm{Cr}(\mathrm{VI})$ reduction. This was consistent with the findings at fixed $\mathrm{H}_{2} \mathrm{~S}$ but varying $\mathrm{N}_{2}$ flow experiments as described above. In all the following experiments, $\mathrm{H}_{2} \mathrm{~S}$ concentration was set at $340 \mathrm{ppm}_{\mathrm{v}}$.

Effects of Water Moisture Content: $\mathrm{Cr}(\mathrm{VI})$ reduction by gaseous $\mathrm{H}_{2} \mathrm{~S}$ depends on the relative humidity of the gas phase, as demonstrated in Figure 6-3. Four solid samples contaminated with soluble chromium (i.e. $\left.\mathrm{K}_{2} \mathrm{CrO}_{4}\right)$ were used in the tests. The concentrations of $\mathrm{Cr}$ were $(\mu \mathrm{g} \mathrm{Cr} / \mathrm{g})$ : $\mathrm{GA}=127.3 ; \mathrm{GB}=201.3 ; \mathrm{GC}=271.3$; and $\mathrm{SA}=549.8$. The reaction time was set at $15 \mathrm{~min}$, followed by determining the fraction of $\mathrm{Cr}(\mathrm{VI})$ reduced. The effect of relative humidity was quite 
complex. In the sample GA (with a diameter of $0.600 \mathrm{~mm}$ ), there was less than $15 \%$ of $\mathrm{Cr}(\mathrm{VI})$ reduction when the humidity was in the range of 0 to $60 \%$. As the humidity was increased from 60 to $85 \%$, the fraction of $\mathrm{Cr}(\mathrm{VI})$ reduced jumped to over $70 \%$, then remained at that level when the humidity was increased to $96.7 \%$. The result clearly indicated that water moisture was essential for $\mathrm{Cr}(\mathrm{VI})$ reduction.

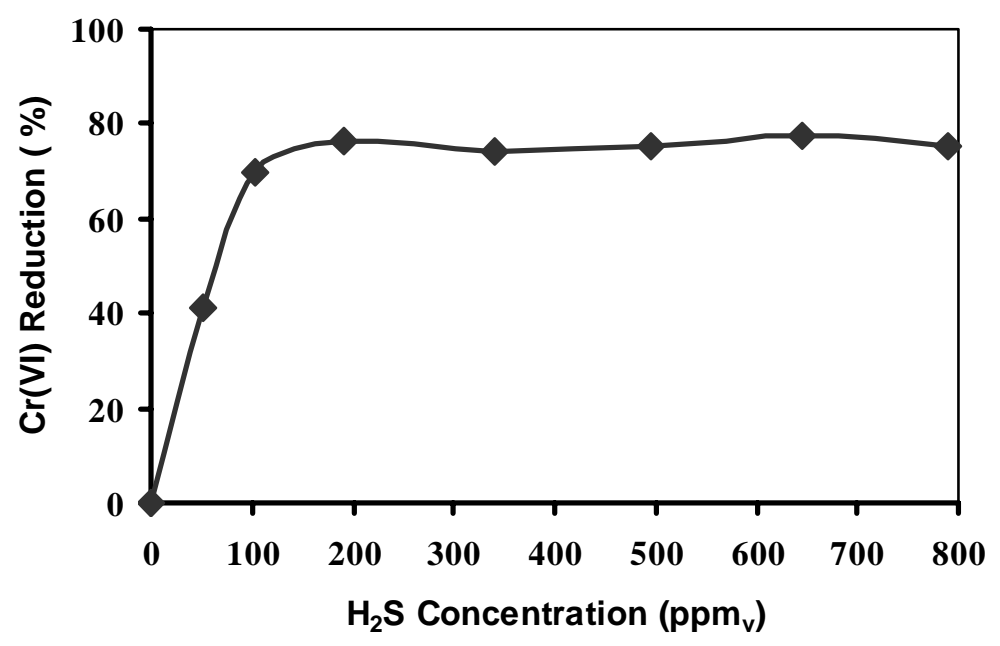

Figure 6-2. Effect of gaseous $\mathrm{H}_{2} \mathrm{~S}$ concentration on $\mathrm{Cr}(\mathrm{VI})$ reduction (GA: $0.600 \mathrm{~mm} ; \mathrm{N}_{2}$ flow rate $=800 \mathrm{~mL} / \mathrm{min}$; Reaction time $=20 \mathrm{~min}$; Relative humidity $=96.7 \%$ )

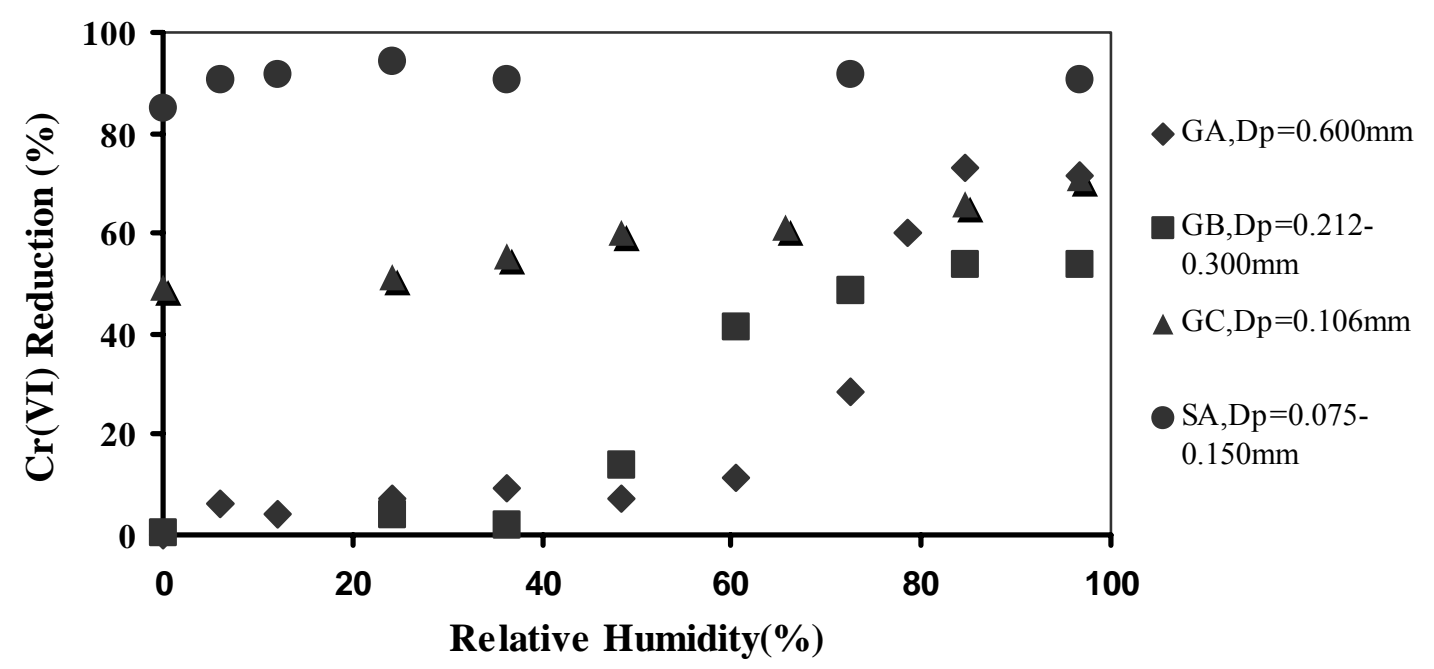

Figure 6-3. Effect of water moisture content on $\mathrm{Cr}(\mathrm{VI})$ reduction by gaseous $\mathrm{H}_{2} \mathrm{~S}\left(\left[\mathrm{H}_{2} \mathrm{~S}\right]_{\mathrm{g}}=\right.$ $340 \mathrm{ppm}_{\mathrm{v}} ; \mathrm{N}_{2}$ flow rate $=800 \mathrm{~mL} / \mathrm{min}$; Reaction time $=15 \mathrm{~min}$ )

Samples with different diameters, GB, GC and SA, were tested to investigate the effects of particle sizes on $\mathrm{Cr}(\mathrm{VI})$ reduction under various humidity conditions. Figure 6-3 showed that for GB with a diameter from 0.212 to $0.300 \mathrm{~mm}$, the profile for $\mathrm{Cr}(\mathrm{VI})$ reduction was similar to GA, with less than $20 \%$ of $\mathrm{Cr}(\mathrm{VI})$ reduction at the humidity lower than $50 \%$, followed by a rapid jump 
of $\mathrm{Cr}(\mathrm{VI})$ reduction. The humidity range corresponding to this jump, however, occurred at 50 $72 \%$ relative humidity, slightly lower than the 60 to $85 \%$ humidity for GA. This suggested that the required humidity for facile $\mathrm{Cr}(\mathrm{VI})$ reduction was lower when the particle size was decreased. This point was confirmed when particles with even smaller sizes were used: GC with a diameter of $0.106 \mathrm{~mm}$ and SA with a diameter of $0.075-0.150 \mathrm{~mm}$. For GC, $50 \%$ of $\mathrm{Cr}(\mathrm{VI})$ was reduced at near zero humidity (no dilution $\mathrm{N}_{2}$ gas passed through the water bottle), and the fraction of reduced $\mathrm{Cr}(\mathrm{VI})$ was increased slightly to $70 \%$ as the humidity was increased to $96.7 \%$. There was no abrupt increase of $\mathrm{Cr}(\mathrm{VI})$ reduction with increasing humidity. Similar result was obtained for SA, with as high as $85 \%$ of $\mathrm{Cr}(\mathrm{VI})$ reduction at near zero humidity, and reached $91 \%$ of $\mathrm{Cr}(\mathrm{VI})$ reduction when the humidity was at $6 \%$. The percentage of $\mathrm{Cr}(\mathrm{VI})$ reduction remained at $91 \%$ level at higher humidity, with no abrupt change of $\mathrm{Cr}(\mathrm{VI})$ reduction observed.

Reactivity of $\mathrm{Cr}(\mathrm{VI})$ Compounds with Different Solubilities: $\mathrm{Cr}(\mathrm{VI})$ compounds with differing water solubility demonstrated significantly different reactivity in coupling with $\mathrm{H}_{2} \mathrm{~S}$ oxidation (Figure 6-4). All the tests were conducted using GA under $96.7 \%$ humidity, because water moisture, as discussed earlier, was needed for efficient $\mathrm{Cr}(\mathrm{VI})$ reduction. The amounts of $\mathrm{Cr}(\mathrm{VI})$ determined by $\mathrm{CH} 90$ extraction in the untreated samples were the original amounts of $\mathrm{Cr}(\mathrm{VI})$ in the systems, which were used as references for assessing the reactivies of soluble and barely soluble $\mathrm{Cr}(\mathrm{VI})$ compounds. It was clear from Figure 6-4a that for $\mathrm{GA}-\mathrm{K}_{2} \mathrm{CrO}_{4}$, approximately $75 \%$ of $\mathrm{Cr}(\mathrm{VI})$ was reduced during the $20 \mathrm{~min}$ of $\mathrm{H}_{2} \mathrm{~S}$ treatment, and for $\mathrm{GA}-\mathrm{CaCrO}_{4}$, the reduction of $\mathrm{Cr}(\mathrm{VI})$ was $50 \%$. For both $\mathrm{GA}-\mathrm{BaCrO}_{4}$ and $\mathrm{GA}-\mathrm{PbCrO}_{4}$, however, the untreated and treated samples had the same amount of $\mathrm{CH} 90$-extractable $\mathrm{Cr}(\mathrm{VI})$. The results suggested that the insoluble $\mathrm{BaCrO}_{4}$ and $\mathrm{PbCrO}_{4}$ were not reduced under the experimental conditions. This was in agreement with the results reported in the literature (Vitale et al., 1997).

In addition, tests were performed under the same conditions except for using distilled water (DW) as an extraction solution for $\mathrm{Cr}(\mathrm{VI})$ analysis (Figure 6-4b). The result for $\mathrm{GA}_{-} \mathrm{K}_{2} \mathrm{CrO}_{4}$ and GA$\mathrm{CaCrO}_{4}$ was the same as using $\mathrm{CH} 90$ extraction. It was known that soluble $\mathrm{K}_{2} \mathrm{CrO}_{4}$ could be extracted by both extraction procedures with the same efficiency (James et al., 1995), so our result was as expected. The data also showed that less soluble $\mathrm{CaCrO}_{4}$ had the same characteristics as $\mathrm{K}_{2} \mathrm{CrO}_{4}$, i.e., can be reduced by $\mathrm{H}_{2} \mathrm{~S}$ treatment. For insoluble $\mathrm{BaCrO}_{4}$ and $\mathrm{PbCrO}_{4}$, no DW-extractable $\mathrm{Cr}(\mathrm{VI})$ was detected for both treated and untreated samples, showing that while these two compounds were not reduced, they were already in the immobilized forms and thus should not contribute significantly to the migration of $\mathrm{Cr}(\mathrm{VI})$ in groundwater and soil systems. 

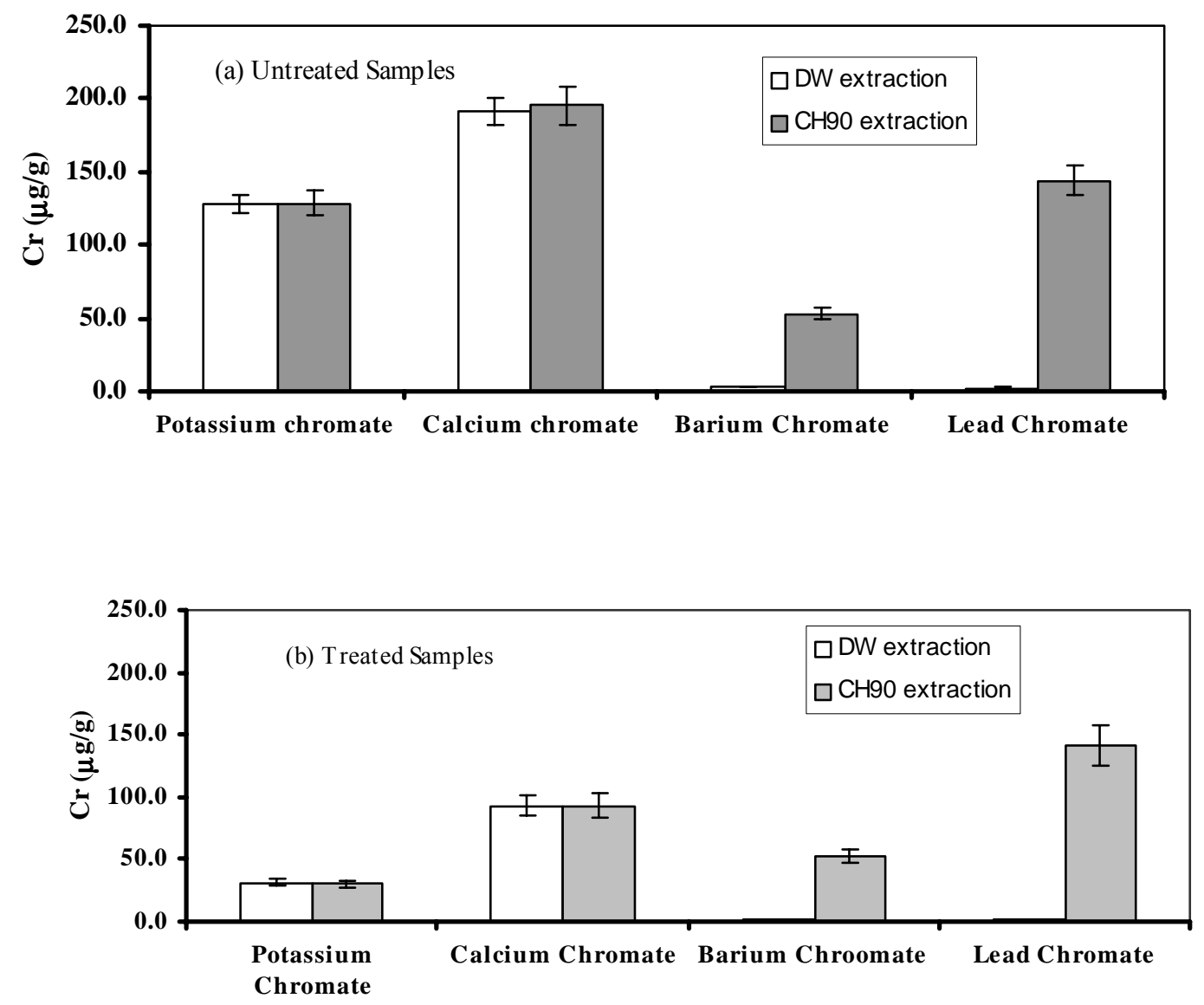

Figure 6-4. Reduction of $\mathrm{Cr}(\mathrm{VI})$ compounds with various solubilities by gaseous $\mathrm{H}_{2} \mathrm{~S}$. The error bar shows the range of duplicate testing. (GA: $0.600 \mathrm{~mm}$; Reaction time $=20.0 \mathrm{~min}$, $\left[\mathrm{H}_{2} \mathrm{~S}\right]_{\mathrm{g}}=340 \mathrm{ppm}_{\mathrm{v}}, \mathrm{N}_{2}$ flow rate $=800 \mathrm{~mL} / \mathrm{min}$, Relative humidity $=96.7 \%$ )

Kinetics of $\mathrm{Cr}(\mathrm{VI})$ reduction under different initial concentrations: Reduction of $\mathrm{Cr}(\mathrm{VI})$ by $\mathrm{H}_{2} \mathrm{~S}$ was measured as a function of time using four $\mathrm{GA}_{-} \mathrm{K}_{2} \mathrm{CrO}_{4}$ samples with various initial $\mathrm{Cr}(\mathrm{VI})$ contents. The $\mathrm{H}_{2} \mathrm{~S}$ concentration was maintained at $340 \mathrm{ppm}_{\mathrm{v}}$ and humidity at $96.7 \%$. As shown in Figure 6-5, the time courses under all concentration conditions were found to be similar, with a rapid initial $\mathrm{Cr}(\mathrm{VI})$ reduction, followed by a more gradual stage. To illustrate, for GA sample with $127.3 \mu \mathrm{g} / \mathrm{g}$ of $\mathrm{Cr}(\mathrm{VI})$, the fraction of $\mathrm{Cr}(\mathrm{VI})$ reduced reached $52 \%$ within the initial three minutes, followed by a slower reaction that resulted in a $95 \%$ of $\mathrm{Cr}(\mathrm{VI})$ reduction within $60 \mathrm{~min}$. Overall, the fraction of $\mathrm{Cr}(\mathrm{VI})$ reduced was decreased as the initial $\mathrm{Cr}(\mathrm{VI})$ concentration was increased. At $60 \mathrm{~min}$, the fractions of reduced $\mathrm{Cr}(\mathrm{VI})$ were 95, 90, 71, and $66 \%$ in the systems with $127.3,150.7,319.3$, and $474.7 \mu \mathrm{g} \mathrm{Cr} / \mathrm{g}$, respectively. 


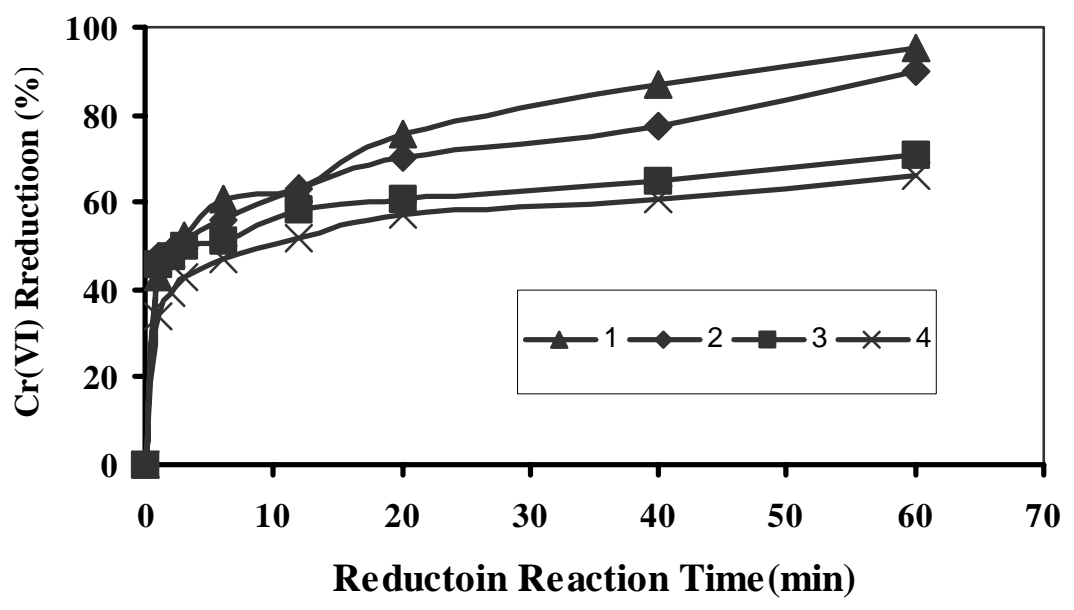

Figure 6-5. Kinetics of $\mathrm{Cr}(\mathrm{VI})$ reduction by gaseous $\mathrm{H}_{2} \mathrm{~S}$ at various initial concentrations (127.3 $\mu \mathrm{g} / \mathrm{g}(1) ; 150.7 \mu \mathrm{g} / \mathrm{g}(2) ; 319.3 \mu \mathrm{g} / \mathrm{g}(3) ;$ and $474.7 \mu \mathrm{g} / \mathrm{g}(4)$. (GA: $0.600 \mathrm{~mm} ;\left[\mathrm{H}_{2} \mathrm{~S}\right]_{\mathrm{g}}$ $=340 \mathrm{ppm}_{\mathrm{v}} ; \mathrm{N}_{2}$ flow rate $=800 \mathrm{ml} / \mathrm{min}$; and Relative humidity $=96.7 \%$ )

\section{DISCUSSION}

Importance of Water Moisture Content on Cr(VI) Reduction: Experimental results shown in Figure 6-3 have demonstrated that the efficiency for $\mathrm{Cr}(\mathrm{VI})$ reduction by $\mathrm{H}_{2} \mathrm{~S}$ relies on both the relative humidity and the size of particles on which $\mathrm{Cr}(\mathrm{VI})$ is deposited. For GA with a diameter of $0.600 \mathrm{~mm}$, there is minimal $\mathrm{Cr}(\mathrm{VI})$ reduction at a humidity lower than $60 \%$ but the reactivity is greatly increased in a relatively narrow range from 60 to $82 \%$. This observation indicates that (i) the reduction of $\mathrm{Cr}(\mathrm{VI})$ is not directly proportional to the partial pressure of water vapor, and the mass action law may not be applicable for interpreting the effects of water vapor; and (ii) the presence of water vapor is essential for the reaction and the water partial pressure should be higher than certain point to have rapid $\mathrm{Cr}(\mathrm{VI})$ reduction. Any mechanistic understanding of the system should also account for the effect of particle sizes on the $\mathrm{Cr}(\mathrm{VI})$ reduction efficiency.

We propose that in the reaction system examined here, $\mathrm{Cr}(\mathrm{VI})$ reduction by gaseous $\mathrm{H}_{2} \mathrm{~S}$ occur according to a conceptual model as illustrated in Figure 6-6. A water film forms first on the particle surfaces under appropriate humidity condition, which leads to the dissolution of $\mathrm{Cr}(\mathrm{VI})$ compounds originally deposited on the solid particles. The dissolution process is controlled by the solubility of the specific compound and its dissolution rate. Gaseous $\mathrm{H}_{2} \mathrm{~S}$ is subsequently transferred to the aqueous film via gas/liquid exchange process, resulting in $\mathrm{Cr}(\mathrm{VI})$ reduction in the aqueous film.

Evidences supporting this model include the effects of humidity on $\mathrm{Cr}(\mathrm{VI})$ reduction associated with various sizes of glass bead particles. Condensation of water molecules onto particle surfaces depends on both the partial pressure of water vapor and particle size. For a single particle system, the critical value above which the condensation will occur at certain temperature can be calculated according to the Young-Laplace' equation and the definition for relative humidity (Levine, 1978): 


$$
\begin{aligned}
\Delta P & =\frac{2 \sigma}{R} \\
H^{0} & =\frac{P^{0}-\Delta P}{P^{0}}
\end{aligned}
$$

where $P$ is the partial pressure of water vapor, $\sigma$ is the surface tension of water, $R$ is the radius of glass beads, $P^{0}$ is the saturated pressure of water vapor, and $H^{0}$ is the saturation humidity (the lowest humidity needed for the formation of water film on a particle surface). Under the experimental condition with a temperature of $23{ }^{\circ} \mathrm{C}, P^{0}=2.81 \mathrm{kPa}$ and $\sigma=72.28 \mathrm{mN} / \mathrm{m}$ (Lide, 1992). For the sample GA with the particle radius $R=0.300 \mathrm{~mm}$, assuming that point contacts existing among the spherical particles in the loosely packed bed do not affect the single particle behavior, the calculated $H^{0}$, i.e., the lowest humidity for the formation of a water film, is $82.9 \%$. This humidity is almost the same as the relative humidity in Figure 6-3 where the rapid $\mathrm{Cr}(\mathrm{VI})$ reduction is observed for GA.

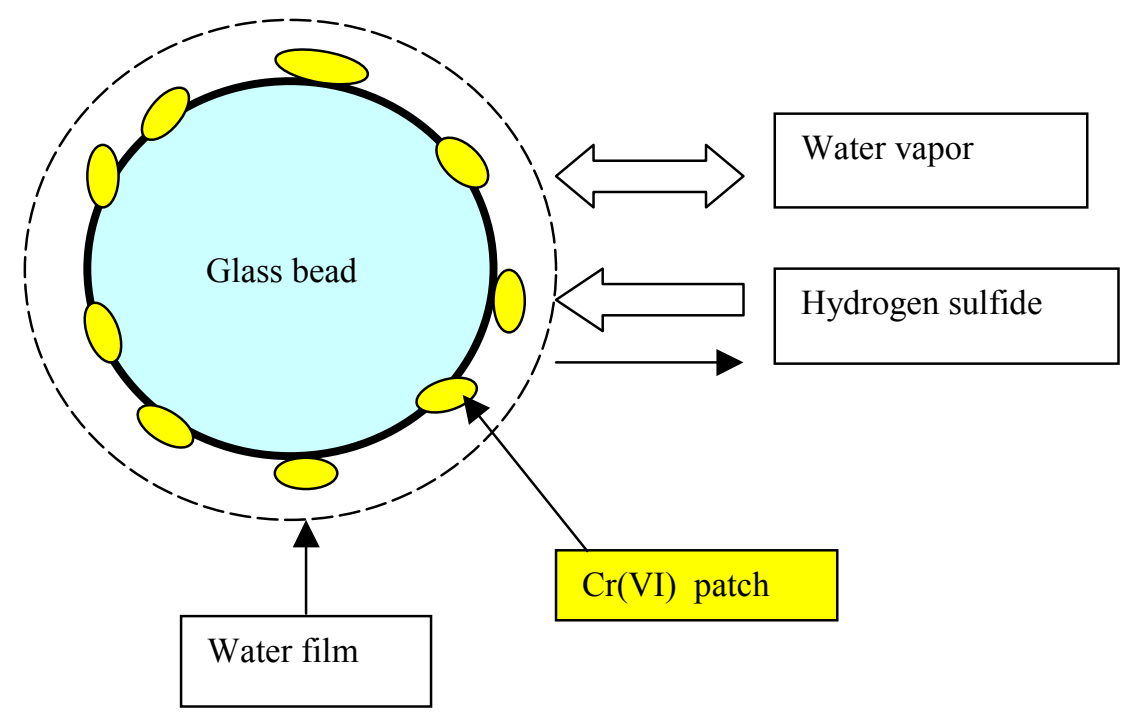

Figure 6-6. A conceptual model showing the process of $\mathrm{Cr}(\mathrm{VI})$ reduction by gaseous $\mathrm{H}_{2} \underline{\mathrm{S}}$.

For all four solid samples investigated, the correlation between the calculated saturation humidity and the observed humidity of rapid $\mathrm{Cr}(\mathrm{VI})$ reduction is presented in Figure 6-7. The theoretic values of saturation humidity are $82.9 \%(\mathrm{GA}), 59.8 \%(\mathrm{~GB}), 8.6 \%(\mathrm{SA})$, and $2.9 \%(\mathrm{GC})$. The experimental results are $85 \%(\mathrm{GA}), 61 \%(\mathrm{~GB}), 6 \%(\mathrm{SA})$, and $0 \%(\mathrm{GC})$, very close to the calculated values. The results suggest that a water film is formed on the particle surfaces, which serves as an aqueous medium for $\mathrm{Cr}(\mathrm{VI})$ dissolution and reduction. The reduction of $\mathrm{Cr}(\mathrm{VI})$ by gaseous $\mathrm{H}_{2} \mathrm{~S}$ is, therefore, not a "true" solid/gas interface reaction, but takes place in a three phase system. While water molecule in the water film is likely involved in the redox reaction, a water molecule in the gas phase is not directly a reactant. 


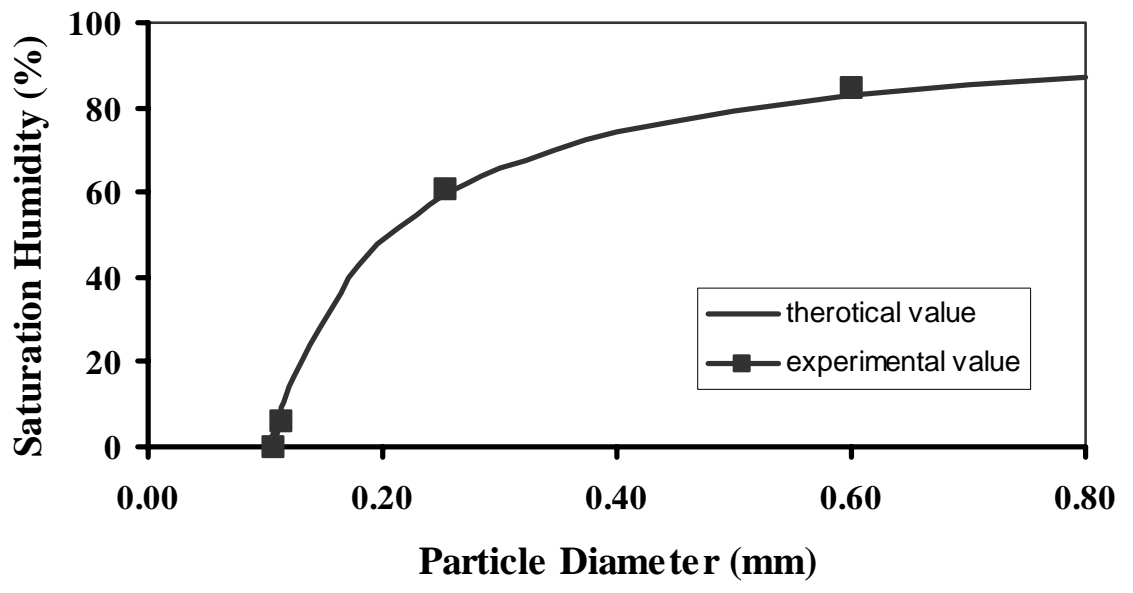

Figure 6-7. A plot of measured and calculated saturation humidity versus particles diameter (Temperature: $23^{\circ} \mathrm{C}$ )

Reactivity of Various $\mathrm{Cr}(\mathrm{VI})$ Compounds: Common $\mathrm{Cr}(\mathrm{VI})$ compounds identified at contaminated soils include $\mathrm{K}_{2} \mathrm{CrO}_{4}, \mathrm{CaCrO}_{4}, \mathrm{BaCrO}_{4}, \mathrm{PbCrO}_{4}$, and $\mathrm{Cr}(\mathrm{VI})$ species associated with calcium carbonate (Thornton and Ammonette, 1999; James et al., 1995). Chromium speciation is often accomplished by X-ray diffraction and/or spectroscopic studies (Thornton and Ammonette, 1999). In addition, information collected from the selective extraction using various solutions has been used to deduce information on Cr(VI) speciation in soils (James et al., 1995). Our tests with some $\mathrm{Cr}(\mathrm{VI})$-contaminated soils from the Hanford site, Washington, indicates that CH90 could extract $30 \%$ more Cr(VI) than P-buffer (data not shown). This shows the presence of insoluble $\mathrm{Cr}(\mathrm{VI})$ salts in the contaminated soils. James et al. (1995) also reported that CH90 extracted more $\mathrm{Cr}(\mathrm{VI})$ than P-buffer for some soil samples from Warren county, NJ.

The tests with two most common insoluble $\mathrm{Cr}(\mathrm{VI})$ salts, $\mathrm{BaCrO}_{4}$ and $\mathrm{PbCrO}_{4}$, show the same amounts of extractable $\mathrm{Cr}(\mathrm{VI})$ for both untreated and $\mathrm{H}_{2} \mathrm{~S}$-treated samples, suggesting that $\mathrm{Cr}(\mathrm{VI})$ in the insoluble salts could not be reduced (Figure 6-4). The mobility of $\mathrm{Cr}(\mathrm{VI})$ in these insoluble forms, however, is low because of the low solubility. No $\mathrm{Cr}(\mathrm{VI})$ is detected in this study with DW extraction (Fig. 6-4b). For $\mathrm{K}_{2} \mathrm{CrO}_{4}$ and $\mathrm{CaCrO}_{4}$, treatment with $\mathrm{H}_{2} \mathrm{~S}$ for 20 minutes has significantly reduced the extractable amounts of $\mathrm{Cr}(\mathrm{VI})$ (Fig. 6-4). The percentage reduction of $\mathrm{K}_{2} \mathrm{CrO}_{4}(75 \%)$ is higher than that for $\mathrm{CaCrO}_{4}(50 \%)$, probably due to the lower solubility of $\mathrm{CaCrO}_{4}$. It is expected that a longer reaction time will result in a higher fraction of $\mathrm{Cr}(\mathrm{VI})$ reduction for both of these compounds. Based on the fact that a water film on the solid particles is needed for facile $\mathrm{Cr}(\mathrm{VI})$ reduction and only soluble $\mathrm{Cr}(\mathrm{VI})$ species can be reduced by $\mathrm{H}_{2} \mathrm{~S}$, it appears that $\mathrm{Cr}(\mathrm{VI})$ compounds are dissolved into the water film prior to the redox reaction with sulfide.

The results with the insoluble $\mathrm{BaCrO}_{4}$ and $\mathrm{PbCrO}_{4}$ agree with the reported studies in the literature. It was found that $\mathrm{PbCrO}_{4}(\mathrm{~s})$ spiked to an anoxic sediment sample was partially recovered with $\mathrm{CH} 90$ extraction, indicating that $\mathrm{PbCrO}_{4}(\mathrm{~s})$ could not be easily reduced (Vitale et al., 1997). In an alkaline soil enriched with chromite ore processing residue, not all of the "nonexchangeable" Cr(VI) could be reduced by added Fe(II) species (James et al., 1995; Vitale et al., 1997). In another study, Burge and Hug (1999) found that when $\mathrm{Cr}(\mathrm{VI})$ was present as 
$\mathrm{BaCrO}_{4(\mathrm{~s})}$ salt, its reduction by $\mathrm{Fe}(\mathrm{II})$ was much less than $\mathrm{K}_{2} \mathrm{CrO}_{4}$ and essentially determined by its dissolution.

Cr(VI) Reduction Kinetics by $\mathrm{H}_{2} \underline{S}$ : Aqueous $\mathrm{Cr}(\mathrm{VI})$ reduction by $\mathrm{H}_{2} \mathrm{~S}$ has been well documented (1618). Under the anaerobic system, the reaction takes place according to the following stoichiometry:

$$
2 \mathrm{CrO}_{4}{ }^{2-}+3 \mathrm{H}_{2} \mathrm{~S}+4 \mathrm{H}^{+} \rightarrow 2 \mathrm{Cr}(\mathrm{OH})_{3(\mathrm{~S})}+3 \mathrm{~S}_{(\mathrm{S})}+2 \mathrm{H}_{2} \mathrm{O}
$$

which indicates that elemental sulfur is the main product of $\mathrm{H}_{2} \mathrm{~S}$ oxidation (Kim et al., 2001). The reduction kinetics depends on the reactant concentrations and solution $\mathrm{pH}$, and can be described by:

$$
\frac{d[C r(V I)]}{d t}=k\left\{\frac{\left[H^{+}\right]^{2}}{\left[H^{+}\right]^{2}+\left[H^{+}\right] K_{1}+K_{1} K_{2}}\right\}\left[\mathrm{CrO}_{4}{ }^{2-}\right]\left[\mathrm{H}_{2} \mathrm{~S}\right]_{T}
$$

where $k$ is a second order rate constant, and $K_{1}$ and $K_{2}$ are the dissociate constants of hydrogen sulfide in water. Experiments conducted in anaerobic aqueous systems with various $\mathrm{pHs}$, ionic strengths, and concentrations of $[\mathrm{Cr}(\mathrm{VI})]$ and $\left[\mathrm{H}_{2} \mathrm{~S}\right]_{\mathrm{T}}$ agreed with this kinetics equation. The kinetics could be interpreted by a three-step mechanism: formation of an inner-sphere chromatesulfide intermediate complex $\left(\left\{\mathrm{O}_{3} \mathrm{Cr}^{\mathrm{VI}} \mathrm{S}\right\}^{2-}\right)$, intramolecular electron transfer to form $\mathrm{Cr}(\mathrm{IV})$ species, and subsequent fast reactions leading to $\mathrm{Cr}(\mathrm{III})$.

For $\mathrm{Cr}(\mathrm{VI})$ reduction by gaseous $\mathrm{H}_{2} \mathrm{~S}$ examined here, it is proposed that the reaction takes place according to the conceptual model in Figure 6-6, i.e., dissolution of reactants in a water film on the particle surfaces is needed for the reaction to occur. Therefore, studies of aqueous $\mathrm{Cr}(\mathrm{VI})$ reduction by $\mathrm{H}_{2} \mathrm{~S}$ is still relevant. A number of steps are involved in this process: (i) dissolution and diffusion of $\mathrm{Cr}(\mathrm{VI})$ into the water film, (ii) diffusion of gaseous $\mathrm{H}_{2} \mathrm{~S}$ toward the film surface, (iii) $\mathrm{H}_{2} \mathrm{~S}$ dissolution and diffusion into the water film (gas transfer), (iv) electron transfer reaction between $\mathrm{Cr}(\mathrm{VI})$ and $\mathrm{H}_{2} \mathrm{~S}$, and (v) formation and precipitation of the reaction products, $\mathrm{Cr}(\mathrm{OH})_{3}(\mathrm{~s})$ and elemental sulfur $\left(\mathrm{S}^{0}\right)$, on the glass bead particles. Because the experiments have shown that when the dilution $\mathrm{N}_{2}$ gas flow rate is higher than $500 \mathrm{~mL} / \mathrm{min}$, changes in the flow rate do not affect the efficiency of $\mathrm{Cr}(\mathrm{VI})$ reduction, the steps for supplying the gaseous reductant (ii and iii) may not be rate-limiting. Dissolution of $\mathrm{Cr}(\mathrm{VI})$ compound (step i) is apparently important, as demonstrated by the lack of the reduction of insoluble $\mathrm{BaCrO}_{4}$ and $\mathrm{PbCrO}_{4}$. The overall reaction could also be controlled by the electron transfer processes (step iv) and, at the later stage, by the inhibition or catalytic effect of the reaction products (step v). It has been shown that in the anaerobic aqueous system, elemental sulfur product can catalyze $\mathrm{Cr}(\mathrm{VI})$ reduction by sulfide (Lan et al., 2001).

This study has demonstrated that $\mathrm{Cr}(\mathrm{VI})$ reduction is proportional to gaseous $\mathrm{H}_{2} \mathrm{~S}$ concentration $\left(\left[\mathrm{H}_{2} \mathrm{~S}\right]_{\mathrm{g}}\right)$ when it is lower than $100 \mathrm{ppm}_{\mathrm{v}}$, and is near zero-order at a higher concentration. It is unclear why the rate of $\mathrm{Cr}(\mathrm{VI})$ reduction is independent of $\left[\mathrm{H}_{2} \mathrm{~S}\right]_{\mathrm{g}}$ at the high concentration. Should Henry's law apply and $\mathrm{Cr}(\mathrm{VI})$ reduction were proportional to $\left[\mathrm{H}_{2} \mathrm{~S}\right]_{\text {aqueous }}$, higher $\left[\mathrm{H}_{2} \mathrm{~S}\right]_{\mathrm{g}}$ would have increased sulfide concentration in the water film and resulted in higher reaction rate (Eq., 4). One possibility is the inhibition due to the formation of reaction products such as elemental sulfur and chromium hydroxide precipitates, which may counter balance the effect of increasing $\mathrm{H}_{2} \mathrm{~S}$. Another possibility is that the reaction is controlled by the dissolution process of $\mathrm{Cr}(\mathrm{VI})$ into the water film. Microscopic imagines showed that potassium chromate deposited onto the glass bead samples was not uniform, but in "patches" (see the Supporting Information). Because the water vapor was introduced into the column 5 min earlier than hydrogen sulfide gas, significant amounts of $\mathrm{Cr}(\mathrm{VI})$ may have dissolved in the water film. The dissolved $\mathrm{Cr}(\mathrm{VI})$ would be first reduced by $\mathrm{H}_{2} \mathrm{~S}$, which explains the rapid $\mathrm{Cr}(\mathrm{VI})$ reduction within the initial $3 \mathrm{~min}$. The reduction rate will be much slower afterwards if the overall reduction is now controlled by the dissolution of $\mathrm{Cr}(\mathrm{VI})$ into the water film. For the fixed surface area of glass beads, the relative dissolution rate of $\mathrm{Cr}(\mathrm{VI})$ will be reduced with increasing $\mathrm{Cr}(\mathrm{VI})$ initial concentration. As shown 
in Fig. 6-4, with increasing initial $\mathrm{Cr}(\mathrm{VI})$ concentration, the fraction of $\mathrm{Cr}(\mathrm{VI})$ reduced was decreased, although the absolute amount of reduced $\mathrm{Cr}(\mathrm{VI})$ was increased.

The results obtained in this study have significant implications on the use of ISGR for immobilizing $\mathrm{Cr}$, and probably other contaminants such as Tc and $\mathrm{U}$. Because the $\mathrm{Cr}(\mathrm{VI})$ reduction reaction with gaseous $\mathrm{H}_{2} \mathrm{~S}$ takes place in a water film, it is apparently important to have appropriate moisture content in the subsurface or maintain a suitable humidity in the treatment gas stream to maximize $\mathrm{Cr}(\mathrm{VI})$ reduction. Our preliminary test on a $\mathrm{Cr}(\mathrm{VI})$-contaminated Hanford soil sample indicated that chromium immobilization by dry $\mathrm{H}_{2} \mathrm{~S}$ gas treatment was $30 \%$ lower than by humidified $\mathrm{H}_{2} \mathrm{~S}$ gas treatment. Further work is needed to fully assess the importance of humidity for $\mathrm{Cr}(\mathrm{VI})$ reduction in the field. In addition, $\mathrm{PbCrO}_{4}$ and $\mathrm{BaCrO}_{4}$ can not be reduced under tested conditions in this study due to their low solubility. It appears that contaminant dissolution is a prerequisite for reduction with $\mathrm{H}_{2} \mathrm{~S}$. 


\title{
VII. IMMOBILIZATION OF CHROMIUM, TECHNETIUM, AND URANIUM IN SOILS FROM THE HANFORD SITE, WASHINGTON
}

\author{
(E.C. Thornton, V. Legore, and K. Olsen)
}

\section{INTRODUCTION}

The objectives of testing activities summarized in this section are to determine (i) if Tc- and Ucontaminated sediments can be effectively treated by exposure to diluted hydrogen sulfide gas and (ii) if $\mathrm{H}_{2} \mathrm{~S}$-treated sediments can effectively retard the migration of $\mathrm{Cr}$, $\mathrm{Tc}$, and $\mathrm{U}$ in solutions that may potentially infiltrate through the treated zone. If so, In Situ Gaseous Reduction (ISGR) may have broad applications for reducing the migration of $\mathrm{Cr}, \mathrm{Tc}$, and $\mathrm{U}$ in the vadose zone. Both contaminated and uncontaminated soil samples from the Hanford Site are used for assessing the treatment efficiencies. Possible applications at the Hanford Site include the treatment of contamination existing beneath several single-shell tanks and the prevention of further release of contamination during closure of the tanks.

Previous field and laboratory testing activities have shown that $\operatorname{Cr}(\mathrm{VI})$ species in soil can be efficiently reduced to Cr(III) forms by ISGR treatment and thereby immobilized (Thornton et al. 1999). It is unclear whether $\mathrm{Tc}$ and $\mathrm{U}$ can be similarly immobilized by $\mathrm{H}_{2} \mathrm{~S}$ reduction. In addition, while $\mathrm{Cr}$ is likely to remain in the immobilized forms once reduced, Tc and $\mathrm{U}$ are subject to reoxidation. Thus permanent immobilization of $\mathrm{Tc}$ and $\mathrm{U}$ by reduction may not be possible. However, reaction of hydrogen sulfide with sediments also results in the reduction of the sediment matrix. In particular, ferric iron is reduced to ferrous iron. A significant increase in the reductive capacity of the sediment can potentially serve as a vadose zone permeable reactive barrier (PRB). If the reductive capacity of the treated zone is sufficiently high, the oxidation potential may remain low enough to immobilize technetium and uranium, as well as chromium, for years. Previous testing activities have also revealed that immobilization of contamination occurs after gaseous treatment due to the formation of coatings on grain surfaces (Thornton and Amonette 1999; see also Szecsody et al. 1998).

ISGR treatment of the vadose zone under the waste tanks thus can have two different applications. The first is to immobilize or stabilize pre-existing contamination present in the vadose zone. This process involves reduction of $\mathrm{Cr}$, Tc, and $\mathrm{U}$, and possible sequestration by development of treatment product coatings or precipitates. It is known that $\mathrm{Cr}(\mathrm{VI})$ can be immobilized through reduction. Here we report the preliminary studies on the reduction of Tc and $\mathrm{U}$ and possible sequestration in the contaminated soils at the Hanford site.

A second possible application is to create a permeable reactive barrier, which arises from the reduction of the ferric iron component of vadose zone sediments to the ferrous state. This provides a means for capturing contamination that may subsequently enter the treated zone owing to possible future releases of contamination from a waste tank. Thus, emplacement of the permeable reactive barrier by in situ gaseous treatment can be undertaken as part of a leak mitigation program. The work reported here focuses on assessing the effectiveness of a vadose zone ISGR PRB for capturing contaminants that may be released from a tank as the result of a containment failure.

Assessing the longevity of the treatment for the contaminant immobilization is a critical issue. A test lasting 835 days was performed to see whether reoxidation of $\mathrm{Cr}$ could occur in $\mathrm{H}_{2} \mathrm{~S}$-treated soils from the Hanford site. 


\section{GASEOUS TREATMENT OF Tc-CONTAMINATED SEDIMENT}

Approach and testing procedure: To assess the viability of immobilizing technetium, it is necessary to address several questions. It must be determined, first, if technetium in a sediment sample can be immobilized and reduced from the +VII to +IV oxidation state by treating with diluted hydrogen sulfide. Secondly, it is necessary to determine if technetium will remain immobilized as the sediment is reoxidized. If the technetium is remobilized, it is necessary to determine the rate of release of technetium during the oxidative process. Finally, it is also important to determine if technetium can be efficiently removed from solutions that may later pass through the treated sediment. The testing approach used to answer the first question posed above involved conducting column tests with Tc-contaminated sediment, as described below. In these tests, technetium-contaminated sediment was treated with diluted hydrogen sulfide. Treated and untreated sediments were then leached with water and the rate of sediment reoxidation and technetium release was monitored.

The Tc-contaminated sediment used in these tests was provided by the CH2M Hill Hanford Group and was collected from borehole 299 W23-19 (B8809), located at the south end of the Waste Management Area (WMA) S-SX Tank Farm at the Hanford Site (Serne et al. 2002). Sediment was taken from four sleeves collected in the interval between 126 and $130 \mathrm{ft}$ below ground surface and composited. The sediment in this interval of the borehole has been determined to contain 0.02 to $0.03 \mathrm{ug} / \mathrm{g}$ ( 350 to $500 \mathrm{pCi} / \mathrm{g})$ technetium- 99 . The sediment also contains high concentrations of soluble nitrate ( 700 to $4,000 \mathrm{ug} / \mathrm{g})$ and calcium $(10,000$ to 15,000 $\mathrm{ug} / \mathrm{g})$.

The testing performed involved packing four columns with the Tc-contaminated sediment. The columns were $2.5 \mathrm{~cm}$ in diameter and $12 \mathrm{~cm}$ in length. One of these columns was the untreated control and was leached with oxygenated water at a flow rate of $0.4 \mathrm{ml} / \mathrm{min}$ (approximately one pore volume per hour) using a Gilson HPLC pump. Effluent samples were collected and analyzed for technetium by ICP-MS to determine the total leachable technetium and the rate of release of technetium from untreated sediment.

The second column was treated with hydrogen sulfide diluted in air and the third and fourth with hydrogen sulfide diluted in nitrogen through the use of flow controllers (Figure 7-1). Gas sources included cylinders of nitrogen and air and a small cylinder of $1 \%$ hydrogen sulfide in nitrogen. A 200-ppm hydrogen sulfide mixture was prepared by dilution and passed through the column being treated at a flow rate of $300 \mathrm{ml} / \mathrm{min}$. Breakthrough of hydrogen sulfide at the column outlet was monitored using an EIT hydrogen sulfide sensor. The treated columns were then leached and reoxidized with aerated water (Figure 7-2) that was equilibrated with a gas standard containing $21 \%$ oxygen in nitrogen. The column effluent was passed through an oxygen electrode to obtain the oxygen content of the effluent and samples were collected for analysis by ICP-MS. The concentration of technetium in the effluent from the treated columns was compared to that of the untreated column to determine the degree of immobilization associated with gas treatment. 


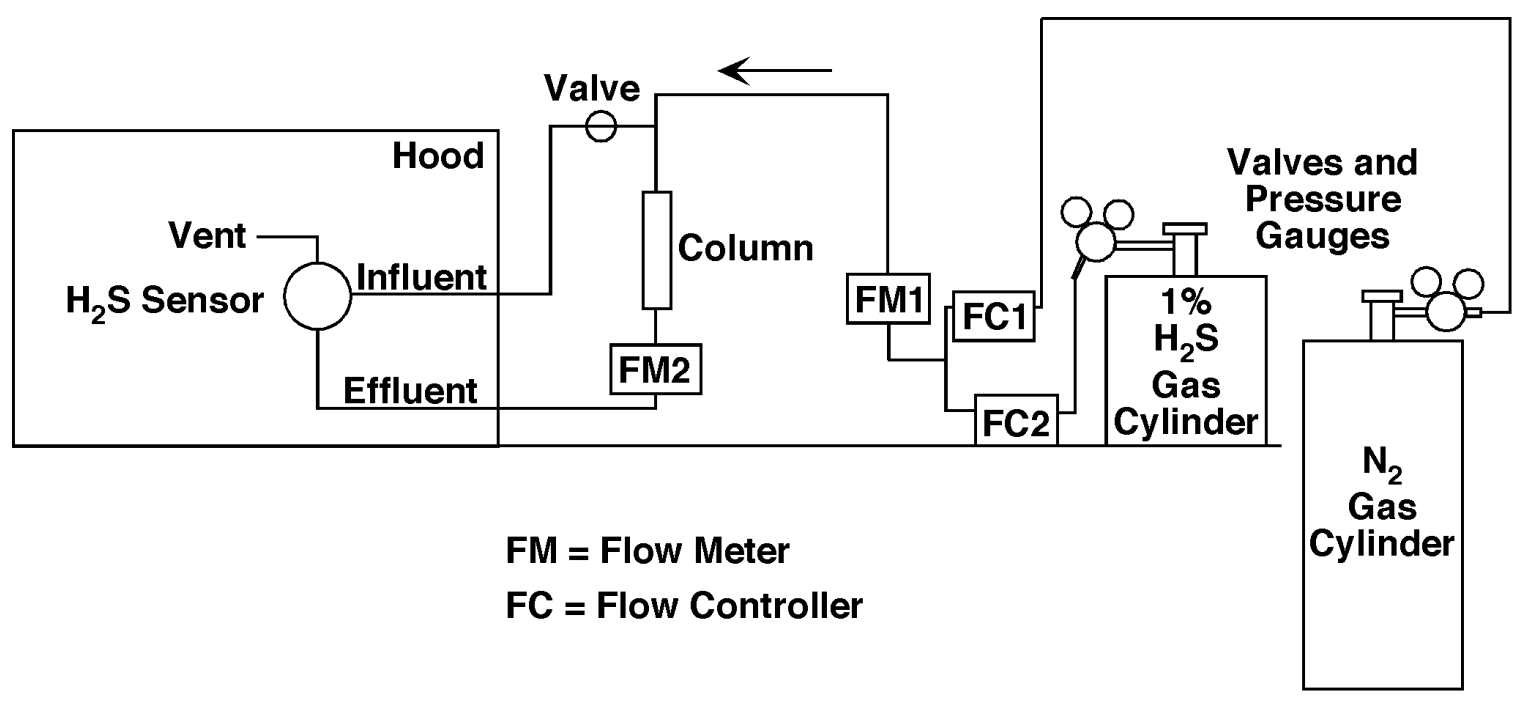

Figure 7-1. Schematic of the Gas Treatment System

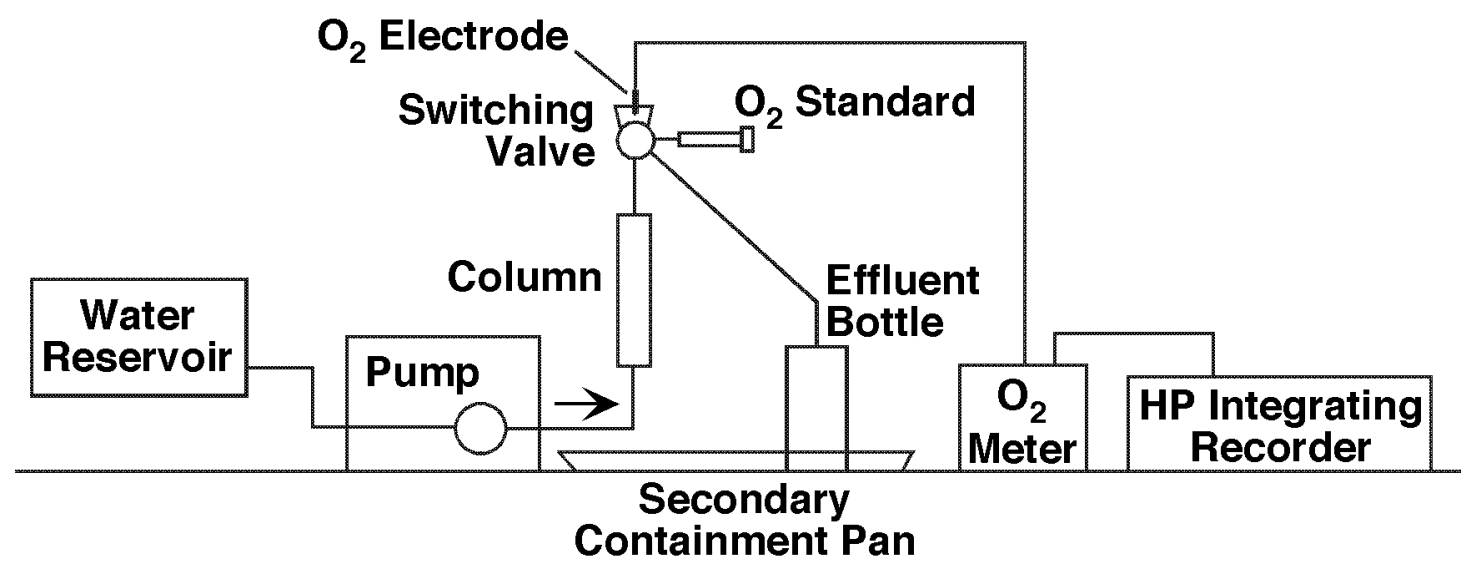

Figure 7-2. Schematic of the Reoxidation System

Results: The release of technetium during leaching of the untreated sediment (test Tc1) is illustrated in Figure 7-3, where the concentration of technetium in the column effluent is plotted versus time. Note that a concentration of $155 \mathrm{ug} / 1$ technetium was measured in the first sample, which represented the first 0.4 column pore volumes, and was much lower in subsequent samples. Technetium was not detected in samples collected after 6 hours ( 6 column pore volumes) into the test, which continued for two weeks. A cumulative amount of $0.020 \mathrm{ug}$ technetium was leached per gram of sediment. About $98 \%$ of this was leached from the column in the first sample ( 0 to 0.4 column pore volumes). 


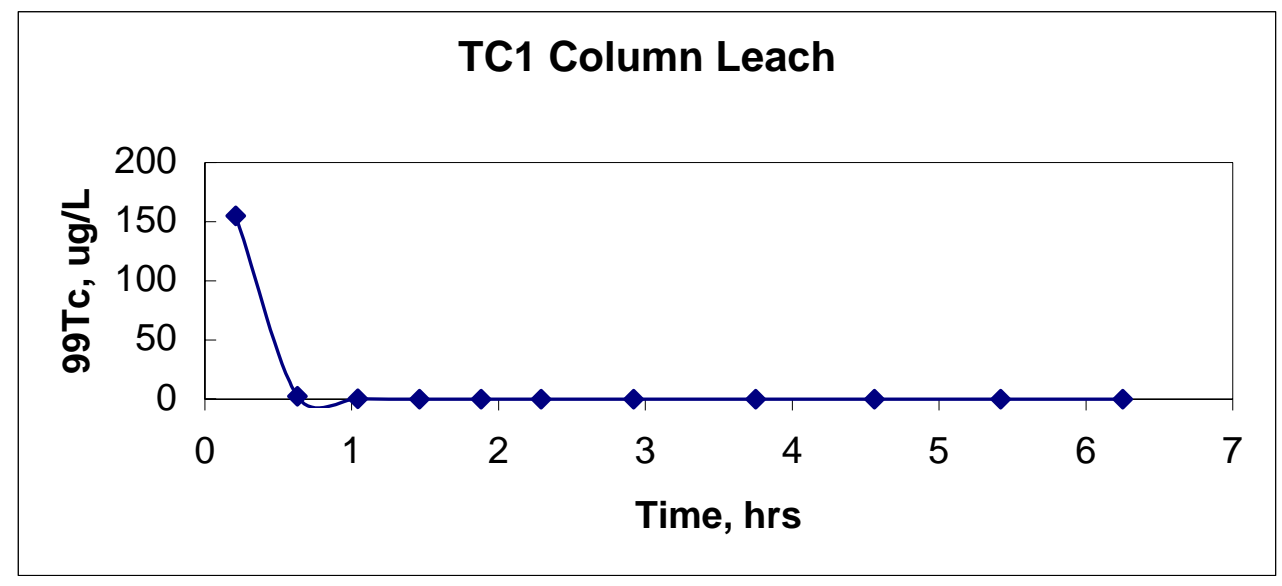

Figure 7-3. Release of Tc-99 from the Untreated Sediment

The second column was treated with 200-ppm hydrogen sulfide in air at a gas flow rate of 300 sccm during test TcA1. The breakthrough of hydrogen sulfide is illustrated in Figure 7-4 as the ratio of effluent concentration, $C$, to influent concentration, $C_{0}$. Gas treatment was performed over period of 73.5 hours, although most of the consumption of hydrogen sulfide occurred in the first 24 hours. A cumulative amount of $1.24 \times 10^{-5}$ moles of hydrogen sulfide was consumed per gram of sediment. The treated sediment was then leached with aerated water. The oxygen concentration of the effluent from the column was similar to that of the influent, indicating that no reductive capacity was generated in the sediment as the result of $\mathrm{H}_{2} \mathrm{~S}$ /air treatment.

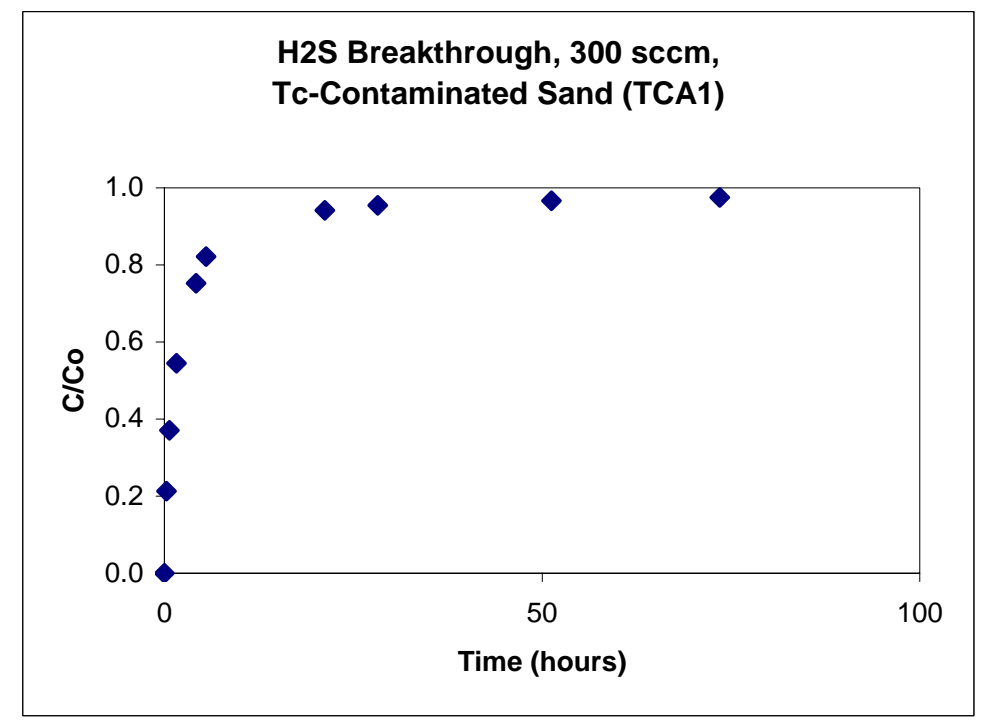

Figure 7-4. Breakthrough of Hydrogen Sulfide During Treatment Test TcA1

The release of technetium from the column during the water-leaching step is shown in Figure 7-5. The concentration of technetium in the first effluent sample ( 0.4 column pore volumes) was 34.4 ug/L, about $22 \%$ of that of the first sample collected from test Tc1. Technetium continued to be 
released over much of the two-week duration of leaching but was below the limits of detection $(0.02 \mathrm{ug} / \mathrm{l})$ by the end of the test. A cumulative amount of $0.0107 \mathrm{ug}$ technetium was leached per gram of sediment. Thus about $49 \%$ of the technetium was immobilized as a result of gas treatment, based on the amount of technetium released in this test relative to water-leaching results obtained for the test with the untreated sediment.

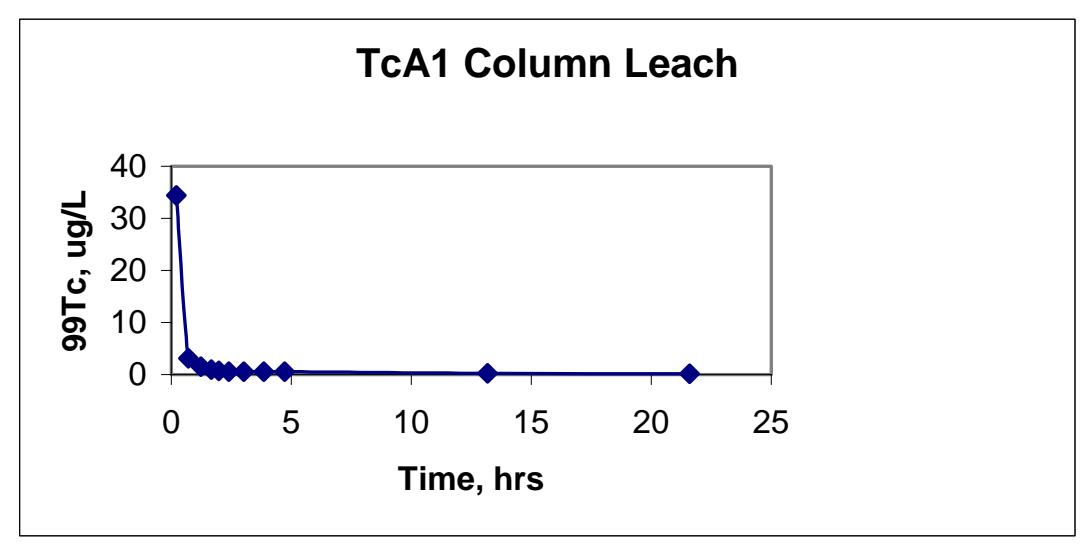

Figure 7-5. Release of Tc-99 During Leaching of the $\mathrm{H}_{2} \mathrm{~S} /$ Air Treated Sediment

The third and fourth columns were treated with 200-ppm hydrogen sulfide in nitrogen at a gas flow rate of $300 \mathrm{sccm}$ during duplicate tests TcN1 and TcN2. Gas treatment was conducted over a period of 69.33 hours in test $\mathrm{TcN} 1$ with most of the consumption of hydrogen sulfide again taking place within the first 24 hours (Figure 7-6). A cumulative total of $9.26 \times 10^{-6}$ moles of hydrogen sulfide were consumed per gram of sediment. The reoxidation of the treated sediment is illustrated in Figure 7-7 for test $\mathrm{TcN} 2$ and illustrates that a significant amount of reductive capacity was generated as a result of treatment of the sediment with the $\mathrm{H}_{2} \mathrm{~S} / \mathrm{N}_{2}$ gaseous mixture. The release of technetium from the column during the water-leaching step is shown in Figure 7-8 for test TcN1. The concentration of technetium in the first effluent sample $(0.4$ column pore volumes) was $10.1 \mathrm{ug} / \mathrm{L}$, about $6.5 \%$ of that of the first sample collected from test $\mathrm{Tc} 1$. Technetium continued to also be released from this experiment over the two-week duration of leaching, but decreased to a concentration of only $0.03 \mathrm{ug} / 1$ by the end of the test. A cumulative amount of $0.00947 \mathrm{ug}$ technetium was leached per gram of sediment. Thus about $51 \%$ of the technetium was immobilized as a result of gas treatment, based on the amount of technetium released in this test relative to water-leaching results obtained for the test with the untreated sediment. 


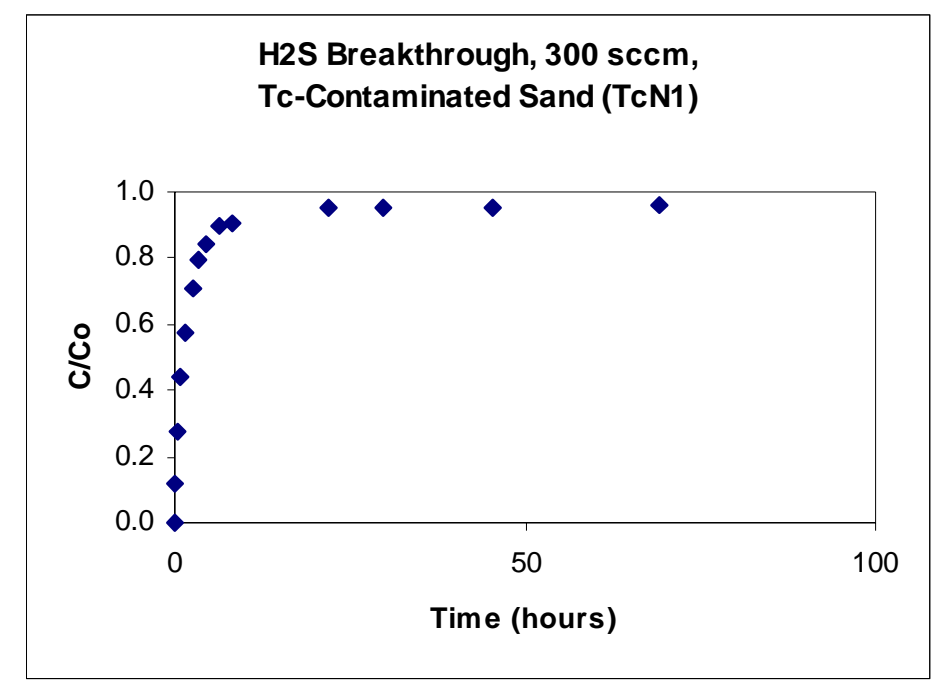

Figure 7-6. Breakthrough of Hydrogen Sulfide During Treatment Test TcN1

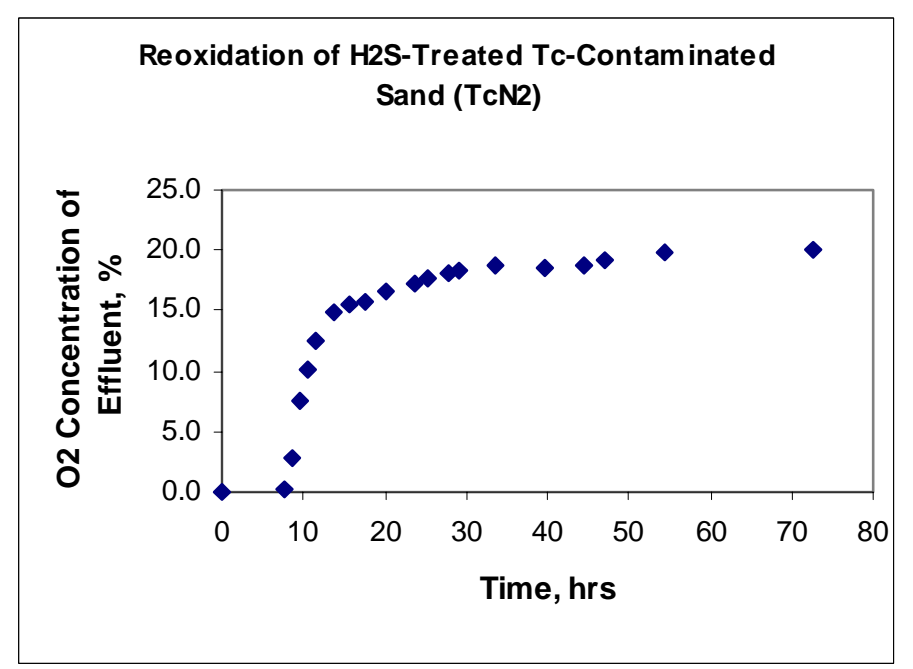

Figure 7-7. Oxygen Breakthrough During the Reoxidation Step of Test TcN2

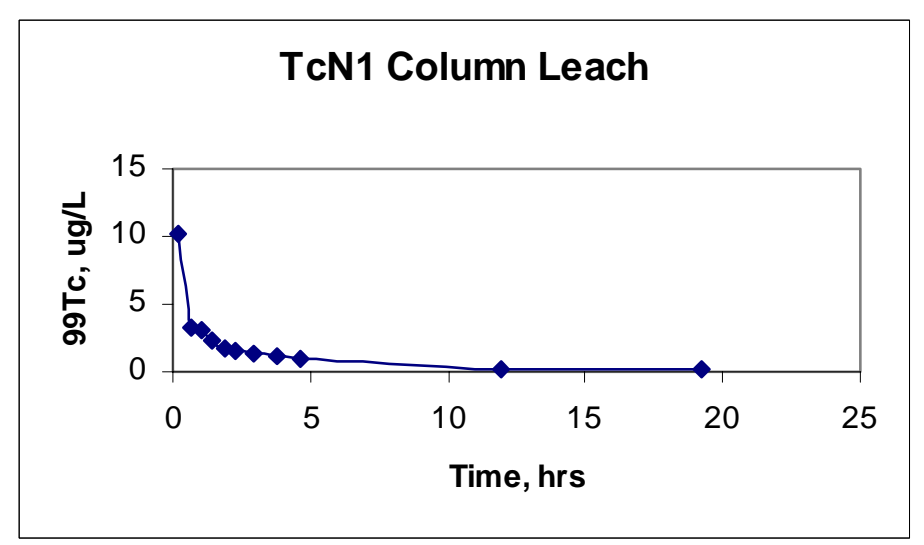

Figure 7-8. Release of Tc-99 During Leaching of the $\mathrm{H}_{2} \mathrm{~S} / \mathrm{N}_{2}$ Treated Sediment 
Conclusions: The results obtained during this study indicate that $\sim 50 \%$ of the technetium present in the contaminated sediment was immobilized by treatment with diluted hydrogen sulfide. The amount released in the first 0.4 column pore volumes during water leaching of the sediment treated with $\mathrm{H}_{2} \mathrm{~S} /$ air was about $22 \%$ of the untreated control. About $6.5 \%$ was released from the sediment treated with $\mathrm{H}_{2} \mathrm{~S} / \mathrm{N}_{2}$ relative to the control. No reductive capacity was produced as a result of treatment of the sediment with $\mathrm{H}_{2} \mathrm{~S}$ /air. A limited amount of reductive capacity was generated by treatment with $\mathrm{H}_{2} \mathrm{~S} / \mathrm{N}_{2}$, but oxygen breakthrough resulted in only about 8 hours. The relatively low reductive capacity of the $\mathrm{H}_{2} \mathrm{~S} / \mathrm{N}_{2}$ treated sediment may be related to a low available iron content for the sediment. Previous tests with Hanford sediment typically indicates that about 30 column pore volumes of aerated water can be pumped through $\mathrm{H}_{2} \mathrm{~S} / \mathrm{N}_{2}$ treated sediment prior to oxygen breakthrough. The color of this sediment is pale gray, suggesting that the iron oxide content is low. The relatively high flow rate $(0.4 \mathrm{ml} / \mathrm{min})$ used during the reoxidation/leaching stage of test $\mathrm{TcN} 2$ may also have resulted in a measured reductive capacity less than the true reductive capacity.

It is concluded that treatment of the vadose zone with $\mathrm{H}_{2} \mathrm{~S} /$ air could provide a means of partially stabilizing technetium contamination present beneath a tank. The partial immobilization of technetium observed in the $\mathrm{H}_{2} \mathrm{~S} /$ air treatment test may be due to the incorporation of reduced technetium in iron oxide product phases or perhaps through formation of a coating (e.g., elemental sulfur). These processes would result in the retardation of transport of technetium through the vadose zone and lowering of the concentration levels ultimately reaching groundwater. Thus, the level of risk to groundwater associated with technetium would be reduced because concentration levels and total mass of technetium ultimately reaching the groundwater would be reduced. Treatment of the vadose zone with $\mathrm{H}_{2} \mathrm{~S} /$ air would not be useful in generating a permeable reactive barrier, however, since no reductive capacity appears to result from treatment of sediment with this mixture.

Treatment with $\mathrm{H}_{2} \mathrm{~S} / \mathrm{N}_{2}$, however, may serve to stabilize technetium contamination present in the vadose zone as well as creating a permeable reactive barrier. Stabilization of existing contamination could occur owing to the reduction of technetium and the generation of products sequestering technetium. The generation of a permeable reactive barrier would result from the reductive capacity generated by reduction of the iron component present in vadose zone sediments, as indicated by the testing results presented above. The longevity of the barrier would be a function of the reducible iron content of the sediment and the rate of barrier reoxidation. Barrier reoxidation will occur in response to the flux of oxygen through the barrier, which is related to water infiltration rates and the diffusion of oxygen through the vadose zone. Thus an estimate of barrier lifetime can be obtained based on a laboratory-measured reductive capacity of treated sediment in conjunction with information regarding vadose zone characteristics at a site where gaseous treatment is to be undertaken.

\section{GASEOUS TREATMENT OF U-CONTAMINATED SEDIMENT}

Approach and testing procedure: To assess the viability of immobilizing uranium, it is necessary to address several questions. It must be determined, first, if $U$ in a sediment sample can be immobilized and reduced from the +VI to +IV oxidation state by treating with diluted hydrogen sulfide. Secondly, it is necessary to determine if $U$ will remain immobilized as the sediment is reoxidized. If $U$ is remobilized, it is necessary to determine the rate of release of $U$ during the oxidative process. Finally, it is also important to determine if $U$ can be efficiently removed from solutions that may later pass through the treated sediment. The testing approach used to answer the first question posed above involved conducting column tests with U- 
contaminated sediment, as described below. In these tests, U-contaminated sediment was treated with diluted hydrogen sulfide. Treated and untreated sediments were then leached with water and the rate of sediment reoxidation and uranium release was monitored.

The U-contaminated sediment used in these tests was provided by the $\mathrm{CH} 2 \mathrm{M}$ Hill Hanford Group and was collected from borehole BX102, located in Waste Management Area (WMA) BX Tank Farm at the Hanford Site. Sediment was taken from a composite of sleeves 78A, 78B, 78C, and $78 \mathrm{D}$ collected in the depth range of 159 to 161 below ground surface and located in the Hanford formation $\mathrm{H} 2$ Unit middle sand sequence. The total uranium content of the sediment is about 150 $\mathrm{ug} / \mathrm{g}$. The sediment contains low to non-detect concentrations of water-extractable Tc-99 $(<0.001$ $\mathrm{ug} / \mathrm{g})$ and $\mathrm{Cr}(<0.05 \mathrm{ug} / \mathrm{g})$.

The testing performed involved packing three columns with the U-contaminated sediment. The columns were $2.5 \mathrm{~cm}$ in diameter and $12 \mathrm{~cm}$ in length. One of these columns was an untreated control and was leached with aerated water at a flow rate of $0.4 \mathrm{ml} / \mathrm{min}$ (approximately one pore volume per hour) using a Gilson HPLC pump. Effluent samples were collected and analyzed for uranium by ICP-MS to determine the total leachable uranium and the rate of release of uranium from untreated sediment.

The second column was treated with hydrogen sulfide diluted in air and the third with hydrogen sulfide diluted in nitrogen through the use of flow controllers. Gas sources included cylinders of nitrogen and air and a small cylinder of $1 \%$ hydrogen sulfide in nitrogen. A 200-ppm hydrogen sulfide mixture was prepared by dilution and passed through the column being treated at a flow rate of $300 \mathrm{ml} / \mathrm{min}$. Breakthrough of hydrogen sulfide at the column outlet was monitored using an EIT hydrogen sulfide sensor. The treated columns were then leached and reoxidized with aerated water. The column effluent was passed through an oxygen electrode to obtain the oxygen content of the effluent, and samples were collected for analysis by ICP-MS. The concentration of uranium in the effluent from the treated columns was compared to that of the untreated column to determine the degree of immobilization associated with gas treatment.

Results: The release of uranium during leaching of the untreated sediment (test U2) is illustrated in Figure 7-9, where the concentration of uranium in the column effluent is plotted versus time. A concentration of $7928 \mathrm{ug} / 1$ uranium was measured in the first sample, which represented the first 0.7 column pore volumes, and gradually declined in subsequent samples. Uranium was detected in samples collected for the duration of the test, which continued for two weeks. However, a steady state concentration of about $40 \mathrm{ug} / \mathrm{L} \mathrm{U}-238$ was observed after the first six days of leaching. A cumulative amount of $9.05 \mathrm{ug}$ uranium was leached per gram of sediment. Thus, most of the uranium appears to be present in mineral phases of low solubility (the total uranium content is about $150 \mathrm{ug} / \mathrm{g}$ ).

The second column was treated with 200-ppm hydrogen sulfide in air at a gas flow rate of 300 sccm during test UA1. The breakthrough of hydrogen sulfide is illustrated in Figure 7-10 as the ratio of effluent concentration, $\mathrm{C}$, to influent concentration, $\mathrm{C}_{\mathrm{o}}$. Gas treatment was performed over period of 102.9 hours, although most of the consumption of hydrogen sulfide occurred in the first 24 hours. A cumulative amount of $8.55 \times 10^{-6}$ moles of hydrogen sulfide was consumed per gram of sediment. The treated sediment was then leached with aerated water. The oxygen concentration of the effluent from the column was similar to that of the influent, indicating that no reductive capacity was generated in the sediment as the result of $\mathrm{H}_{2} \mathrm{~S} /$ air treatment. The release of uranium from the column during the water-leaching step is shown in Figure 7-11. The concentration of technetium in the first effluent sample $(0.7$ column pore volumes $)$ was 8741 $\mathrm{ug} / \mathrm{L}$, similar to that of the first sample collected from test U2. Uranium continued to be released 
over much of the two-week duration of leaching and was at a level of about $25 \mathrm{ug} / \mathrm{L}$ by the end of the test. A cumulative amount of 7.66 uranium was leached per gram of sediment. Thus only about $15 \%$ of the uranium was immobilized as a result of gas treatment, based on the amount of uranium released in this test relative to water-leaching results obtained for the test with the untreated sediment.

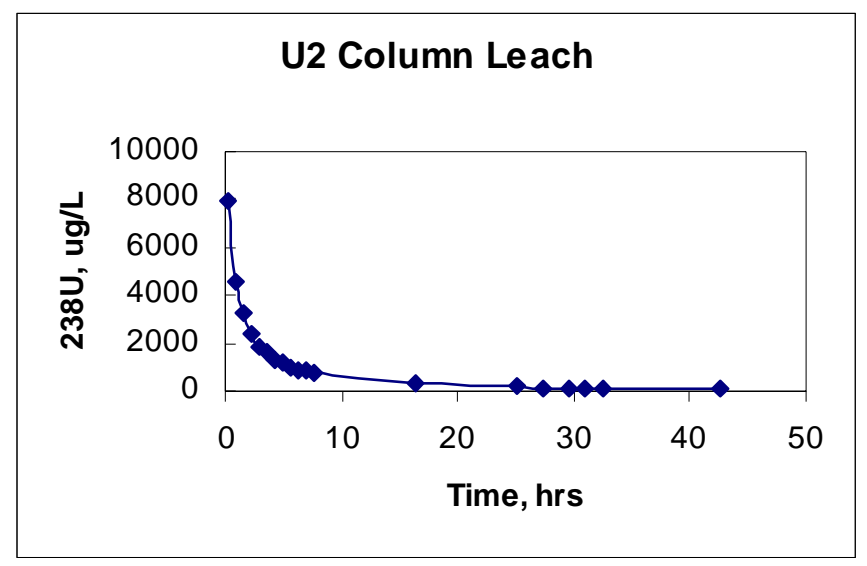

Figure 7-9. Release of U-238 from the Untreated Sediment during Water Leaching

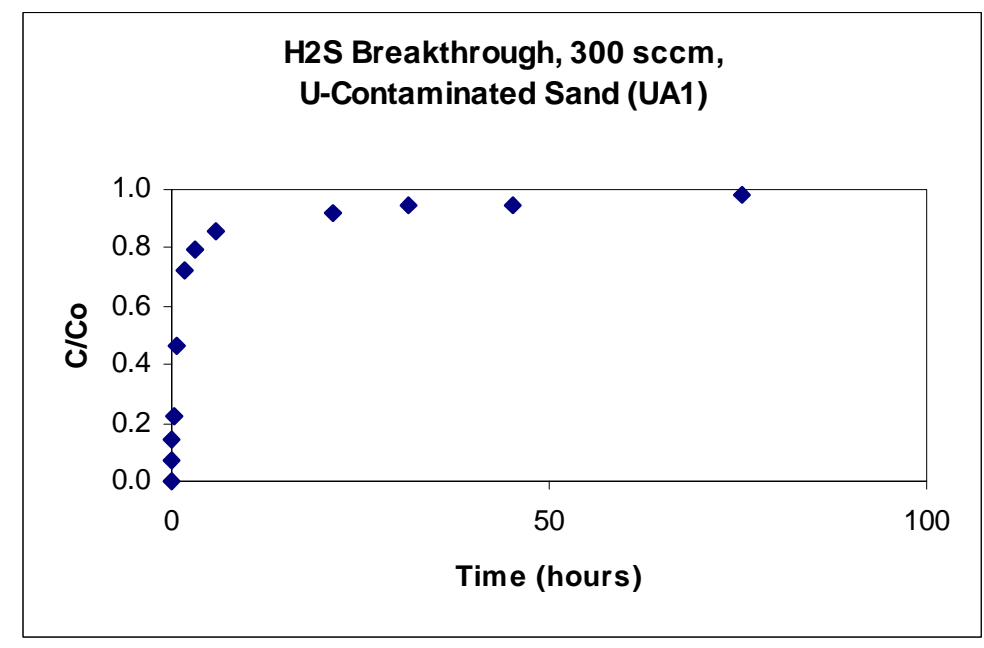

Figure 7-10. Breakthrough of Hydrogen Sulfide During Treatment Test UA1 


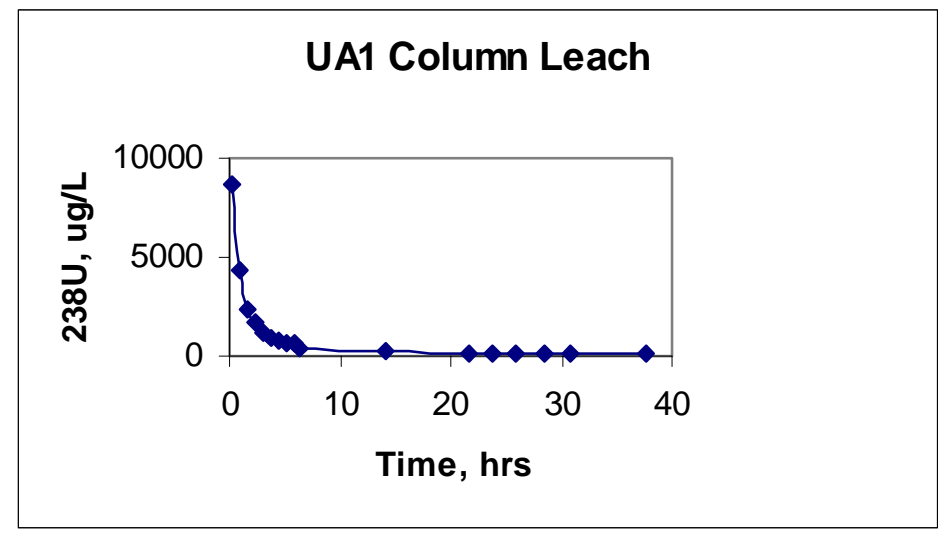

Figure 7-11. Release of U-238 During Leaching of the $\mathrm{H}_{2} \mathrm{~S} /$ Air Treated Sediment

The third column was treated with 200-ppm hydrogen sulfide in nitrogen at a gas flow rate of 300 sccm during test UN1. Gas treatment was conducted over a period of 102.3 hours in test UN1 with most of the consumption of hydrogen sulfide again taking place within the first 24 hours (Figure 7-12). A cumulative total of $1.26 \times 10^{-5}$ moles of hydrogen sulfide were consumed per gram of sediment. The reoxidation of the treated sediment is illustrated in Figure 7-13 for test UN1 and illustrates that a significant amount of reductive capacity was generated as a result of treatment of the sediment with the $\mathrm{H}_{2} \mathrm{~S} / \mathrm{N}_{2}$ gaseous mixture $\left(1.58 \times 10^{-6}\right.$ moles of $\mathrm{O}_{2}$ was consumed per gram of sediment during reoxidation). The release of uranium from the column during the water-leaching step is shown in Figure 7-14 for test UN1. The concentration of uranium in the first effluent sample ( 0.7 column pore volumes) was $2349 \mathrm{ug} / \mathrm{L}$, about $30 \%$ of that of the first sample collected from test U2. Uranium continued to be released over the two-week duration of leaching and appeared to reach a steady state level of about $40 \mathrm{ug} / \mathrm{L}$ at the end of the test. A cumulative amount of 8.24 ug of uranium was leached per gram of sediment versus 9.05 for the untreated sample. Thus less than $10 \%$ of the uranium was immobilized as a result of gas treatment, based on the amount of technetium released in this test relative to water-leaching results obtained for the test with the untreated sediment.

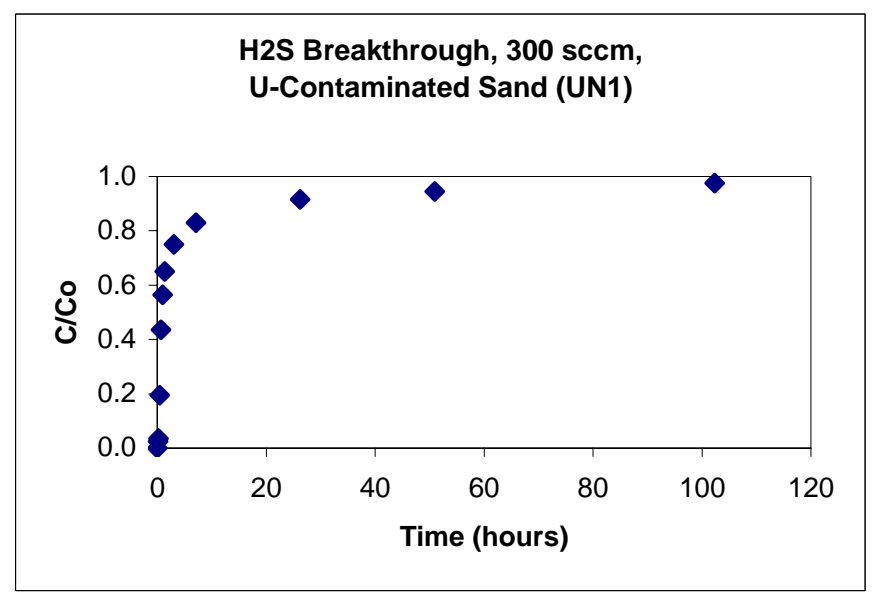

Figure 7-12. Breakthrough of Hydrogen Sulfide During Treatment Test UN1 


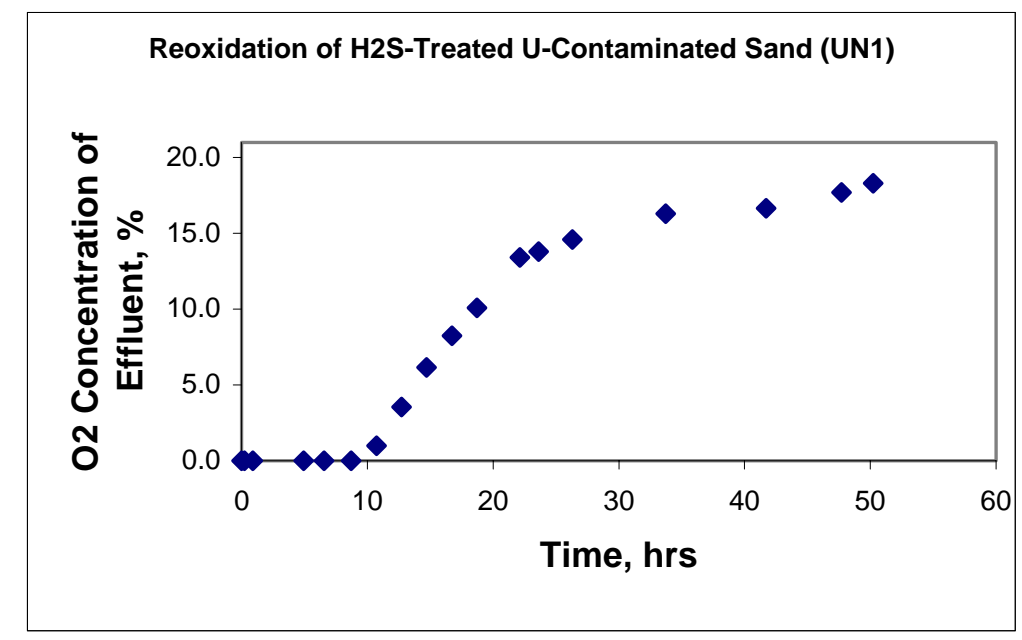

Figure 7-13. Oxygen Breakthrough During the Reoxidation Step of Test UN1

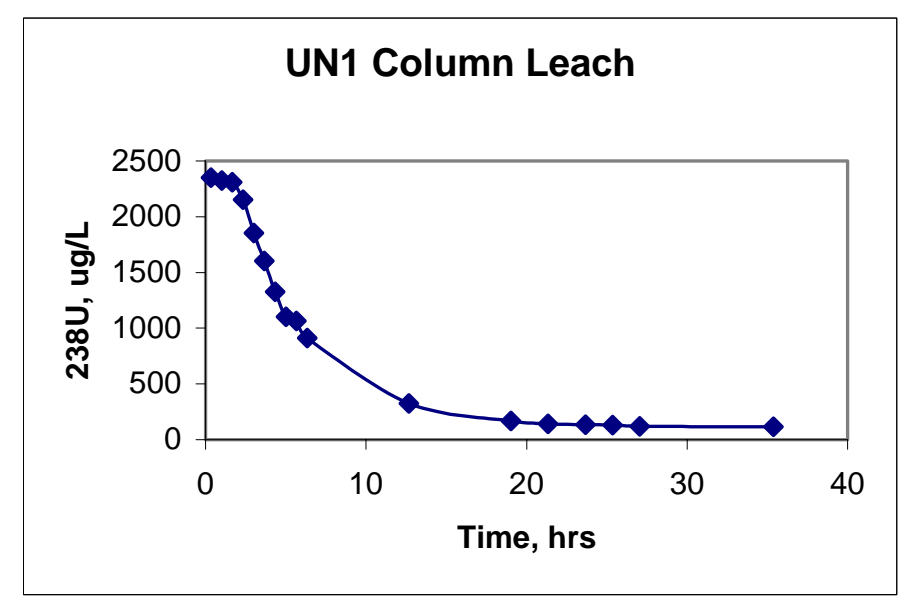

Figure 7-14. Release of U-238 During Leaching of the $\mathrm{H}_{2} \mathrm{~S} / \mathrm{N}_{2}$ Treated Sediment

Conclusions: The results obtained during this study indicate that only about $10 \%$ of the uranium present in the contaminated sediment was immobilized by treatment with diluted hydrogen sulfide. The amount released in the first 0.7 column pore volumes during water leaching of the sediment treated with $\mathrm{H}_{2} \mathrm{~S} / \mathrm{N}_{2}$ was about $30 \%$ of the untreated control, however. No reductive capacity was produced as a result of treatment of the sediment with $\mathrm{H}_{2} \mathrm{~S} /$ air. A limited amount of reductive capacity was generated by treatment with $\mathrm{H}_{2} \mathrm{~S} / \mathrm{N}_{2}$, though oxygen breakthrough resulted in only about 10 hours. The relatively low reductive capacity of the $\mathrm{H}_{2} \mathrm{~S} / \mathrm{N}_{2}$ treated sediment may be related to a low available iron content for the sediment. In addition, a relatively high flow rate $(0.4 \mathrm{ml} / \mathrm{min})$ was maintained during the reoxidation/leaching stage of test UN1 and the total reductive capacity may be larger than was measured.

It is concluded that treatment of the vadose zone with $\mathrm{H}_{2} \mathrm{~S} /$ air would probably not provide a means of stabilizing uranium contamination present beneath a tank. Treatment with $\mathrm{H}_{2} \mathrm{~S} / \mathrm{N}_{2}$, however, may serve to stabilize uranium contamination present in the vadose zone to some extent 
as well as creating a permeable reactive barrier. Stabilization of existing contamination could occur owing to the reduction of uranium and the generation of products sequestering uranium. The generation of a permeable reactive barrier would result from the reductive capacity generated by reduction of the iron component present in vadose zone sediments, as indicated by the testing results presented above. The longevity of the barrier would be a function of the reducible iron content of the sediment and the rate of barrier reoxidation. Barrier reoxidation will occur in response to the flux of oxygen through the barrier, which is related to water infiltration rates and the diffusion of oxygen through the vadose zone. Thus an estimate of barrier lifetime can be obtained based on a laboratory-measured reductive capacity of treated sediment in conjunction with information regarding vadose zone characteristics at a site where gaseous treatment is to be undertaken.

\section{EVALUATION OF THE ISGR PRB CONCEPT FOR IMMOBILIZATION OF CHROMIUM, TECHNETIUM, AND URANIUM IN THE VADOSE ZONE}

Approach and testing procedure: The uncontaminated sediment used in these tests was provided by the CH2M Hill Hanford Group and is referred to as the "borehole fine sand". It was collected during the drilling of well 299-W22-50, located just southeast of the Waste Management Area (WMA) SX Tank Farm in the 200 West Area of the Hanford Site (Serne et al. 2002). The sediment was collected in the depth range of 62.5 to 97 feet below ground surface in Hanford formation sand.

The testing performed involved packing two columns with the uncontaminated sediment. The columns were $2.5 \mathrm{~cm}$ in diameter and $12 \mathrm{~cm}$ in length. One of these columns was used as an untreated control, while the second column was treated with a diluted hydrogen sulfide gas mixture. Gas sources included a cylinder of nitrogen and a small cylinder of $1 \%$ hydrogen sulfide in nitrogen. A 200-ppm hydrogen sulfide mixture was prepared by dilution with flow controllers and passed through the column being treated at a flow rate of $300 \mathrm{ml} / \mathrm{min}$. Breakthrough of hydrogen sulfide at the column outlet was monitored using an EIT hydrogen sulfide sensor.

An aerated solution $\left(21.5 \% \mathrm{O}_{2}\right)$ was prepared containing $1 \mathrm{ppm}$ of $\mathrm{Cr}(\mathrm{VI}), 2.4 \mathrm{ppm}$ of $\mathrm{Tc}(\mathrm{VI})$, and $0.9 \mathrm{ppm}$ of $\mathrm{U}(\mathrm{VI})$ at a $\mathrm{pH}$ of 3 . This solution was pumped at a flow rate of $0.4 \mathrm{ml} / \mathrm{min}$ (approximately one column pore volume per hour) through both columns using a syringe pump for about six days (untreated test) and ten days (treated test). The column effluent was passed through an oxygen electrode to obtain the oxygen content of the effluent. Effluent samples were collected and analyzed for Tc-99 and U-238 by ICP-MS, Cr(total) by ICP-OES, and Cr(VI) by spectrophotometry using EPA Method 7196 (EPA 1992). The concentrations of chromium, technetium, and uranium in the effluent from the treated column were compared to that of the untreated column to determine the degree of immobilization associated with gas treatment.

Results: The concentration of $\mathrm{Cr}$ (total), Tc-99, and U-238 in the effluent from the column containing the untreated sediment (test SSC1) is illustrated in Figure 7-15, where the concentration of these constituents is plotted versus time over the period of the test (155 hours). The concentration of $\mathrm{Cr}$ in the untreated column effluent ranged from 732 to $1002 \mathrm{ug} / \mathrm{L}$, which was similar to the influent concentration $(1 \mathrm{ppm}$ or $1000 \mathrm{ug} / \mathrm{L})$. The samples that were analyzed for $\mathrm{Cr}(\mathrm{VI})$ also yielded values in the range from 890 to $980 \mathrm{ug} / \mathrm{L}$, indicating that essentially all of the chromium in the influent and effluent samples was in the hexavalent oxidation state. The 
concentration of Tc-99 in the column effluent was also similar to that of the influent $(2400 \mathrm{ug} / \mathrm{L}$ Tc-99) throughout the test, indicating no adsorption or precipitation processes were occurring. The concentration of U-238 in the untreated column effluent was initially low, $<20 \mathrm{ug} / \mathrm{L}$, but increased to about $300 \mathrm{ug} / \mathrm{L}$ after several weeks (versus about $900 \mathrm{ug} / \mathrm{L} \mathrm{U}-238$ in the influent). It is suggested that $\mathrm{U}(\mathrm{VI})$ may have precipitated as a carbonate phase in the column. The $\mathrm{pH}$ of the column effluent was near neutral through most of the experiment, due to the high buffering capacity of the sediment, but decreased slowly with time.

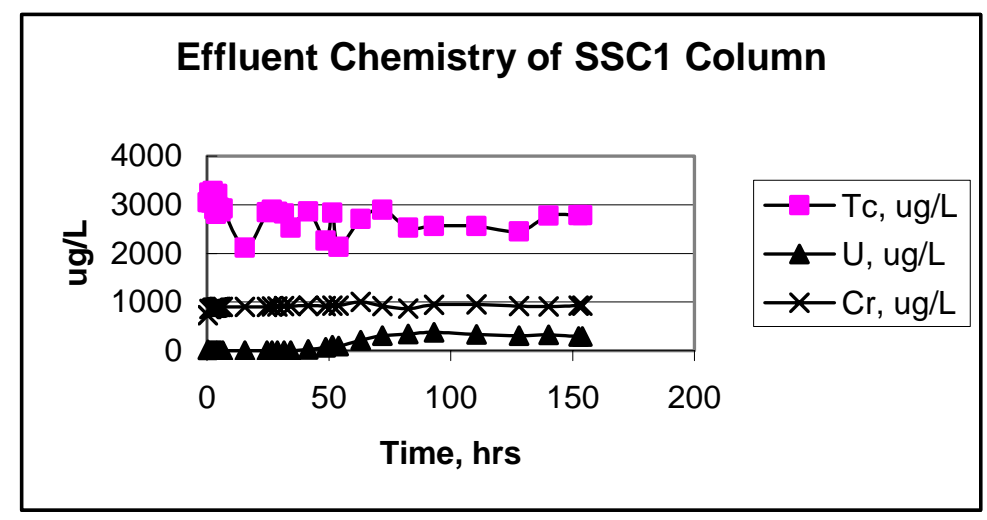

Figure 7-15. Concentration of $\mathrm{Cr}$ (total), Tc-99, and U-238 in the Effluent of the Untreated Sediment Column

The second column was treated with 200-ppm hydrogen sulfide in nitrogen at a gas flow rate of $300 \mathrm{sccm}$ (test SSC2). The breakthrough of hydrogen sulfide is illustrated in Figure 7-16 as the ratio of effluent concentration, $\mathrm{C}$, to influent concentration, $\mathrm{C}_{\mathrm{o}}$. Gas treatment was performed over a period of 102.3 hours, although most of the consumption of hydrogen sulfide occurred in the first 24 hours. A cumulative amount of $2.70 \times 10^{-3}$ moles of hydrogen sulfide was consumed per gram of sediment.

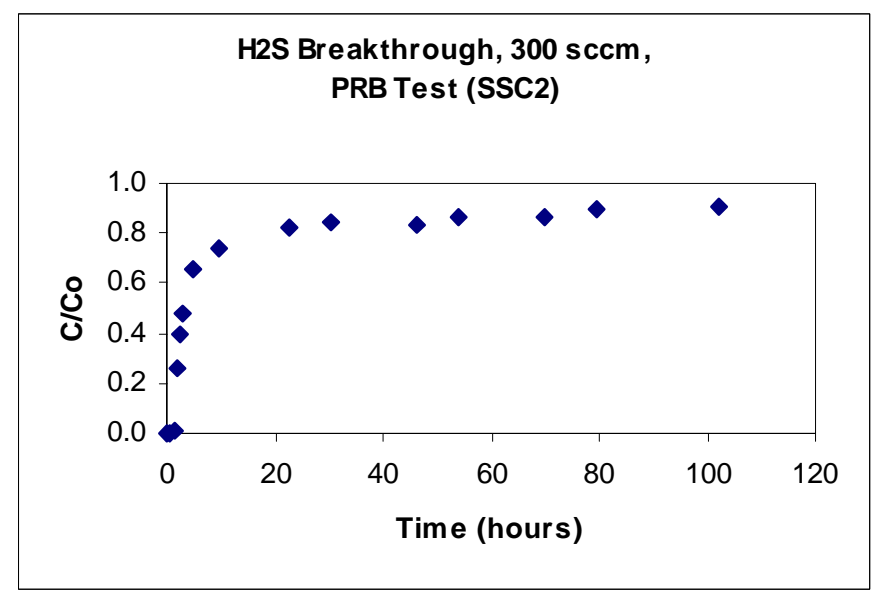

Figure 7-16. Breakthrough of Hydrogen Sulfide During Treatment Test SSC2 
The reoxidation of the treated sediment by the aerated solution is illustrated in Figure 7-17 for test SSC2 and illustrates that a significant amount of reductive capacity was generated as a result of treatment of the sediment with the $\mathrm{H}_{2} \mathrm{~S} / \mathrm{N}_{2}$ gaseous mixture.

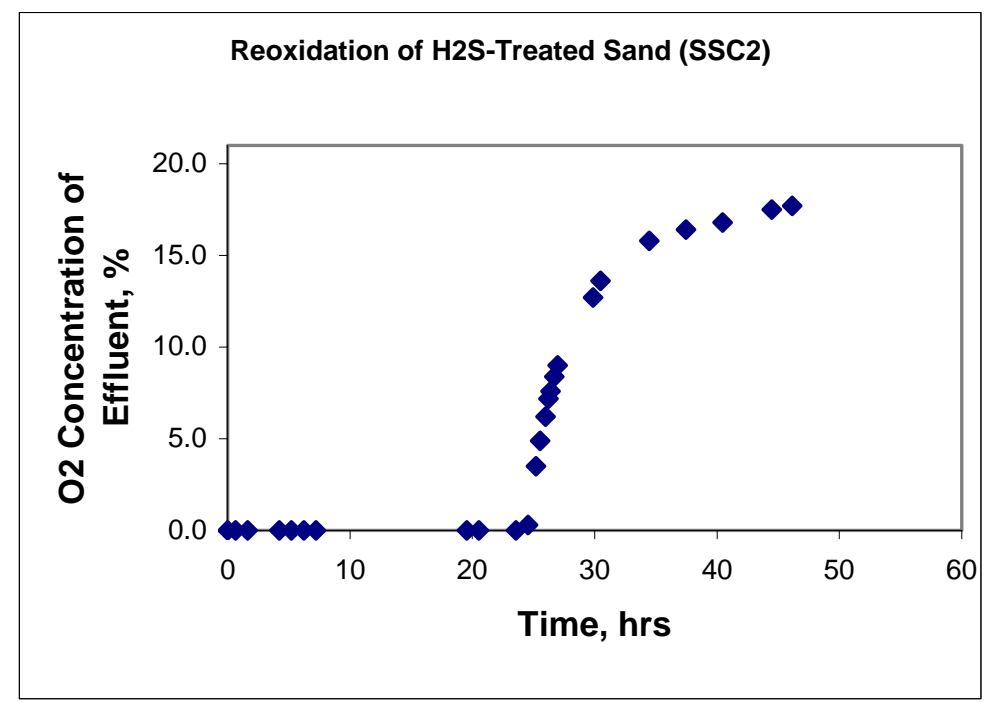

Figure 7-17. Oxygen Breakthrough During the Reoxidation Step of Test SSC2.

The composition of the column effluent is presented in Figure 7-18 for the first 60 hours of the period when the aerated water was pumped through the treated column in test SSC2 (total period $=235$ hours). Note that the concentration of $\mathrm{Cr}(\mathrm{VI})$ and $\mathrm{Cr}$ (total) was low during the period when the system was reduced (prior to 25 hours or about 25 column pore volumes) but increased subsequent to reoxidation (compare figures 7-17 and 6-18). Thus $\operatorname{Cr}(\mathrm{VI})$ was reduced and precipitated while the system was depleted of oxygen, but was unaffected once the system became oxygenated. The concentration of technetium in the effluent was only $107 \mathrm{ug} / \mathrm{L}$ in the first sample at 0.7 hours but increased as reoxidation progressed and was approximately equal in concentration to the influent $(2400 \mathrm{ug} / \mathrm{L})$ at 25 hours. Uranium concentration trends in the column effluents of both tests were similar.

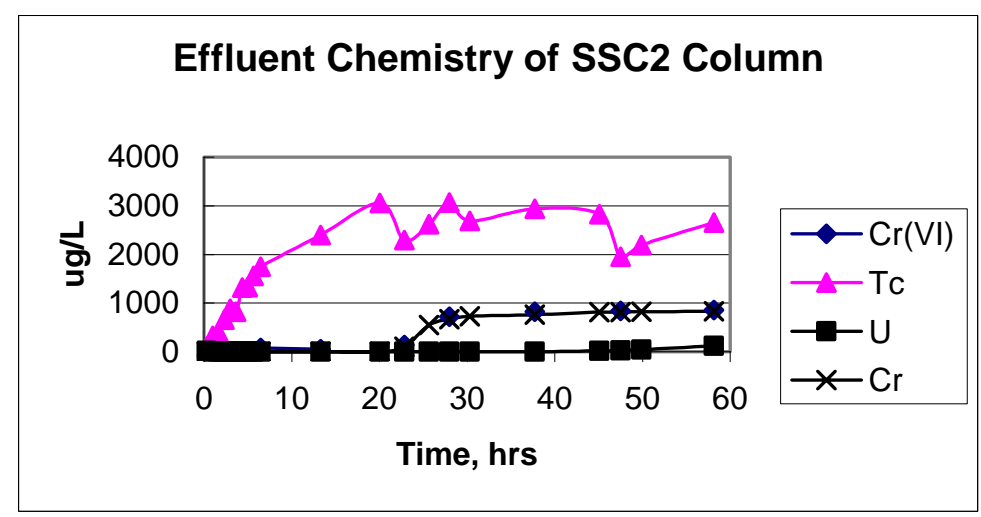

Figure 7-18. Concentrations of $\mathrm{Cr}(\mathrm{VI}), \mathrm{Cr}$ (total), Tc-99, and U-238 in the Effluent of the Treated Sediment Column 
Conclusions: The results obtained during this study suggests that a PRB generated by treatment with an $\mathrm{H}_{2} \mathrm{~S} / \mathrm{N}_{2}$ gas mixture would be very effective at immobilizing $\mathrm{Cr}(\mathrm{VI})$ present in solutions released into the vadose zone. This results from the ease with which $\mathrm{Cr}(\mathrm{VI})$ is reduced to $\mathrm{Cr}(\mathrm{III})$, which is essentially insoluble. Once reduced, chromium is not readily reoxidized or remobilized. However, the barrier would no longer be effective for reducing additional $\mathrm{Cr}(\mathrm{VI})$ once the sediment is reoxidized. The barrier lifetime is estimated to be hundreds to several thousands of years depending on sediment iron content, barrier thickness, and transport rates of oxygen through the vadose zone.

These results also indicate that limited immobilization can be achieved for Tc(VII) using an ISGR vadose zone PRB. It appears the degree of immobilization is high when the reductive capacity of the treated sediment is great, but decreases as the sediment is reoxidized. This is related to the lower oxidation potential of the $\mathrm{Tc}(\mathrm{VII}) / \mathrm{Tc}(\mathrm{IV})$ couple relative to that of chromium. It is also important to note that the Tc couple is reversible under natural conditions and thus Tc could be remobilized from the barrier once it is reoxidized. This suggests that an ISGR PRB could be useful as a short term measure for capturing Tc(VII) that might be released during waste tank closure operations. The long-term viability of the barrier, however, is difficult to assess. It is possible that a mid to long-term barrier useable lifetime could be achieved if the barrier is periodically recharged by treatment with additional $\mathrm{H}_{2} \mathrm{~S}$.

Uranium was immobilized to a similar extent in both the untreated and treated column tests. The mechanism responsible for the relatively low mobility of U(VI) in these tests is not clear. It is suggested that uranium may have precipitated in the columns as a carbonate or hydroxide phase. Further work is obviously needed to assess the mobility of uranium in terms of the application proposed here.

The results of the proof-of-principle tests performed during this study thus suggest that an ISGR vadose zone PRB could be very effective in immobilizing chromium and, to a lesser extent, technetium. It should be noted that reduction processes are often relatively slow, so a better understanding of barrier effectiveness could be developed if information is gathered regarding the kinetics of the reduction processes involved. In particular, the flow rates utilized in these experiments were relatively high. Performance of additional tests under lower flow rates and a better knowledge of the reaction kinetics involved in immobilization could greatly help in assessing the performance of an ISGR PRB. This is particularly important for assessing the potential for immobilizing technetium in the vadose zone. Assessment of the mobility of uranium with respect to the barrier appears to require a better knowledge of the oxidation-reduction processes and aqueous and solid species involved.

\section{EVALUATION OF THE POTENTIAL FOR LONG-TERM CHROMIUM REOXIDATION IN $\underline{\mathrm{AN} \mathrm{H}_{2}} \underline{\underline{\mathrm{S}} \text {-TREATED SEDIMENT }}$}

Hexavalent chromium in soil is readily reduced to the trivalent oxidation state by reaction with hydrogen sulfide. It is generally regarded as stable in this form in the natural environment and relatively insoluble. In this study, a long-term test has been conducted to provide information regarding whether or not reoxidation of chromium can occur after $\operatorname{Cr}(\mathrm{VI})$ is reduced in a contaminated sediment by gas treatment. 
In this test, a chromate-contaminated sediment sample collected from the $100 \mathrm{~K}$ Area at the Hanford Site was treated with diluted hydrogen sulfide gas and then exposed to air under humid conditions. Analysis of the $\mathrm{Cr}(\mathrm{VI})$ content of sediment samples was conducted by water leaching for one hour and measurement of $\mathrm{Cr}(\mathrm{VI})$ in the leachate by the diphenylcarbazide spectrophotometric method. The untreated sample contains about $110 \mathrm{mg} / \mathrm{kg}$ leachable $\mathrm{Cr}(\mathrm{VI})$, while the treated sediment was determined to contain $3.3 \mathrm{mg} / \mathrm{kg} \mathrm{Cr}(\mathrm{VI})$. Characterization of $\mathrm{Cr}(\mathrm{VI})$ sediment samples collected in the 100D Area at Hanford suggests that a portion of the $\mathrm{Cr}(\mathrm{VI})$ in Hanford Site contaminated sediments may be coprecipitated or sequestered in calcite cement and also as barium chromate. The results of the gas treatment test indicates that immobilization of $\mathrm{Cr}(\mathrm{VI})$ to $\mathrm{Cr}(\mathrm{III})$ is essentially quantitative despite the fact that a portion of the chromate may be contained in solid waste phases.

The treated sample was exposed to air under humid conditions and sampled periodically and analyzed to determine if the concentration of $\mathrm{Cr}(\mathrm{VI})$ changes with time. Results obtained during 835 days of testing are shown in Figure 7-19. Levels of hexavalent chromium in the sediment dropped from about $3.3 \mathrm{mg} / \mathrm{kg}$ in the first year to a level ranging from 2.1 to $2.6 \mathrm{mg} / \mathrm{kg}$. Samples collected at 492,653 , and 835 days all contained about $2.1 \mathrm{mg} / \mathrm{kg}$, suggesting a steady state concentration was attained. Data obtained from this test, which exceeded two years in duration, thus suggests that reduced chromium will not reoxidize to the hexavalent state.

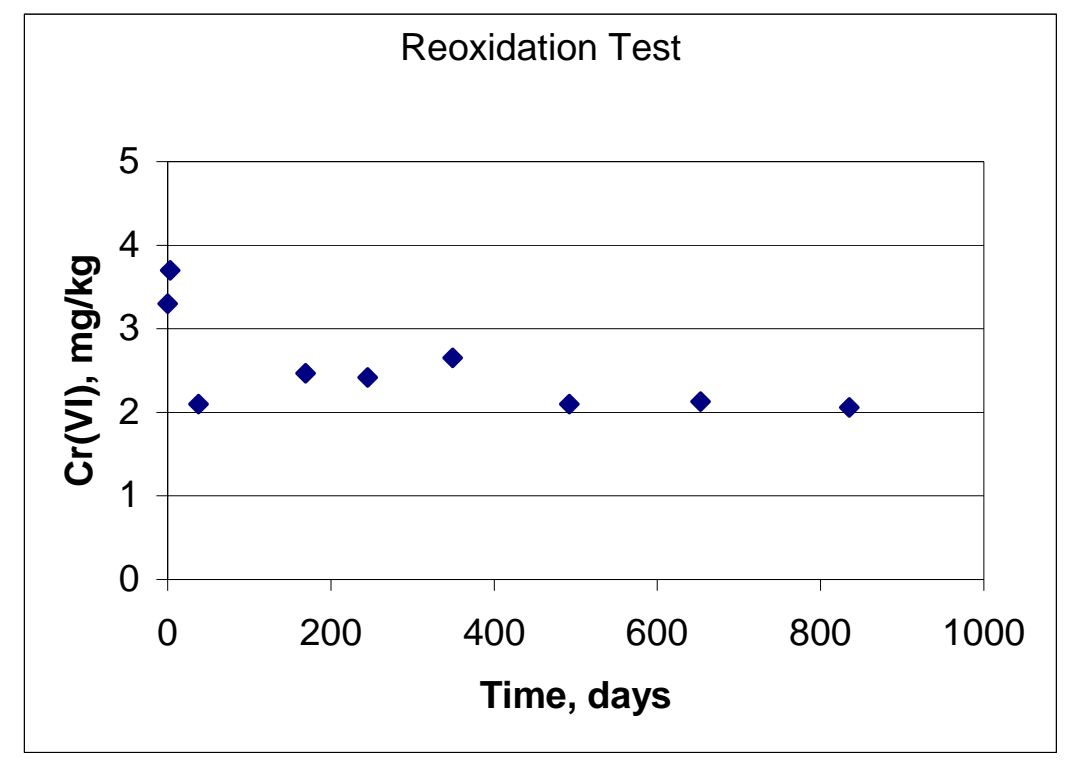

Figure 7-19. Leachable $\mathrm{Cr}(\mathrm{VI})$ from a $\mathrm{H}_{2} \mathrm{~S}$-treated soil sample as a function of time. The sample contained about $110 \mathrm{mg} / \mathrm{kg}$ of leachable $\mathrm{Cr}(\mathrm{VI})$ prior to the $\mathrm{H}_{2} \mathrm{~S}$ treatment. 


\section{Information Access}

Journal papers:

Kim, C.; Zhou, Q.; Deng, B.; Thornton, E. C.; Xu, H. (2001) "Chromium (VI) Reduction by Hydrogen Sulfide in Aqueous Media: Stoichiometry and Kinetics ", Environ. Sci. Technol, Vol. 35, 2219 - 2225.

Cantrell, K. J.; abusaki, S. B.; Engelhard, M. H.; Mitroshkov, A. H.; Thornton, E. C. "Oxidation of $\mathrm{H}_{2} \mathrm{~S}$ by Iron Oxides in the Vadose Zone”, Environ. Sci. Technol. (2003), 37(10), $2192-$ 2199

Hua, B.; Deng, B. (2003) "Influences of Water Vapor on Cr(VI) Reduction by Gaseous Hydrogen Sulfide”, Environ. Sci. Technol. Vol. 37., 4771-4777.

Deng, B.; Lan, L.; Houston K.; Brady, P. (2003) "Effects of clay minerals on Cr(VI) reduction by organic compounds", Environmental Monitoring and Assessment, 84: 5-18.

Kim, C.; Lan, Y.; and Deng, B. (2003) "Goethite effect on the Cr(VI) reduction by hydrogen sulfide under anaerobic condition”, Environ. Sci. Technol. (In Review)

Hua, B, Deng, B; Thornton, E.; Yang, J. (2003) "Chromium Speciation in Hanford Site Soils: a Selective Extraction and Coprecipitation Study", Journal of Environmental Quality (In Review)

Lan Y.; Kim, C.; Deng, B.; Thornton, E. C.; Xu, H. "Chromium(VI) Reduction by Sulfide under Anaerobic Conditions: Catalysis by Elemental Sulfur Product”, (Water Research, in preparation).

Lan Y.; Kim, C.; Deng, B.; Thornton, E. C "Influence of mineral surfaces on Chromium (VI) Reduction by Sulfide under Anaerobic Conditions", (Water Research, in preparation).

\section{Presentations:}

Lan, Y.; Kim C.; Deng, B.; and Thornton, E. C. (2004) "Influence of illite and kaolin on chromium(VI) reduction by sulfide" $227^{\text {th }}$ ACS National Meeting, Anaheim, CA, March 28 - April 1, 2004.

Youxian Wu and Baolin Deng (2004) "Effects of FeS on chromium oxidation mediated by manganese oxidizers", $227^{\text {th }}$ ACS National Meeting, Anaheim, CA, March 28 - April 1, 2004.

Hua, B. and Deng, B. (2003) "Influences of Water Vapor on Cr(VI) Reduction by Gaseous Hydrogen Sulfide", Symposia papers to be presented before the Division of Environmental Chemistry, $226^{\text {th }}$ ACS National Meeting, New York, NY September 7-11, 2003. Vol. 43, No. 2.

Hua, B, Deng, B; Thornton, E.; Yang, J. (2003) "Chromium Speciation in Hanford Site Soils: a Selective Extraction and Coprecipitation Study ", To be presented at the $226^{\text {th }}$ ACS National Meeting, New York, September 2003.

$\mathrm{Wu}$, Y. and Deng, B. (2003) "Chromium(III) oxidation coupled with microbially-mediated oxidation of manganese(II)". 103rd ASM General Meeting, Washington, DC, May 2003.

Wu, Y. and Deng, B. (2003) "Chromium(III) oxidation in the presence of Pseudomonas putida". $225^{\text {th }}$ ACS national meeting, New Orleans, March 2003.

Deng, B. (2003) "Chromium (VI) Reduction by Hydrogen Sulfide: Kinetics, Mechanism, and Application to Site Remediation", (Invited seminar), Washington University (St Louis).

Hua, B. and Deng B. (2002) "Chromate coprecipitates with calcium carbonate", $7^{\text {th }}$ Annual MidAmerican Environmental Engineering Conference, Rolla, MO, (October $25-26^{\text {th }}$ ) 
Deng B., (2002) “Groundwater and Soil Remediation through Redox Reactions”, (Invited seminar), Missouri UM-Rolla.

Deng, B. (2002) "Chromium (VI) Reduction: Kinetics, Mechanism, and Applications to Site Remediation”, (Invited seminar), School of Natural Resources and Environmental Sciences, Wuhan University, Wuhan, China.

Cantrell, K. J.; Yabusaki, S. B.; Mitroshkov, A. V.; Amonette, J. E.; Thornton, E. C. (2001) "H2S Oxidation by Iron Oxide: Experimental Determination of Mechanisms and Rates for Modeling Gas Phase Treatment of the Vadose Zone", Platform Presentation at the $222^{\text {th }}$ ACS National Meeting, Chicago, IL, August 26-30, 2001

Deng, B.; Kim, C.; Lan, Y. and Thornton, E. C. (2001) "Chromium (VI) reduction by hydrogen sulfide in aquatic systems", Platform Presentation at the $222^{\text {th }}$ ACS National Meeting, Chicago, IL, August 26-30, 2001.

Thornton, E. C.; Deng, B.; Cantrell, K. J.; Olsen, K. B.; Amonette, J. E.; Kim, C., Lan, Y. (2001) "Interfacial Reduction-Oxidation Mechanisms Governing Fate and Transport of Contaminants in the Vadose Zone", Poster Presentation at the $222^{\text {th }}$ ACS National Meeting, Chicago, IL, August 26-30, 2001.

Deng, B. (2001) "Redox Processes in the Aquatic Environment: Applications to Site Remediation", EMSL, Pacific Northwest National Laboratory, June 12, 2001.

Deng, B. Kim, C.; Lan, Y.; Thornton, E. C. (2001) "Kinetics Of Cr(VI) Reduction By Hydrogen Sulfide In Aquatic Systems: Direct And Catalyzed Reactions", (Oral Presentation), $11^{\text {th }}$ Goldschmidt Conference, Hot Spring, Virginia, May 20 - 24, 2001

Kim, C.; Lan, Y.; Deng, B.; Thornton, E. C. (2001) "Catalytic Effects of Goethite on Chromium(VI) Reduction by Hydrogen Sulfide in Anaerobic Aqueous Phase", (Oral Presentation), The $221^{\text {th }}$ ACS National Meeting, San Diego, April 1-5, 2001.

Lan, Y.; Kim, C.; Deng, B.; Thornton, E. C. (2001) "Chromium(VI) Reduction by Sulfide under Anaerobic Conditions: Catalysis of Elemental Sulfur Product", (Oral Presentation), The $221^{\text {th }}$ ACS National Meeting, San Diego, April 1-5, 2001.

Zhou, Q.; Kim, C.; Deng, B.; Thornton, E. C. (2000) "Effects of Mineral Surfaces on Chromium(VI) Reduction by Hydrogen Sulfide", Preprints of the Extended Abstracts, Division of the Environmental Chemistry, The $220^{\text {th }}$ ACS National Meeting, Washington D.C. August 20-24, 2000., pp $592-593$.

Kim, C.; Zhou, Q.; Deng, B.; Thornton, E. C. (2000) "Chromium (VI) Reduction by Hydrogen Sulfide in the Aqueous Phase" Preprints of the Extended Abstracts, Division of the Environmental Chemistry, The $220^{\text {th }}$ ACS National Meeting, Washington D.C. August 2024, 2000., pp 669-670.

Thornton, E. C.; Cantrell, K. L.; Olsen, K. B.; Amonette, J. E.; Yabusaki, S. B.; Deng, B. (1999) "Laboratory Evaluation of Surface-Catalyzed Reduction Mechanisms in the $\mathrm{H}_{2} \mathrm{~S}_{-} \mathrm{O}_{2}$ $\mathrm{Cr}(\mathrm{VI})$-Sediment System" (Oral Presentation), Geological Society of America Annual Meeting, Denver, CO. 


\section{References}

Allen, H. E.; Fu, G.; Deng, B. Environmental Toxicology and Chmeistry.1993, 12, 1441-1453. Amonette, J. E.; Workman, A.J.;Kennedy, D. W.;Fruchter, J. S.;Gorby, Y. A. Environmental Science \& Technology 2000, 34, 4606-4613.

Anderson, L. D.; Kent, K. B.; Davis, J. A. Environ. Sci. Technol. 1994, 28, 178-185.

APHA; AWWA; WPCF Standard Methods for the Examination of Water and Wastewater, 20 ed.; American Public Health Association: Washington, D. C., 1998.

ASME (1999) Technical Peer Review Report in Assessment of Technologies Supported by the Office of Science and Technology, Department of Energy, The American Society of Mechanical Engineers.

Baldea, I. Chemia, 1989, 34(1), 80-8.

Bartlett, R. J.; Kimble, J. M. J. Environ. Qual. 1976, 5, 383-386.

Berner R. A. Am. J. Sci. 1967, 265, 773.

Blowes, D. W.; Ptacek, C. J.; Jambor, J. L. Environ. Sci. Technol. 1997, 31, 3348-3357.

Buerge, I. J.; Hug, S. J. Environ. Sci. Technol. 1997, 31, 1426-1432.

Buerge, I. J.; Hug, S. J. Environ. Sci. Technol. 1998, 32, 2092-2099.

Buerge, I. J.; Hug, S. J. Environ. Sci. Technol. 1999, 33, 4285-4291.

Chen, K. Y.; Morris, J. C. Environ. Sci. Technol. 1972, 6, 529-537.

Chilakapati, A. 1995, RAFT A Simulator for ReActive Flow and Transport of Groundwater Contaminants. PNL-10636, Pacific Northwest Laboratory, Richland, Washington.

Chilakapati, A. Ginn, T., Szecsody J. 1998, Water Resour. Res., 34(7), 1767-1780.

Chilakapati, A. Yabusaki, S., Szecsody J., MacEvoy, W. 2000, J. Contamin. Hydrol., 43(3-4), 303-325.

Cline, J. D.; Richards, F. A. Environ. Sci. Technol. 1969, 3, 838-843.

Connett, P. H.; Wetterhahn, K. E. J. Am. Chem. Soc. 1985, 107, 4282-4288.

Costa, M. Crit. Rev. Toxicol. 1997, 27, 431-442.

Davydov, A. D.; Chuang, D. T.; Sanger, A. R. J. Phys. Chem. 1998, 102, 4745-4752.

Dean, J. A. Lange's handbook of chemistry; $14^{\text {th }}$ ed.; McGraw-Hill: New York, 1992.

Deng, B. Chromium(VI) reduction by naturally-occurring organic compounds-Kinetics of direct and surface catalyzed reactions, Ph.D. thesis, The Johns Hopkins University, 1995.

Deng, B.; Stone, A. T. Environ. Sci. Technol. 1996, 30, 2484-2494.

Deng, B.; Stone, A. T. Environ. Sci. Technol. 1996, 30, 463-472.

Dixon, D. A.; Dasgupta, T. P.; Sadler, N. P. J. Chem. Soc. Dalton 1995, 13, 2267-2271.

Eary, L. E.; Rai, D. Am. J. Sci. 1989, 289, 180-213.

Eary, L. E.; Rai, D. Environ. Sci. Technol. 1988, 22, 972-977.

Eary, L. E.; Rai, D. Soil Sci. Soc. Amer. J. 1991, 55, 676-683.

Elovitz, M. S.; Fish, W. Environ. Sci. Technol, 1994, 28, 2161-2169.

Fendorf, S. E.; Li, G. Environ. Sci. Technol. 1996, 30, 1614-1617.

Fruchter. J. Environ. Sci. Technol. 2002, 36, 464A-472A.

Fude, L.; Harris, B.; Urrutia, M. M.; Beveridge, T. J. Appl. Environ. Microbiol. 1994, 60, 15251531.

Goodgame, D. M. L.; Hayman, P. B. Inorganica Chimica Acta 1984, 91, 113-115.

Hallberg, R. O. Neues Jahrb. Mineralogie 1972, 11, 481.

Heron, G.; Crouzet C.; Bourg, A. C. M.; Christensen, T. H. Environ. Sci. Technol. 1994, 28, 1698.

Ilton, E. S.; Veblen, D. R. Geochim. Cosmochim. Acta 1994, 58, 2777-2788.

Ilton, E. S.; Veblen, D. R.; Moses, C. O.; Raebur, S. P. Geochim. Cosmochim. Acta 1997, 61, 3543-3563.

James, B. R. J. Environ. Qual. 1994, 23, 227-233. 
James, B. R.; Petura, J. C., Vitale, R. J.; Mussoline, G. R. Environ. Sci. Technol. 1995, 29, $2377-$ 2381.

James, B.; Bartlett, R. J. J. Environ. Qual. 1983, 12, 177-181.

Jardine, P. M.; Fendorf, S. E.; Mayes, M. A.; Larsen, I. L.; Brooks, S. C.; Bailey, W. B. Environ. Sci. Technol. 1999, 33, 2939-2944.

Kattner, J. E.; Samuels, A.; Wendt, R. P. J. Petr. Technol. 1988-(Sept), 1237.

Katz, S. A.; Salem, H. The biological and environmental chemistry of chromium, VCH: New York, NY, 1994.

Kim, C.; Zhou, Q.; Deng, B.; Thornton, E.C.; Xu, H. Environ. Sci. Technol., 2001, 35, 22192225.

Kohl, A. L.; Riesefedl, F. S. Gas Purification; Gulf: Houston, 1985: Chapter 4.

Lan, Y.; Kim, C.; Deng, B.; Thornton, E.C. Preprints of Extended Abstract, Environmental Chemistry Division, the $221^{\text {th }}$ ACS National Meeting, 2001, San Diego, CA.

Lennie, A. R.; Redfern, R. A. T.; Champness, P. E.; Stoddart, C. P.; Schofield, P. F.; Vaughan, D. J. Am. Mineral. 1997, 82, 302.

Lennie, A. R.; Vaughan, D. J. In Mineral Spectroscopy: A Tribute to Roger G. Burns; Dyar, M. D.; McCammon, C.; Schaefer, M. W., Eds.; Special Publication No. 5, The Geochemical Society, 1996; p 117.

Levenspiel, O. 1998, Chemical Reaction Engineering, $3^{\text {rd }}$ Ed., John Wiley \& Sons, New York, NY.

Levine, I. N. Physical chemistry; McGraw-Hill: New York, 1978.

Lide, D. L. Handbook of Chemistry and Physics; $73^{\text {rd }}$ ed.; CRC press: Boca Raton, 1992-1993.

Loeppert, R. L.; Inskeep, W. P. In Methods of Soil Analysis, Part 3 - Chemical Methods; Soil Science Society of America: Madison, WI, 1996; pp 639-664.

Lovley, D.R.; Philips, E. J. P. Appl. And Environ. Microbiol 1986, 52, 751-757.

Luther, G. W. III Geochim. Cosmochim. Acta 1991, 55, 2839.

Morse, J. W.; Millero, F. J.; Cornell, J. C.; Rickard, D. Earth Sci. Rev. 1987,24,1.

Nriagu, J. O.; Nieboer E. Chromium in the Natural and Human Environments, Wiley \& Sons: New York, NY, 1988.

O’Brien, D. J.; Birkner, F. G. Environ. Sci. Technol. 1977, 11, 1114-1120.

Patterson, R. R and Fendorf, S. Environ. Sci. Technol 1997, 31, 2039-2044.

Perry R. H. and Chilton C. H. Chemical Engineer's Handbook 1973 Fifth Ed. Pg. 4-33, McGrawHill, New York.

Peterson, M. L.; Brown, G. E.; Parks, G. A. J. Phys. IV 1997, 7(C2), 781-783.

Pettine, M.; Barra, I.; Campanella, L.; Millero, F. J. Wat. Res. 1998, 32(9), 2807-2813.

Pettine, M.; D'Ottone, L.; Campanella, L.; Millero, F. J.; Passino, R. Geochimica et Cosmochimica Acta 1998, 62, 1509-1519.

Pettine, M.; Millero, F. J.; Passino, R. Marine Chemistry 1994, 46, 335-344.

Poeter E. P. and Hill M. C. Computers and Geosciences 1999, 25(4), 457-462.

Pratt, A. R.; Blowes, D. W.; Ptacek, C. J. Environ. Sci. Technol. 1997, 31, 2492-2498.

Rai, D.; Sass, B. M.; Moore D. A. Inorg. Chem. 1987, 26, 345-349. Chromium(III) hydrolysis constants and solubility of Chromium(III) hydroxide.

Rethmeier, J.; Rabenstein, A.; Langer, M.; Fischer, U. J. Chrom. A 1997, 760, 295-302.

Rickard, D. T. Am. J. Sci. 1975, 275, 636.

Saleh, F. Y.; Parkerton, T. F.; Lewis, R. V.; Huang, J. H.; Dickson, K. L. Sci. Total Environ. $1989,86,25-41$.

Schroeder, D. C.; Lee, G. F. Water, Air, Soil Pollut. 1975, 4, 355-365.

Seaman, J. C.; Bertsch, P. M.; Schwallie, L. Environ. Sci. Technol. 1999, 33, 938-944.

Sedlak, D. L.; Chan, P. G. Geochim. Cosmochim. Acta 1997, 61, 2185-2192.

Serne RJ, HT Schaef, BN Bjornstad, BA Williams, DC Lanigan, DG Horton, RE Clayton, VL LeGore, MJ O'Hara, CF Brown, KE Parker, IV Kutnyakov, JN Serne, AV Mitroshkov, 
GV Last, SC Smith, CW Lindenmeier, JM Zachara, and DB Burke. 2002. Characterization of Uncontaminated Vadose Zone Sediment from the Hanford

Reservation - RCRA Borehole Core Samples and Composite Samples. PNNL-13757-1, Pacific Northwest National Laboratory, Richland, Washington.

Shi, X. L.; Chiu, A.; Chen, C. T.; Halliwell, B.; Castranova, V.; Vallyathan, V. J. Toxicol. \& Environ. Health B-Crit. Rev. 1999, 2, 87-104.

Smillie, R. H.; Hunter, K.; Loutit, M. Water Res. 1981, 15, 1351-1354.

Stumm, W.; Morgan, J. J. Aquatic chemistry; Chemical equilibria and rates in natural waters, 3rd Ed. Wiley Interscience, 1996.

Szecsody J. E, K. J. Cantrell, K. M. Krupka, C. T. Resch, M. D. Williams, and J. S. Fruchter. 1998. Uranium Mobility During In Situ Redox Manipulation of the 100 Areas of the Hanford Site. PNL-12048, Pacific Northwest Laboratory, Richland, Washington.

Szecsody, J. E.; Zachara J. M.; Bruckhart P. L. Envir. Sci. Tech. 1994, 28(9), 1706-1716.

Thornton, E. C.; Amonette, J. E. Environ. Sci. Technol. 1999, 33, 4096-4101.

Thornton, E. C.; Amonette, J. E. Gas treatment of Cr(VI)-contaminated sediment samples from the north 60's pits of the chemical waste landfill; PNNL-11634, Pacific Northwest National Laboratory: Richland, WA, 1997.

Thornton, E.C., J.T. Giblin, T.J. Gilmore, K.B. Olsen, J.M. Phelan, and R.D. Miller (1999) In Situ Gaseous Reduction Pilot Demonstration - Final Report. PNNL-12121, Pacific Northwest National Laboratory.

U.S. Environmental Protection Agency (1992) Test Methods for Evaluating Solid Wastes: Physical/Chemical Methods, $3^{\text {rd }} \mathrm{ed}$. SW-846, Office of Solid Waste and Emergency Response, Washington, D.C.

USEPA, (1984). Health assessment document for chromium. USEPA Rep. 600/8-83-014F. Environ. Assess. and Criteria Office, Research Triangle Park, NC.

Vitale, R. J.; Mussoline, G. R.; Rinehimer, K. A.; Petura, J.C.; James, B. R. Environ. Sci. Technol. 1997, 31, 390-394.

Wieckowska, J. Catalysis Today 1995, 24, 405-465.

Wittbrodt, P. R.; Palmer, C. D. Environ. Sci. Technol. 1995, 29, 255-263.

Xu, F. ;Wang, Y. J. Nuclear Materials, 2000, 279, 100-1-6.

Zhang, J.; Millero, F. J. Geochim. Cosmochim. Acta 1993, 57, 1705-1718. 